University of Nebraska - Lincoln

DigitalCommons@University of Nebraska - Lincoln

Nutrition \& Health Sciences Dissertations \&

Theses

Nutrition and Health Sciences, Department of

$5-2013$

Reliability and validity of a culturally appropriate food frequency

questionnaire to measure the omega-3 fatty acid intakes of

Midwestern African American women of childbearing age

Narissa Scales

University of Nebraska-Lincoln, narissa_s@yahoo.com

Follow this and additional works at: https://digitalcommons.unl.edu/nutritiondiss

Scales, Narissa, "Reliability and validity of a culturally appropriate food frequency questionnaire to measure the omega-3 fatty acid intakes of Midwestern African American women of childbearing age" (2013). Nutrition \& Health Sciences Dissertations \& Theses. 43.

https://digitalcommons.unl.edu/nutritiondiss/43

This Article is brought to you for free and open access by the Nutrition and Health Sciences, Department of at DigitalCommons@University of Nebraska - Lincoln. It has been accepted for inclusion in Nutrition \& Health Sciences Dissertations \& Theses by an authorized administrator of DigitalCommons@University of Nebraska - Lincoln. 


\title{
Reliability and Validity of a Culturally Appropriate Food Frequency Questionnaire to Measure Omega-3 Fatty Acid Intakes in Midwestern African American Women of Childbearing Age
}

By

\author{
Narissa E. Scales \\ A DISSERTATION \\ Presented to the Faculty of \\ The Graduate College at the University of Nebraska \\ In Partial Fulfillment of Requirements \\ For the Degree of Doctor of Philosophy
}

Major: Interdepartmental Area of Nutrition

Under the Supervision of Professor Julie A. Albrecht

Lincoln, Nebraska

May, 2013 


\title{
Reliability and Validity of a Culturally Appropriate Food Frequency Questionnaire to Measure Omega-3 Fatty Acid Intakes in Midwestern African American Women of Childbearing Age
}

\author{
Narissa Scales, Ph.D.
}

University of Nebraska, 2013

Adviser: Julie A. Albrecht

Omega-3 fatty acid intakes may play an important role in maternal health outcomes and infant brain and neural development. Research has shown that pregnant African American women have intakes below recommended levels for optimal health. The aim of this study was to determine the reliability and validity of a culturally specific food frequency questionnaire (FFQ) to measure total omega-3 fatty acid, alpha-linolenic acid (ALA), eicosapentaenoic acid (EPA) and docosahexaenoic acid (DHA) intake of Midwestern African American women ( $\mathrm{n}=49)$ of childbearing age and examine associations of maternal health issues from previous pregnancies. The omega-3 FFQ questionnaire was developed by 24 hour recall interviews, analyzed for content validity and pilot tested. The final culturally appropriate 187 item FFQ was then completed by women three times, via interview by an $\mathrm{RD}$, along with three non-consecutive 24 hour recalls, in a two week period. Maternal health issues were assessed by demographic questionnaire. The reliability and validity of the FFQ was assessed by Cronbach's coefficient alpha and Pearson correlation coefficients, respectively. Mean daily consumption of total omega-3 fatty acid, ALA, EPA, DHA and DPA, as estimated by the three administrations of the FFQ, were $2.68 \pm 1.37 \mathrm{~g} / \mathrm{day}, 2.45 \pm 1.30 \mathrm{~g} /$ day, $0.07 \pm 0.07$ 
$\mathrm{g} / \mathrm{day}, 0.12 \pm 0.11 \mathrm{~g} / \mathrm{day}$ and $0.03 \pm 0.02 \mathrm{~g} /$ day, respectively. The Cronbach's coefficient alpha, for reliability of the FFQ, was 0.89 for total omega-3, 0.89 for ALA, 0.89 for EPA, 0.88 for DHA and 0.83 for DPA. The Pearson correlation coefficients as measured for validity between the FFQ and the recalls, were $0.44,0.44,0.59$ and 0.60 for total $n-3$ fatty acid, ALA, EPA and DHA ( $\mathrm{P}<.01)$, respectively. African American women with past history of low birth weight, preterm labor, premature rupture of membranes and postpartum depression had a significant difference $(\mathrm{p}<.05)$ in omega-3 fatty acid intakes when compared to those without prior history. In conclusion, this culturally appropriate FFQ seems to be reliable and valid in measuring omega-3 fatty acid intake in Midwestern African American women. This tool may be used to assess other populations of African American women's intake of omega-3 fatty acids. 


\section{Acknowledgements}

I would like to thank Dr. Julie Albrecht for your guidance, support and patience throughout the process of finishing my dissertation, as well as, trying to provide me opportunities to further and enhance my career. I have really appreciated and enjoyed having you as my advisor.

I would like to thank Dr. Kaye Stanek-Krogstrand for the years of support and encouragement. You have been my advisor for a very large part of my collegiate career. You have always been there to guide me and provide insight. It is because of you and taking your Introduction to Nutrition class that I am here today and I would very much like to say, "Thank you!"

Dr. Kent Eskridge, thank you for your patience and statistical help. Even though I have asked the same statistical question over and over again, you are always willing to explain. Thanks to Dr. Timothy Carr for joining my committee. I have always admired your intelligence and appreciate you pushing students to challenge ourselves. Dr. Michelle Rupiper thanks for your assistance and guidance throughout this process.

I would like to say a special thank you to the Nutrition and Health Sciences staff, Connie, Lori and Jeannie. You have always been so helpful and willing to provide assistance at any time. I would like to say thank you to Dr. Georgia Jones. You have been someone I can talk too about various subjects, including my research and I appreciate your support.

I would like to say thank you to my friends, Melissa, Bethany and Kris. You have all been so supportive during this process. It was always a joy to be in the office together 
or have lunch and share feelings, frustrations and hopes for the future. I would like to say thank you to my best friend, Michele, for providing me the opportunity to rearrange my life so that I can focus on finishing school. I would like to thank my family for their support, my sister Celyce and my cousin Jaime, you both hold special places in my heart. I would like to thank one of my favorite people, someone who has taught me a great deal about life and has always given me unconditional love, my mother Portia. I love you Mom. You have helped mold me into the person I am today and words cannot express my gratitude.

And lastly, I would like to say thank you to God for without you, none of this would be possible. 


\section{Table of Contents}

Page

List of Tables VIII

List of Figures. X

Introduction. .11

\section{Review of Literature}

I. Polyunsaturated fatty acids....

II. Dietary sources and intake recommendations of omega-6 and omega-3 fatty acids. .16

III. Omega-3 fatty acids and maternal outcomes...........................18

IV. Omega-3 fatty acids and infant outcomes.............................24

V.Omega-3 fatty acid intake of pregnant women in the United States..........27

VI. Dietary assessment in pregnant women...............................27

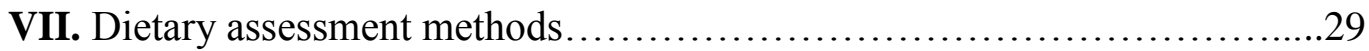

VIII. Reliability and validity of food frequency questionnaires................39

IX. Reliability and validity of FFQs measuring omega-3 fatty acid and fish intakes

X. Reliability and validity of FFQs measuring omega-3 fatty acid intake in pregnant populations.

XI. Reliability and validity of FFQs measuring omega-3 fatty acid intake in pregnant African American populations.

XII. References 
Study I. Reliability and validity of a culturally appropriate food frequency questionnaire to measure omega-3 fatty acid intakes in Midwestern African American women of childbearing age

Abstract.........................................................66

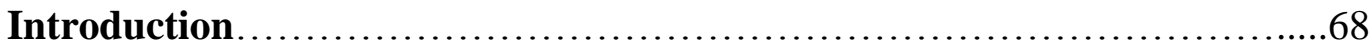

Methods..................................................................

Results........................................................... 75

Discussion..................................................... 78

References........................................................ 101

\section{Appendices}

Appendix A: Institutional Review Board Letters........................109

Appendix B: Letter to Manager of Special Supplemental Nutrition Program for Women, Infants and Children (WIC)....................119

Appendix C: Letter of Consent from WIC Manager........................121

Appendix D: Flier used for Recruitment of Participants................... 123

Appendix E: Preliminary Interview Questions........................ 125

Appendix F: Pilot Test Questionnaire.................................128

Appendix G: Sociodemographic Questionnaire.........................130

Appendix H: Twenty-four Hour Recall................................134

Appendix I: Food Frequency Questionnaire............................136 


\section{List of Tables}

Page

\section{Review of Literature:}

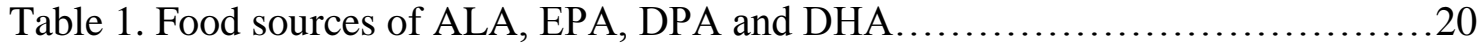

Table 2. Omega-3 fatty acid intakes of pregnant and lactating women in the United

States

\section{Study I:}

Table 1. Demographic characteristics of Midwestern African American women of

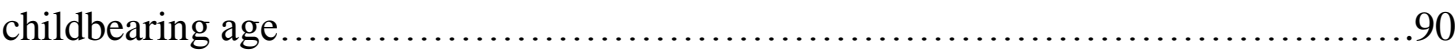

Table 2. Mean intakes ( + SD) of total omega-3 (Total n-3), alpha-linolenic acid (ALA) eicosapentaenoic acid (EPA), docosapentaenoic acid (DPA) docosahexaenoic acid (DHA) estimated by the three FFQs and three 24-hour recalls with correlations between the two methods

Table 3. Mean intakes $( \pm$ SD) of total omega-3 (Total n-3), alpha-linolenic acid (ALA) eicosapentaenoic acid (EPA), docosapentaenoic acid (DPA) and docosahexaenoic acid (DHA) by food groups as estimated by three FFQs $\ldots \ldots \ldots \ldots \ldots \ldots \ldots \ldots \ldots \ldots \ldots . \ldots 2$

Table 4. Rank order listing of food groups that provided total omega-3 fatty acid intakes consumed by African American women, as measured by three FFQs

Table 5. Rank order listing of foods that provided approximately $90 \%$ of eicosapentaenoic acid (EPA) and docosahexaenoic acid (DHA) in the study population, as assessed by the mean of the FFQs......................................... 94 
Table 6. Cronbach's coefficient alphas of total omega-3 (Total n-3), $\alpha$-linolenic acid (ALA), eicosapentaenoic acid (EPA), docosapentaenoic acid (DPA) and docosahexaenoic acid (DHA) from the three FFQs.

Table 7. Cronbach's coefficient alphas of food groups by total omega-3 (Total n-3) $\alpha$-linolenic acid (ALA), eicosapentaenoic acid (EPA), docosapentaenoic acid (DPA) and docosahexaenoic acid (DHA) between the three FFQs

Table 8. Mean intakes of total omega-3 (Total n-3), $\alpha$-linolenic acid (ALA), eicosapentaenoic acid (EPA), docosapentaenoic acid (DPA) and docosahexaenoic acid (DHA) of pregnant and non-pregnant African American women.....................97 Table 9. Midwestern African American women’s body mass index (BMI). .98

Table 10. Mean intakes of total omega-3, $\alpha$-linolenic acid (ALA), eicosapentaenoic acid (EPA), docosapentaenoic acid (DPA) and docosahexaenoic acid (DHA) of African American women by education level, from the three FFQs 


\section{List of Figures}

\section{Page}

\section{Review of Literature}

Figure 1. Omega-6 and omega-3 metabolic pathways............................17

\section{Study $\mathbf{I}$.}

Figure 1. Previous pregnancy maternal health outcomes as assessed by questions adapted from the 2008 Maternal and Infant Health Assessment................................99 


\section{Introduction}

Dietary intake of omega-3 fatty acids may play an important role in positive maternal and infant health outcomes. ${ }^{1}$ Alpha-linolenic acid (ALA), an essential omega-3 fatty acid, must be obtained from the diet and is needed for optimal health. ${ }^{2,3}$ The Adequate Intake (AI) for ALA is $1.4 \mathrm{~g} / \mathrm{d}$ and $1.1 \mathrm{~g} / \mathrm{d}$ for pregnant and non-pregnant females, between the ages of 14-50. ${ }^{4}$ Food sources of ALA are vegetable oils, such as soybean, canola and flaxseed, as well as, nuts and seeds. ${ }^{5}$ Once acquired from the diet, ALA can be further metabolized to eicosapentaenoic acid (EPA) and docosahexaenoic acid (DHA), which are both needed by the body, especially during pregnancy. ${ }^{1-3,6}$ EPA and DHA are reported to possibly decrease the risk of maternal health issues, including preterm birth and low birth weight, ${ }^{7-10}$ preeclampsia ${ }^{11,12}$ and postpartum depression. ${ }^{13,14}$ DHA seems to be important for growth and development, evidenced by it comprising $97 \%$ and $93 \%$ of all omega-3 fatty acids found in brain and retinal tissue, respectively. ${ }^{15,16}$ Researchers have found that conversion of ALA to EPA and DHA is inefficient and varies, with estimates of $0.2 \%$ $21 \%^{3}$ and $<1 \%{ }^{6}$ of dietary ALA converted to EPA and DHA, respectively. Increasing ALA intake has been found to have little effect on increasing blood levels of $\mathrm{DHA}^{2,17,18}$; however, DHA from food sources is well absorbed and readily incorporated into human plasma and blood cell lipids. ${ }^{6,19}$ There is not an AI for EPA and DHA, but The International Society for the Study of Fatty Acids and Lipids (ISSFAL) recommends 500 mg of EPA and DHA per day for cardiovascular health and that pregnant and lactating women should attempt to achieve an average of $200 \mathrm{mg}$ DHA per day. ${ }^{20,21}$ Non-pregnant, 
pregnant and lactating mothers should obtain EPA and DHA from food sources including eggs, poultry and cold water fish, i.e. salmon, tuna and shellfish. ${ }^{6}$

According to the National Health and Nutrition Examination Survey 2009-2010, women of child-bearing age are not meeting their needs for EPA and DHA. ${ }^{22}$ These same results have been observed in several populations of American pregnant and lactating women, ${ }^{23-27}$ suggesting that women from the United States are potentially not meeting the recommendations for omega-3 fatty acids, according to experts and government agencies. Research on omega-3 fatty acid intakes of African American women of childbearing age is very limited. In comparison to Caucasians, researchers have reported African Americans suffer increased rates of preterm birth which may be partially explained by an imbalance of omega-3 and omega- 6 fatty acid intakes found more often in African Americans when compared to Caucasions. ${ }^{28}$

Food frequency questionnaires are often used to assess nutrient intakes because they are often self-administered, inexpensive to process and tend to alleviate changes in diet when being completed. ${ }^{29}$ FFQs should be culturally and population specific and can be created or adapted to fit the population or purpose needed for the specific study by adding foods commonly eaten by the study population. ${ }^{30-32}$ This dietary assessment method has been developed and/or validated to measure omega-3 fatty acids in several diverse pregnant populations, including Mexican, ${ }^{33}$ Finnish, ${ }^{34}$ Dutch, ${ }^{35}$ and Canadians. ${ }^{36}$ FFQs that measure n-3 fatty acids have been validated in African American pregnant populations, ${ }^{36,37}$ but to date there has not been an omega-3 fatty acid FFQ specifically created to measure African American female intakes. 
Therefore, the purpose of this research was to develop a valid, culturally appropriate food frequency questionnaire to measure omega-3 fatty acid intakes in non-pregnant and pregnant Midwestern African American females and assess possible associations between intakes and maternal/infant health outcomes.

The primary objectives were as follows:

1. To measure the reliability and validity of a culturally appropriate food frequency questionnaire (and adjust accordingly) to estimate total omega-3 fatty acid, ALA, EPA, DPA and DHA intakes of low income Midwestern African American women of childbearing age.

2. To examine the association of health outcomes from prior pregnancies with the omega-3 fatty acid intake of low income Midwestern African American women of childbearing age. 


\section{Review of Literature}

\section{Polyunsaturated fatty acids}

In terms of human health and nutrition, as well as occurrence in the food supply, the most important families of polyunsaturated fatty acids (PUFAs), fatty acids that contain more than one double bond, are the omega 3 and omega 6 fatty acids. ${ }^{2}$ The terms omega- 3 and omega- 6 refer to the placement of the first double bond 3 or 6 carbon atoms away from the methyl carbon, respectively. ${ }^{2,39}$ Through de novo fatty acid synthesis, the body has the ability to produce other PUFAs, but due to the inability of mammals to add double bonds after the $10^{\text {th }}$ carbon on the methyl terminal end of a fatty acid chain, the omega-3 fatty acid ALA (18:3n-3) and the omega-6 fatty acid linoleic acid (18:2n-6) (LA) cannot by synthesized by humans. LA and ALA are "essential fatty acids", meaning they have to be obtained from the diet and they are both substrates to other fatty acids that are needed for physiological functions in the body. ${ }^{2,3}$

LA is the parent to a metabolically important omega- 6 fatty acid, arachidonic acid, 20:4n-6 (AA). ${ }^{2,3,40}$ AA is a major component of phospholipids found in the cell membranes of brain tissue, retinal tissue and platelets, as well as, a substrate for signaling molecules called eicosanoids. ${ }^{2,3,39.40}$ A cell's response to outside stimuli is the production of eicosanoids which are involved in a variety of processes, including muscle contraction, immune response, inflammation, stimulation/inhibition of platelet aggregation and cell adhesion. ${ }^{2,3,39}$ Eicosanoids derived from AA promote inflammation, stimulation/inhibition of platelet aggregation, as well as cell growth and proliferation. ${ }^{2,3}$

ALA is the parent to the omega-3 fatty acid, DHA via EPA and DPA. Both EPA and DHA play important roles in human health. EPA is a substrate for eicosanoids that 
promote vasodilation and inhibition of inflammation and platelet aggregation, and is released from membrane phospholipids to compete with AA for enzymatic metabolism thus creating a less inflammatory environment. ${ }^{3}$ Researchers suggests an imbalance of eicosanoid production could have deleterious effects on health, so both AA and EPA derived eicosanoids seem to be important. ${ }^{2}$ DHA is found in high concentrations in the brain cells, retinal cells, sperm and cardiomyocytes and is the substrate for docosanoids, signaling molecules similar to eicosanoids, which are anti-inflammatory and protective of neural tissue. ${ }^{2}$ EPA and DHA are also important in maternal and infant outcomes. ${ }^{1}$ Researchers have reported a possible impact of increased EPA and DHA intakes leading to decreased risk of maternal health, including preeclampsia, ${ }^{11,12}$ postpartum depression ${ }^{13,14}$ and preterm labor. ${ }^{7-10}$ These effects have also been seen in infant health outcomes, including decreased risk of low birth weight and proper neural and retinal development. ${ }^{15,16}$

Research suggest that the efficiency of the conversion of ALA to longer chain polyunsaturated fatty acids (EPA, DPA and DHA) is low and depends on intake of ALA and LA in the diet. ${ }^{41-43}$ Western diets are estimated to have a ratio of omega- 6 to omega-3 fatty acids of about 10:1 to 20-25:1, which leads to a deficiency in the conversion of ALA to longer chain polyunsaturated fatty acids (LCPUFAs). ${ }^{3}$ Harnack and others found that maximum conversion of ALA to EPA and DHA, $17 \%$ and $0.7 \%$, respectively, was seen with a mixture of LA/ALA at a ratio of $1: 1 .^{42}$ The same results were reported in piglets with a ratio of 4:1 to 2:1 for LA/ALA ${ }^{43}$ As illustrated in figure 1, omega- 6 and omega-3 fatty acid metabolism share a common set of enzymes, so a diet rich in LA 
would competitively inhibit ALA metabolism to LCPUFAs. ${ }^{41,44}$ This situation is further compounded by the observation that increased ALA intake increases the level of ALA, EPA and DPA but has little or no impact on DHA levels. ${ }^{2,17,18,41}$ Even conversion of ALA to EPA is limited and variable with estimates between $0.2 \%$ to $21 \% .^{3}$ Intake of preformed DHA seems to be the most efficient way to increase blood and tissue DHA. ${ }^{19,45}$ In a meta-regression analysis of 12 studies, researchers found that plasma phospholipid DHA is highly sensitive to dietary DHA and increases in a dose-dependent manner up to two grams of DHA intake per day. ${ }^{19}$ Both preformed EPA and DHA are well absorbed and readily incorporated into human plasma and blood cell lipids, which has led to the theory that the best way to increase an omega-3 fatty acid in plasma or tissues is to supplement with that specific fatty acid. ${ }^{6,19}$

\section{Dietary sources and intake recommendations of omega-6 and omega-3 fatty acids}

Food sources of LA include vegetable oils (corn, safflower, sunflower and soybean) and animal meats. ${ }^{46}$ The AI for LA is 11 grams (g) and $12 \mathrm{~g} / \mathrm{d}$ for women between the ages of 14-18 and 19-50, respectively and $13 \mathrm{~g} / \mathrm{d}$ for pregnant women. ${ }^{4}$ According to NHANES 2009-2010, females between the ages of 16-49 eat an average of $13.65 \mathrm{~g} / \mathrm{d}$ of LA, which meets the Adequate Intake. AA is found in animal sources like meat, egg and dairy products. ${ }^{22}$ Experts from the Food and Agricultural Organization (FAO) and the World Health Organization (WHO) determined that for healthy adults with habitual intake of LA greater than $2.5 \%$ of energy, AA is not essential, so this PUFA does not have an $\mathrm{AI} .^{47}$ 


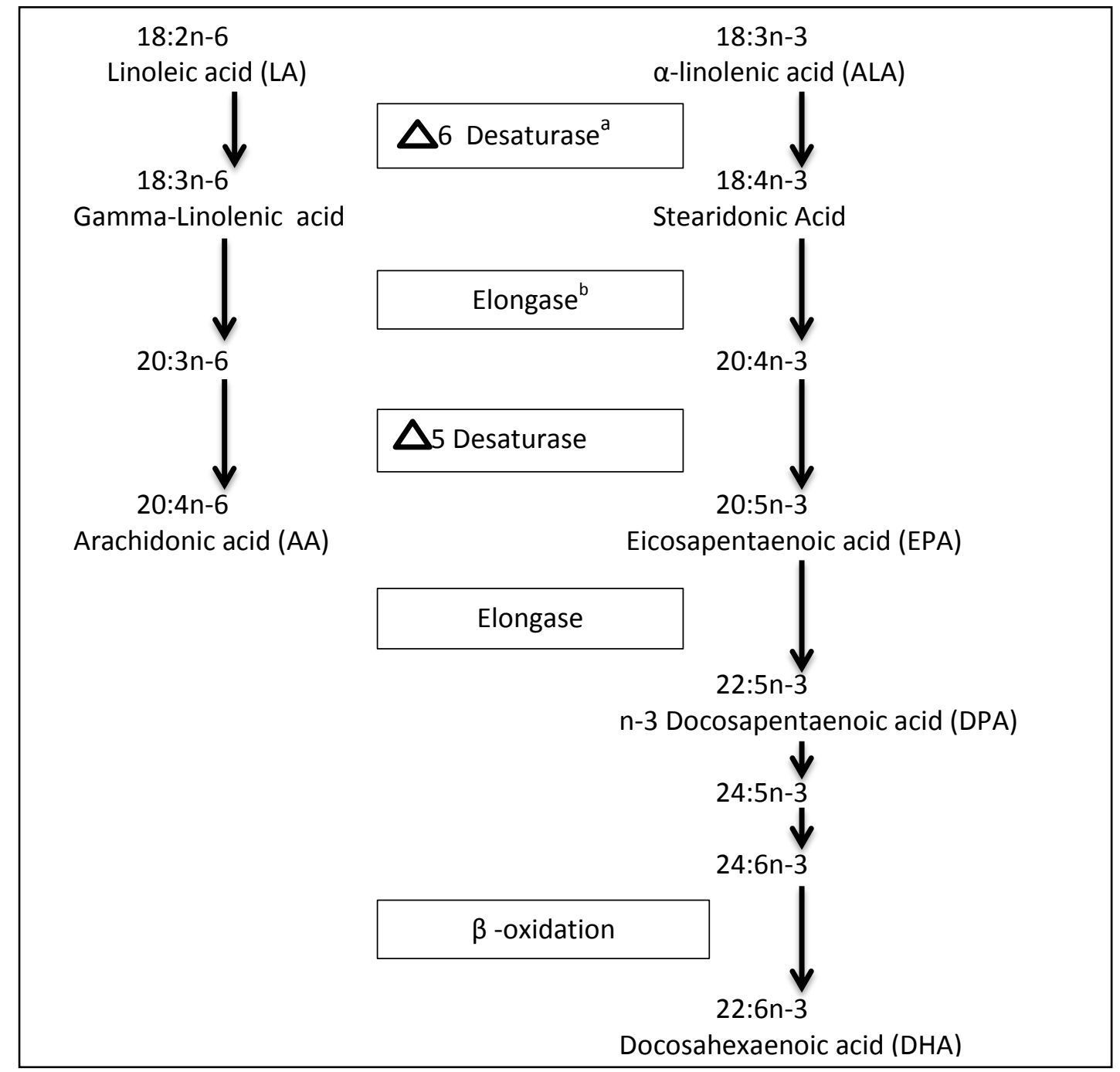

Figure 1. Omega-6 and omega-3 metabolic pathways. Adapted from reference Ratnayake et al. ${ }^{2}$

${ }^{\mathrm{a}}$ Desaturase enzyme adds a double between two carbons.

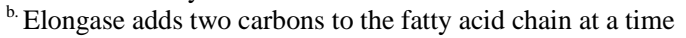

The major food source of ALA is vegetable oils, with soybeans, nuts and seeds also being rich sources. Flaxseed oil is not commonly used as a food oil but is rich in ALA. $^{5,48}$ The AI for non-pregnant and pregnant females, between the ages of 14-50, is $1.1 \mathrm{~g} / \mathrm{d}$ and $1.4 \mathrm{~g} / \mathrm{d}$, respectively and an Acceptable Macronutrient Distribution Range of .6-1.2 percent of energy for ages $\geq 16$ with up to $10 \%$ coming from EPA and DHA. ${ }^{4}$ The 
International Society for the Study of Fatty Acids and Lipids (ISSFAL) recommends ALA be $.7 \%$ of energy for maintenance of a healthy cardiovascular system, with no specific recommendations for pregnant women possibly because intake of ALA has less of an impact on fetal brain DHA deposition than intake of preformed DHA. ${ }^{20}$

The major food source of EPA and DHA is fish. Fatty fish like halibut, mackerel, herring and salmon are especially rich sources. ${ }^{6}$ There is not an AI for EPA and DHA, but the ISSFAL recommends a minimum of $500 \mathrm{mg}$ of EPA + DHA intake per day for cardiovascular health ${ }^{20}$ and an average of $200 \mathrm{mg}$ DHA per day for pregnant and lactating women. ${ }^{21}$ Since preformed EPA and DHA have the greatest impact on health outcomes, pregnant and lactating mothers should obtain these LCPUFAs from food sources including eggs, poultry and cold water fish, i.e. salmon, tuna and shellfish. ${ }^{6,21}$ The U.S. Food and Drug Administration recommends that women of childbearing age, pregnant or lactating eat up to 12 ounces ( 2 average meals) a week of a variety of fish and shellfish that are lower in mercury, which should meet the recommendations for DHA $^{21,49}$. Food sources of omega-3 fatty acids are found in Table 1.

\section{Omega-3 fatty acids and maternal outcomes}

Consumption of omega-3 fatty acids during pregnancy may have a beneficial impact on several maternal health outcomes, including gestation duration, birth weight, blood pressure and depression, but results are inconclusive and still being investigated. ${ }^{50}$ 
Table 1. Food sources of ALA, EPA, DPA and DHA ${ }^{\mathrm{a}}$

Omega-3 fatty acid content of foods (g)

\begin{tabular}{|c|c|c|c|c|c|}
\hline Foods & Serving & ALA & EPA & DPA & DHA \\
\hline Flaxseed oil & 1 tbsp & 7.258 & 0 & 0 & 0 \\
\hline Canola oil & 1 tbsp & 1.279 & 0 & 0 & 0 \\
\hline Soybean oil & 1 tbsp & 0.923 & 0 & 0 & 0 \\
\hline Flaxseed, ground & 1 tbsp & 1.597 & 0 & 0 & 0 \\
\hline Walnuts, black & $1 \mathrm{oz}$ & 0.569 & 0 & 0 & 0 \\
\hline Tuna, light, packed in water & $3 \mathrm{oz}$, raw & 0 & 0.400 & .008 & 0.190 \\
\hline Salmon, Chinook & $3 \mathrm{oz}$, raw & .076 & .857 & .256 & .802 \\
\hline Crab, Dungeness & $3 \mathrm{oz}$, raw & Not reported & .359 & .016 & .143 \\
\hline Trout, rainbow & $3 \mathrm{oz}$, raw & .101 & .142 & .090 & .357 \\
\hline Large egg & $1 \mathrm{egg}$ & .018 & 0 & .004 & .029 \\
\hline
\end{tabular}

${ }^{\text {a. }}$ Adapted from the USDA National Nutrient Database for Standard Reference ${ }^{51}$

\section{Preterm birth and low birth weight}

Duration of gestation less than 37 weeks and a birth weight of less than $2500 \mathrm{~g}$ or 5 pounds 5 ounces are considered preterm birth (PTB) and low birth weight (LBW), respectively. ${ }^{28,52}$ Both PTB and LBW are a leading causes of mortality for infants, with African Americans having 2.3 times the infant mortality rate of non-Hispanic whites. ${ }^{28,53}$ Intake of omega-3 fatty acids, especially EPA, may influence increased gestation and higher birth weights. Researchers theorize that increased levels of AA, the consequence of a linoleic rich diet, leads to the formation of eicosanoids, specifically PGE2 and PGF2 $\alpha$, involved in contractions and preterm labor. ${ }^{7,16}$ EPA and DHA play a protective role by competitively inhibiting AA production, leading to lower circulating amounts of these eicosanoids. Furthermore, EPA, is the precursor to eicosanoids, specifically PGE3 and PGI3, that relax the uterine wall. ${ }^{16}$

In 2000, Olsen and others examined the preventative and therapeutic effects of omega-3 fatty acid intake on several maternal health outcomes. In a total of six mutually 
exclusive multicenter trials, women were randomly assigned to receive fish oil (rich in omega-3 fatty acids) or olive oil (deficient in omega-3 fatty acids) capsules. The prophylactic trials consisted of women who were currently greater than 16 weeks pregnant, with no complications, but had previous experience with (1) preterm delivery or (2) intrauterine growth retardation or (3) preeclampsia or (4) women with current twin pregnancies. These women received a total of four oil capsules per day. The two therapeutic trials enrolled women with (5) threatening preeclampsia or (6) suspected intrauterine growth retardation, and they were given nine oil capsules per day. Among women who had previously experienced preterm delivery, the reoccurrence was reduced from $33.3 \%$ to $21.3 \%$ (OR $0.54,95 \%$ CI $0.30-0.98$ ), in the fish oil group, in comparison to the olive oil group. The preterm delivery trial also reported a significant difference in pregnancy duration $(\mathrm{P}=.01)$ and mean birth weight $(\mathrm{g})(\mathrm{P}=.02)$, between the fish oil and olive oil groups. In the fish oil group, when combining all trials, there was a delay in spontaneous delivery $(\mathrm{P}=.002)$ when compared to the olive oil group. No effect was seen on pregnancy induced hypertension, intrauterine growth retardation or prematurity in twins. $^{8}$

In 2002, Olsen and others looked at pregnant women's consumption of fish and its' impact on birth weight, preterm delivery and intrauterine growth retardation. At 16 weeks gestation, Danish women $(n=8729)$ filled out a self-administered questionnaire. The subjects were placed in six frequency categories based on their consumption of fish servings per 28 days. Women consumed an estimated average of $15.8 \mathrm{~g}$ of fish and 0.182 g of long chain n-3 fatty acids a day. Out of 8707 subjects, low birth occurred in $2.7 \%$, 
preterm delivery occurred in $3.4 \%$ and intrauterine growth retardation occurred in $6.6 \%$. The results showed that as fish consumption increased, low birth weight $(\mathrm{P}<.001)$, preterm birth $(\mathrm{P}=.001)$ and intrauterine growth retardation $(\mathrm{P}=.001)$ all tended to decrease. The author noted that these associations were mainly apparent at the lower end of fish intakes.

Olafsdottir et al. also looked at the effects of fish and cod liver oil consumption on birth weight in an observational study. Healthy, low risk pregnant Icelandic women $(n=436)$ filled out a semi-quantitative food frequency questionnaire, two different times during their pregnancy. Higher birth weight was positively correlated with liquid cod liver oil intake in early pregnancy $(\mathrm{r}=0.107, \mathrm{P}=0.026)$, but not with concentrated cod liver oil capsules or fish consumption. ${ }^{10}$

\section{Preeclampsia}

Preeclampsia is when a pregnant woman develops high blood pressure (Blood pressure $\geq 140 / 90 \mathrm{~mm} \mathrm{Hg}$ over time) and protein in the urine, after 20 weeks of pregnancy. ${ }^{54}$ Affecting at least $5-8 \%$ of all pregnancies, preeclampsia is one of the leading causes of maternal death. ${ }^{55,56}$ A possible cause may be Thromboxane $\mathrm{A}_{2}$, an AA derived eicosanoid which promotes vasoconstriction. ${ }^{11,16,57}$ As mentioned previously, a balance of AA and EPA derived eicosanoids seems to be important to health. ${ }^{2}$ Researchers have found that erythrocyte AA is higher in preeclamptic women when compared to normotensive women. ${ }^{11}$ While, omega-3 fatty acids tended to be lower in placental tissues of women with preeclampsia, possibly leading to an environment where production of AA derived eicosanoids is favored. ${ }^{58,59}$ 
A small case control study looked at the relationship between dietary intake of marine omega-3 fatty acids and risk of preeclampsia. Researchers measured the erythrocyte content of PUFAs in preeclamptic (case) and normotensive (control) pregnant women. Women who had the lowest intake of omega-3 fatty acids and the lowest omega3/omega-6 ratio value, had a 7.6 times $(95 \% \mathrm{CI}=1.4-4.06)$, and 7.3 times $(\mathrm{OR}=7.2 ; 95 \%$ $\mathrm{CI}=1.1-46.5$ ) higher risk of preeclampsia, respectively, when compared to those with the highest intakes and the highest ratio values. With just a $15 \%$ decrease in the omega3/omega-6 ratio, there was a $46 \%$ reduction in preeclampsia $(\mathrm{OR}=0.54 ; 95 \% \mathrm{CI}=0.41$ 0.72). These results were adjusted for parity and pre-pregnancy body mass index $(\mathrm{BMI}){ }^{11}$

Olafsdottir et al. found opposite results, with women who took cod liver oil being 4.7 times as likely to develop hypertensive disorders during pregnancy (95\% CI 1.812.6). When the omega-3 LCPUFA was divided into different levels of intake, risk of hypertensive disorders was greater in the lowest and highest intake levels. Researchers theorize that intake of omega-3 fatty acid may have a positive impact on hypertensive disorders and gestational hypertension at certain levels but may become detrimental in high doses. ${ }^{60}$

\section{Postpartum depression}

According to the American Psychological Association, an estimated 9-16\% of postpartum women will suffer from postpartum depression, and prevalence increases to $41 \%$ if the mom has experienced postpartum depression during a previous pregnancy. ${ }^{61}$ Postpartum depression is characterized as a nonpsychotic depressive illness of mild-to 
moderate severity occurring in a mother during the first postnatal year, which is a time of major change and increased responsibilities in the care of a newborn infant. ${ }^{61,62}$ Research has shown that postpartum depression is associated with dysfunctional mother-infant attachment, with mothers being hostile, critical and less responsive to their children, leading to possible cognitive and emotional impairments in the child, that can persist in adolescence. $^{62,63}$ Researchers theorize that DHA deficiency, caused by increased and preferential transfer of DHA from the mother to the fetus, during the $3^{\text {rd }}$ trimester, as well as low DHA intakes, may be related to maternal depressive symptoms. ${ }^{64,65}$ Postpartum depression has also been associated with increased levels of pro-inflammatory eicosanoids, whose creation is competitively inhibited by omega-3 fatty acid derived antiinflammatory eicosanoids. So a DHA deficient pregnant woman may be at increased risk. $^{65}$

In a cross-national ecological analysis, Hibbeln et al. looked at 14,532 subjects, over 23 countries in 41 studies. Prevalence data that used the Edinburgh Postpartum Depression Scale (EDPS) was compared to the DHA, EPA and AA content in mother's breast milk for 16,12 and 15 countries, respectively. The data was also compared to seafood consumption rates found in published reports from 23 countries. Results suggests that lower concentrations of DHA in mother's breast milk and lower national rates of seafood consumption were associated with higher rates of postpartum depression. ${ }^{14}$

Researchers studied the impact of omega-3 fatty acid intake as a treatment for postpartum depression. Postpartum women's pre-treatment scores of the EDPS and another baseline mood rating scale, the Hamilton Rating Scale for Depression (HRSD), 
were compared to post-treatment scores. Participants were randomly assigned to different daily dosage amounts for eight weeks. Across groups, all dose levels combined, scores on the EDPS $(\mathrm{t}=8.47$, d.f.=15, $\mathrm{P}<0.05)$ and $\operatorname{HRSD}(\mathrm{t}=6.76$, d.f. $=15, \mathrm{P}<0.05)$ decreased $51.5 \%$ and $48.8 \%$, respectively, when comparing pre to post-test scores. Authors noted that interpretation of these results is limited by sample size $(n=16)$ and lack of a placebocontrol group. ${ }^{13}$

\section{Omega-3 fatty acids and infant outcomes}

In mammals, DHA is the principle omega-3 fatty acid in the brain, comprising $97 \%$ of all omega-3 fatty acids and $10-20 \%$ of total fatty acid composition. ${ }^{15,16}$ Researchers state DHA is involved in neurotransmission, regulates ion-channel activity, gene expression and promotes fluidity and flexibility of neural and endothelial membranes in the central nervous system (CNS). ${ }^{66,67}$ DHA also comprises approximately $93 \%$ of all omega- 3 fatty acids of the outer segment of retinal rods and cones. ${ }^{68}$ These properties are thought to be associated with DHA's role in proper neural and retinal function. Feeding animals a DHA deficient diet lead to decreased neuron size and dendritic aborization, in rats, and decreased levels of visual acuity at 4-12 weeks of age, in rhesus monkeys, when compared to those animals fed a diet rich in DHA. ${ }^{69,70}$

The fetus is dependent on the mother's intake, as well as, the placenta's transfer ability and metabolism for its' LCPUFA needs. ${ }^{67}$ Higher amounts of DHA and lower amounts of ALA have been found in fetal circulation, with the opposite found in maternal circulation, which may be due to the placental ability to preferentially transfer DHA, over other LCPUFAs, to the fetus. ${ }^{71-73}$ Along with placental transfer and metabolism, the 
mother's intake is important. Donahue et al. found that maternal intake of DHA and EPA correlated with the amount of these PUFAs found in maternal erythrocytes $(r=0.18$, $\mathrm{P}<0.0001)$ and umbilical cord plasma $(\mathrm{r}=0.21, \mathrm{P}<0.001) .{ }^{24}$ Similar results, a correlation between maternal DHA intake and erythrocyte phospholipid DHA $(\beta=0.30,95 \% \mathrm{CI}$ : 0.007-0.60, $\mathrm{P}=0.045)$, were found in a sample of healthy pregnant Mexican women. ${ }^{33}$ During the third trimester and early weeks of life, the fetus needs approximately 50 to 70 $\mathrm{mg} / \mathrm{kg} /$ day of DHA which, research has reported, is selectively incorporated into brain and retinal phospholipids 10 times faster than any other LCPUFA. ${ }^{16,67}$

Researchers used the Avon Longitudinal Study of Parents and Children (ALSPAC) to assess the impact of different levels of maternal seafood consumption during and after pregnancy on a child's development. At 32 weeks gestation, pregnant women filled out food frequency questionnaires to determine seafood intake, as well as, questionnaires, mailed at different times during pregnancy and after the child's birth to obtain socio-demographic information and information on behavioral and developmental outcomes. Seafood consumption was analyzed in grams, so a mom who had seafood three times a week, typically had an intake of 347 grams. Seventy-seven percent of these pregnant women had $\geq 340 \mathrm{~g}$ of seafood each week. Intakes less than $340 \mathrm{~g}$ during pregnancy was associated with increased risk for their children being in the lowest quartile for verbal intelligence quotient (no seafood consumption, OR 1.48, 95\% CI 1.161.90; some, 1.09, 0.92-1.29; overall trend, $\mathrm{p}=0.004)$, when compared with mothers eating $>340$ per week. $^{74}$ 
Several studies have reported similar results. At age four children's "Mental Processing Scores," which serves as a measure of intelligence in the Kaufman Assessment Battery for Children, were significantly correlated with mother's intake of cod liver oil (rich in omega-3 fatty acids) during pregnancy, when compared to those who took corn oil (deficient in omega-3 fatty acids) ( $\mathrm{P}=.049)$, and with plasma phospholipid concentrations of DHA ( $r=0.28, \mathrm{P}=0.02)$, at four weeks of age. ${ }^{75}$ Infants at 18 months of age, who drank formula supplemented with DHA+AA, had higher Mental Development Index (MDI) scores ( $\mathrm{t}=2.51, \mathrm{P}, 0.05)$, when compared to those who drank formula with no omega-3 or omega- 6 fatty acids. The MDI is the scale, in the Bayley Scales of Infant Development, $2^{\text {nd }}$ edition, that assesses memory, problem solving, discrimination, classification, language and social skills. At four months of age, plasma DHA correlated with infant scores at 18 months $(\mathrm{r}=0.32, \mathrm{P}=0.016) .{ }^{76}$ Child's hand and eye coordination scores have also been found to increase with supplementation of fish oil during pregnancy and positively correlate with cord blood erythrocyte levels of EPA ( $\mathrm{r}=0.331$, $\mathrm{p}=0.007)$ and DHA $(\mathrm{r}=0.308, \mathrm{p}=0.009) .^{77}$

A study determining the relationship between DHA and visual and neural development in healthy, term exclusively breast fed infants was completed by Innis and others. Red blood cell phosphatidylethanolamine DHA content, measured at 2 months of age, significantly correlated with visual acuity at 2 months $(\mathrm{r}=0.32, \mathrm{P}=0.01)$ and 12 months of age $(\mathrm{r}=0.30, \mathrm{P}=0.03) .{ }^{78} \mathrm{~A}$ similar positive association between red blood cell DHA content and visual acuity was found in 4 month ${ }^{79}$ and 1 year old ${ }^{80}$ infants. Innis et al. also found that infants of mothers' supplemented with DHA had higher visual acuities 
than those who ate their usual diet $(\mathrm{OR}=3.37, \beta=0.60$, and $\mathrm{SE}=1.93)$, which may suggest that some of the pregnant women were "DHA deficient." 81

\section{Omega-3 fatty acid intake of pregnant women in the United States}

Several studies have shown that pregnant and lactating women's omega-3 fatty acid intake is very important to their pregnancy outcomes as well as their fetus or infant's development, but little research has been done on the omega-3 fatty acid intakes of pregnant women in the United States. In the US, women of childbearing age are not meeting the recommended amounts of EPA and DHA intake, according to the NHANES 2009-2010. ${ }^{22}$ The Continuing Survey of Individuals 1994-1996, 1998 (CSFII) showed that pregnant and lactating women in the United States were getting approximately 50mg of DHA/day. ${ }^{82}$ Nochera et al. found that pregnant and lactating women in the Midwest were eating an average of 1.18 grams/month of EPA+DHA, which is $13 \%$ of the advisable intake of 9 grams/month, $300 \mathrm{mg} /$ day or 2 servings (up to $12 \mathrm{oz}$ ) of fish per week. ${ }^{25}$ Information on African American pregnant women's omega-3 fatty acid intake is limited, as evidenced by the studies presented in Table 2. Stark et al. reported omega-3 fatty acid intakes for an African American population. ${ }^{37}$ The intakes of pregnant and lactating women shown in Table 2, along with the intakes mentioned above, seem to provide evidence that pregnant and non-pregnant women are not meeting their needs for EPA and DHA intake.

\section{Dietary Assessment in Pregnant Women}

Maternal dietary intake has to meet the needs of the mother as well as provide adequate nutrient stores for the growth and development of the fetus and lactation after the baby is 
born. ${ }^{83,84}$ Common health issues that occur during pregnancy, including nausea, heartburn, constipation, emesis and changes in sense of taste and smell may lead to food preferences, aversions and general changes in food habits. ${ }^{85}$ Maternal concerns about the health of the fetus, weight gain and parenting may lead to increased nutrition awareness, leading to possible changes in dietary intake. ${ }^{85}$ In a sample of 278 Belgian women, Verbeke et al. found that significantly more pregnant women, when compared to nonpregnant women, indicated not eating foods with a heightened safety risk, mainly from potential microbiological contamination. ${ }^{86}$ In a cohort of pregnant women, Oken et al. observed that total fish consumption decreased approximately 1.4 servings per month (95\% CI 0.7,2.0), after a national advisory recommending that pregnant women limit certain fish due to possible mercury contamination. These women were surveyed before and after the advisory to assess changes in intake. ${ }^{87}$ Changes in food habits, whether they occur due to pregnancy related health issues like nausea or due to maternal concerns about the health of the fetus, make dietary assessment during pregnancy complicated but important due to the total dependence of the fetus on maternal food and nutrient intake for proper development. ${ }^{67,85}$ 


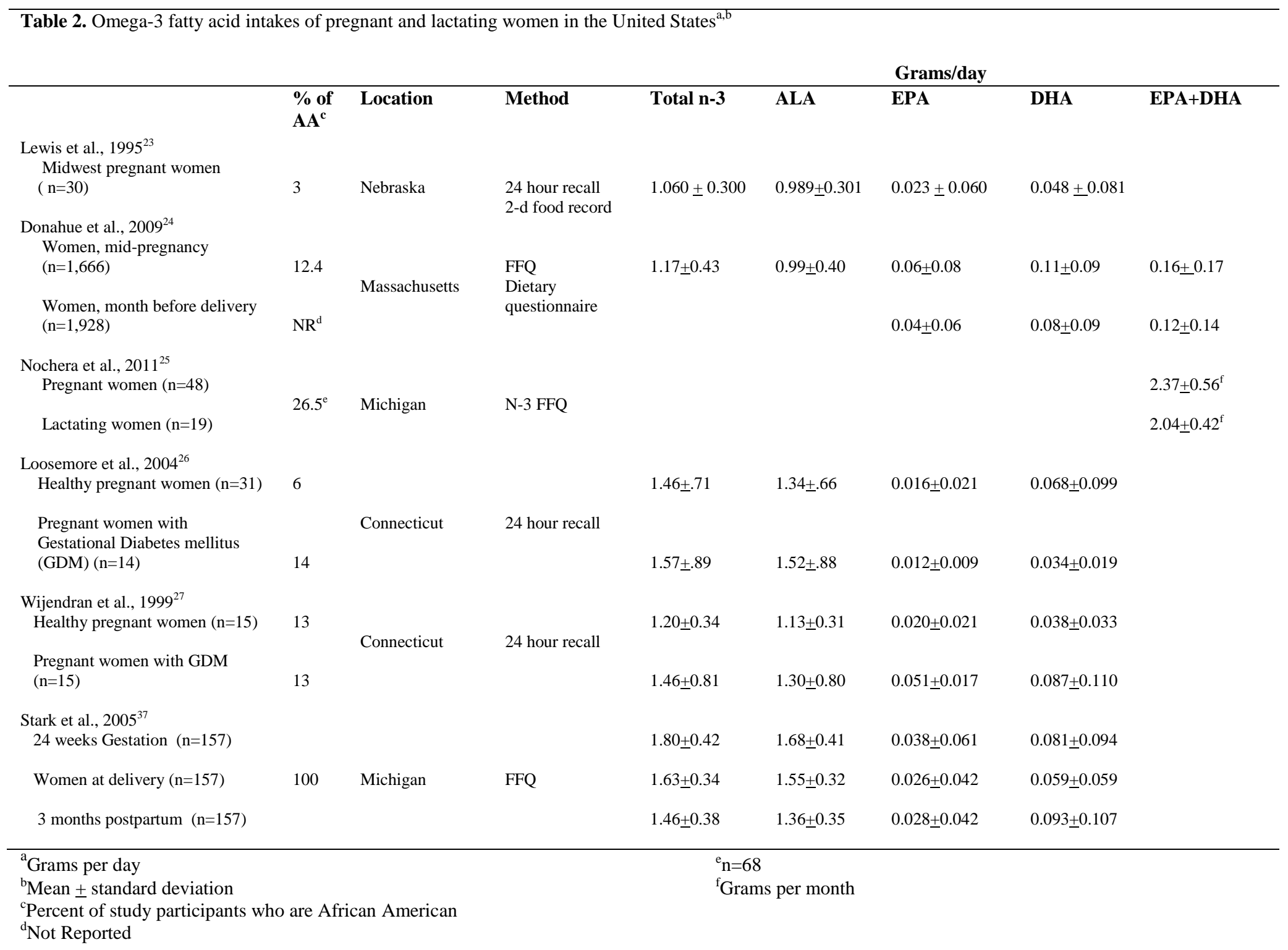




\section{Dietary assessment methods}

According to Gibson, methods used to measure individual's food intake can be placed into two groups. Recalls or records, also referred to as "quantitative daily consumption methods," are designed to measure the quantity of an individual's food intake over a period of one day. Estimation of "usual" intake can also be achieved with these same methods by increasing the number of days measured. Diet histories and food frequency questionnaires make up the other group of dietary assessment methods. These methods provide retrospective information on "usual" food intake patterns for a longer, less defined time period. ${ }^{29}$

All dietary assessment methods have inherent error and are random or systematic. ${ }^{29,32}$ Random errors are accidents like skipping questions and may occur across all subjects and all days. These types of errors can be minimized by increasing the administrations of the dietary method. Systematic errors refer to under- or over-reporting intakes or respondent bias like social desirability and approval biases. These errors may only be associated with some respondents (e.g. elder or obese), specific interviewers or certain foods (e.g. alcohol). ${ }^{29}$

\section{Twenty-four hour recall method}

In a 24-hr recall, subjects are asked, generally by a "trained" interviewer, to recall and report their intake, including all food and beverages, consumed in the previous 24 hours or preceding day. ${ }^{29,31}$ Currently, self-administered electronic recalls are available. ${ }^{31}$ Due to large within-person variations in dietary intake, research suggests that usual intake cannot be sufficiently determined by a single recall, so multiple recalls are required. ${ }^{29,30}$ Also, recalls should be done in such a way that all days of the week are represented, 
which takes into account any effects that different days have on food or nutrient intakes. ${ }^{29}$ Experts suggest a successful interview should be done by someone educated in foods and nutrition, ideally a dietitian or someone trained in how to use a standardized recall form and knowledgeable about foods in the marketplace, regional and ethnic foods, as well as, preparation techniques. ${ }^{31}$ Standardized, nonjudgmental, open-ended probing questions should be used to help the respondent remember foods and specific details, like food preparation techniques. ${ }^{31,32}$ Whenever possible, the interview should happen in the respondent's home, placing the respondent at ease and in familiar surroundings to help improve participation and memory of foods eaten. ${ }^{29,31,32}$

There are advantages and disadvantages to this dietary assessment method. Recall advantages include that subjects are not required to be literate because the interviewer administers the tool and records the answers. Because the recall requires food consumption from the previous day, subjects are generally able to remember most of their dietary intake. When compared to food records: 24-hour recalls are more representative of the population secondary to low subject burden; the trained interviewer is able to gain details so that the food can be accurately researched later; and recalls have less potential to effect dietary behavior since they occur after the food has been consumed. The main disadvantage of 24-hour dietary recalls is that subjects may not accurately report their food intake, related to knowledge, memory or the interview situation. ${ }^{31}$ According to Gibson, a successful 24-hour recall depends on several factors: the subject's memory, the subject's ability to accurately report portion size estimates, the subject's motivation and the interviewer's persistence. ${ }^{31}$ 
A new 24-hour dietary recall instrument is the United States Department of Agriculture's (USDA) 5-step Multiple Pass Method, which is used in the U.S. National Health and Nutrition Examination Survey (NHANES). The first step is a "Quick List," this is where the interviewer collects a list of foods and beverages consumed the previous day. "Forgotten Foods," the second step, is where the interviewer probes for foods forgotten on the quick list. The third step, "Time and Occasion," involves the collection of time and eating occasion for each food. The fourth step, "Detail Cycle," involves the collection of a detailed description, amount and additions for each food. This step is a review for the 24 hour day. The fifth and final step, "Final Probe" is the last probe for any other foods consumed ${ }^{88}$ Research indicates that this method assessed mean intake within $10 \%$ of mean actual intake for normal, overweight and obese women.$^{90}$

\section{Dietary (food) records}

The two categories of food records are estimated food records and weighed food records. In both types of food records, subjects record all foods and beverages (ideally at time of consumption) and amounts consumed over a specified time period. Since all foods and beverages are described in detail, including brand name, their method of preparation and cooking, respondents should be trained, in advance, to do a food record. Common household measuring cups and spoons, scales, food models or pictures can be used to measure or estimate amounts consumed. ${ }^{29,31}$ In weighed food records, the subjects also weigh all foods and beverages consumed. Once the recording period ends, a trained interviewer should review the record with the respondent, to ensure an adequate description of foods and preparation methods. ${ }^{31,32}$ According to Gibson, the number of days for food records depends on the objective of the study. One day is adequate to 
describe intake in a group, as long as all days of the week are equally represented. ${ }^{29}$ Other researchers suggest that if multiple days are recorded, then typically no more than seven days are included, and anything more than four days may lead to an increase in respondent fatigue.$^{31}$

Recording foods when consumed, not relying on memory, is a characteristic of food records that increases the potential for providing more accurate portion sizes, lessening the problem of omission and providing greater food detail. ${ }^{31}$ On the other hand, subjects may delay recording intake for several hours, therefore increasing their reliance on memory, change their eating habits or decrease the amounts consumed to simplify the measuring or weighing process or to impress the investigator. ${ }^{29,31,32}$ Food records have higher respondent burden than 24-hr recalls and require subjects to be highly motivated, trained and literate, which may limit the use of this dietary assessment technique in some populations. ${ }^{29-31}$ Weighed food records result in increased reproducibility, when compared to estimated food records, secondary to the food being weighed. ${ }^{29}$

\section{Dietary history}

The dietary history, introduced by Burke in $1947^{90}$, tries to estimate the individual's usual food intake, which includes characteristics of the foods, and meal patterns over a long period of time. Burke's dietary history included three components. ${ }^{29,31}$ The first component consisted of an interview obtaining a usual pattern of eating, including detailed food descriptions, frequency of consumption and usual portion sizes expressed in common household measures. The second component consisted of a questionnaire that assessed the consumption frequency of certain foods. ${ }^{29}$ 
The third component was a three day food record. Both the second and third component are treated as crosschecks or to check the internal consistency of the first component. ${ }^{29-31}$

A strength of the dietary history method is the combination of assessing meal patterns and food details when compared to other dietary assessment methods that just look at intake for a short period of time or only frequency of consumption. ${ }^{22}$ Time periods for this type of dietary assessment varies and a maximum time has not been established. Shorter time frames, one month or less, leads to increased reproducibility and validity when compared to longer periods. Diet histories that last longer than a year may be unrealistic. ${ }^{21}$ A disadvantage is that subjects have to make many judgments about their usual food intake and amounts consumed which prompts the suggestion that data collected from dietary histories should be considered relative rather than absolute. ${ }^{22}$ Interviews can last from one to two hours which can be labor intensive and require a lot of cooperation from the respondent. ${ }^{29,30}$

\section{Food frequency questionnaire}

The food frequency questionnaire (FFQ) attempts to assess subject's "usual" frequency of food consumption over a specified period of time. ${ }^{29,91}$ The simplest FFQ consists of a list of foods which ask for frequency of use and sometimes include portion sizes. Specific groups of foods, particular foods or foods that are eaten on special events or seasons can be included in the food list, but other characteristics of foods eaten, like preparation methods, are not included. ${ }^{29,31}$ Nutrient intake estimates are derived by adding the products of the reported frequency weight of each food by the amount of nutrient in a specified serving of that food, to produce an estimated daily intake of 
nutrients. For example, an assigned frequency weight of one is given to "once a day," 2.5 to “2-3 times per day” or .43 for 2-4 times per week. ${ }^{29,31}$

The Block Food Frequency Questionnaires, ${ }^{92-95}$ the Harvard University Food Frequency Questionnaires or Willett Questionnaires ${ }^{95-98}$ and the National Cancer Institute's Diet History Questionnaires, ${ }^{96}$ the Fred Hutchinson Cancer Research Center Food Frequency Questionnaires ${ }^{99,100}$ are commonly used FFQs to assess dietary intake. Experts suggest that an FFQ should be culturally and population specific. ${ }^{30,31}$ FFQs can be created or adapted to fit the population or purpose needed for the specific study. ${ }^{31}$ Willet suggests if an FFQ has been created for a different population, then what is being studied, the addition of some population specific foods to the existing questionnaire, may be desirable. $^{32}$

When developing or adapting an existing FFQ, researchers advise to define the purpose of the dietary method. ${ }^{101,102}$ For example, determining the population of interest is important. ${ }^{101,102}$ When creating an FFQ for a specific population subgroup, Subar advises seeking out recent population specific data that can be used to determine the foods, portion sizes and nutrient database to include. ${ }^{103}$ The objective of the FFQ may be to measure either the total daily diet, specific food groups or only specific nutrients. Willet suggests that a more "comprehensive assessment" of the diet is desirable, for example, the end of the study may bring important questions about the diet that were not apparent at the beginning, and a restricted food list may not include a food that, in retrospect, is important. But if the purpose is to focus on a few nutrients or the list is highly restricted, it may be best to select a list of foods identified by other investigators as important predictors of those nutrients, if the cultural background of the study population 
is similar. ${ }^{32}$ The objective of the FFQ may be to rank individuals or to provide a measure of estimated intakes. ${ }^{32,101}$ FFQs meant to measure estimated intakes have to collect more comprehensive information, but researchers have to be careful to not create an excessively long questionnaire, which could lead to respondent fatigue and boredom. Defining the purpose of the FFQ assists in the development of the food list. ${ }^{32,101,104}$

Several approaches can be used to compile the food list, which is important to the success of the questionnaire. ${ }^{102}$ Foods that are rich in the nutrient or nutrients of interest can be identified and compiled from food composition tables, but this strategy may lead to the inclusion of foods, that even though they contain substantial amounts of the nutrient of interest, they are not eaten enough to be important. ${ }^{32}$ According to Willett, for a food item to be informative, it must: be eaten reasonably often by an appreciable amount of individuals, contain a substantial amount of the nutrient of interest and be discriminating, meaning intake varies from person to person. ${ }^{32}$ Another approach is to start with a long list and remove the foods most infrequently eaten, which can be accomplished by pilot testing the questionnaire. The problem with this approach is foods with high between-person variation, which is more informative than those foods that are of similar average use, may be deleted. Or after pilot testing the food list, which may originate from sources including food composition tables, national survey data, or a Registered Dietitian, foods with low predictive values are discarded, then stepwise regression analysis can be used to further determine the foods that are most predictive of the nutrient of interest. ${ }^{32,101}$ Another option is the use of diet records or 24 hour recalls to collect data from the population of interest to determine the foods and portion sizes to appear on the food list. ${ }^{103}$ For example, Jensen et al. created an FFQ to assess the calcium 
intake of Asian, Hispanic and White youth, the foods for the FFQ were selected from food composition tables, existing dietary questionnaires and epidemiological data on food consumption patterns of the population measured. ${ }^{104}$ Twenty-four hour recall data was used to construct a food list for a quantitative food frequency questionnaire (QFFQ) for low-income inner city African Americans. For every food item, the place where the food was obtained, amount consumed, additions such as butter, gravy, skin on chicken, etc. and methods of cooking was recorded. Healthy foods, like baked chips, low fat milk and high-fiber low calorie cereals, that will be highlighted in a nutritional intervention in this population to decrease the risk of chronic disease, were added as well. ${ }^{105}$ Buchowski et al. created a FFQ for use with 40-79 year old men and women living in the southeastern region of the United States. The food list consisted of foods, in the NHANES-III database, that were frequently eaten by African Americans and/or whites in the NHANES-III sample, foods that differentiated between the eating behaviors of the aforementioned racial groups and those that contributed meaningfully to intake of cancerrelated nutrients, including total energy, saturated fat, fiber, vitamin A, vitamin E and vitamin C. ${ }^{106}$

Frequency and portion size are the next issues to consider once the food list is compiled. ${ }^{102}$ Research suggests that frequency options should be anywhere from 1 to 12 , but if every food is given the same options, then five choices would be too few and result in loss of information. ${ }^{32,102}$ Cade et al. suggests that is important to have frequency categories that reflect intake of most foods (e.g. number of times per week); however, for foods that are eaten infrequently but may contain a substantial amount of the food component of interest, it is important to include a less frequent option (e.g. less than once 
a month). ${ }^{102}$ Another option is the use of an open-ended format, where respondents have the option of answering in terms of frequency per day, week or month. In theory, this may enhance some precision in reporting but, Subar, found that multiple choice frequency options increased clarity and reduced errors when compared to open-ended formats. ${ }^{32,107}$

Several options are also available when reporting portion sizes on FFQs. Researchers can collect no portion information, specify a portion size as part of the food line item or include discrete questions, for portion sizes, for each food. ${ }^{101}$ The collection of no portion information is considered a "simple" or "non-quantitative" food frequency questionnaire, which may be useful if the estimated intake of the total diet is not required, the population of interest is homogenous or if it is unlikely that the respondent can answer the portion questions. ${ }^{102}$ Average portion sizes, specific to the population being studied, can be obtained from existing data, including national survey data, to help calculate gram weights and nutrient intakes. ${ }^{101,102}$ A FFQ which collects portion information as part of the food line item is called a "semi-quantitative" food frequency questionnaire. Portion information provides clarity and answering is relatively easy for foods that come in standard units, like one egg, a slice of bread or cookies; however, portion size information for foods without a standard or natural unit, such as meat, rice and pasta can be cognitively difficult. If the respondent's normal intake is twice the given "typical" portion amount, they will then be required to double the amount. The third option is a "quantitative" food frequency questionnaire, which offers discrete portion sizes or additional items for each food to describe the portion size. ${ }^{32,102}$ For example, the Block FFQ provides pictures of each food item in amounts corresponding to the portion 
size choices (e.g. $1 / 4$ cup, $1 / 2$ cup and 1 cup) given. Respondents who are able to conceptualize the portion size clearly and relate it to their own eating habits seem to provide the most useful portion size information. ${ }^{32}$ This would seem to be best accomplished by a "quantitative" FFQ, because they offer the clearest information about portion sizes. ${ }^{101}$

The FFQ dietary assessment method has several strengths. Administration and processing is inexpensive because most FFQ are created to be self-administered and take approximately 30 to 60 minutes to complete based on the subject. Because the FFQ ask information about diet from a prior time period, respondents are able to avoid changes in diet. ${ }^{29} \mathrm{~A}$ disadvantage is the amount of measurement error that can occur, which comes from the inability to list all possible foods, errors in frequency and serving size estimates. ${ }^{29,30} \mathrm{FFQs}$ may not provide estimation of absolute nutrient intake, due to lack of specificity and detail, when compared to 24 hour recalls and diet records. ${ }^{30}$ Due to the error inherent in the FFQ approach, FFQ data is not considered appropriate to use to estimate quantitative parameters such as, the mean and variance of a population's absolute intake. Rather, nutrient intake as measured by an FFQ should be considered an "approximation," and is typically used to rank individuals according to food or nutrient intake or to assess the association between dietary intake and disease risk. ${ }^{31}$

\section{Reliability and validity of food frequency questionnaires}

Reliability refers "to the consistency of questionnaire measurements on more than one administration to the same persons at different times"; validity refers to "the degree to which the questionnaire actually measures the aspect of diet that it was designed to 
measure." ${ }^{, 2,108}$. Reliability and validity should be measured with any new FFQ or a previously tested FFQ that will be used with a different population. ${ }^{32}$

\section{Reliability}

When a dietary assessment method, in this case the FFQ, is administered repeatedly, generally two times, in the same situation and provides similar results, it is considered reliable. ${ }^{29}$ This is also called a "test-retest" design. ${ }^{90}$ Researchers suggest four to eight weeks time between administrations of the questionnaire, because subjects may remember their previous responses if the interval is too short. ${ }^{32,108}$ Changes in food habits or effects of seasons can also influence reliability measurements. An example of this would be decreases in reliability that has been assessed over long intervals, such as several years, should be due to true changes in food habits. ${ }^{29,32}$ Reliability is considered a function of both the uncertainty resulting from true variation in daily nutrient intakes due to both among and within individuals and random measurement errors. ${ }^{29}$

Experts vary on their interpretation of reliability studies. Willet et al. suggests that a low degree of reliability indicates that the questionnaire does not provide a valid measure of long term intake ${ }^{109}$; however, Gibson ${ }^{29}$ suggests that lack of agreement between two nutrient intake results may not reflect poor reliability in the method, but the nutrient intake may have changed in the interval between the two administrations of the method. Researchers do agree that a high degree of reliability does not necessarily mean the FFQ is reliable. For example, FFQs tend to have higher reliability than others because of its design to assess usual food intake over a long period of time, resulting in insensitivity to daily variations in intake. ${ }^{29}$ Or a high correlation between administrations 
could be the result of correlated error (i.e. systematic within-person error), for example, a questionnaire that is missing important sources of a nutrient may have high reliability but does not provide a true measure of intake for that nutrient. ${ }^{109}$ In the literature, typical correlation coefficients between repeat administrations of FFQs range from $0.5-0.8$, for various nutrients. ${ }^{29,108,109}$

Reliability can be assessed statistically by several methods. A review done by Cade, et al. found that the most frequently method used is correlational analysis, ${ }^{102}$ but other methods are used, including: ANOVA, paired test on the mean or median intake, and the Bland-Altman method. ${ }^{29,102}$

Correlation analysis refers to the use of: intraclass correlation coefficients, which are usually used to calculate agreement on an individual basis; Pearson correlation coefficients, which are used for normally distributed data; and/or Spearman's rank nonparametric correlation coefficients for non-normal distributions. ${ }^{29}$ As mentioned previously in this review of literature, Jensen et al. created an FFQ to measure calcium intakes of Asian, Hispanic and White youth. After administration of two FFQs, four weeks apart, the test-retest reliability correlation coefficient was $0.68 .{ }^{104}$ Researchers adapted the 1998 Block FFQ to measure micro- and macronutrients in a population-based sample $(n=166)$ of Canadian women aged 25 to 74 years of age. The first and second FFQ were completed an average of 56 days apart, with reliability correlation coefficients (Pearson's r) ranging from 0.57 (percentage of energy from protein) to 0.90 (percentage of energy from alcohol) for macronutrients and 0.65 (iron) to 0.88 (vitamin C) for micronutrients. ${ }^{110}$ Willet et al. administered two semi-quantitative FFQ to 173 women, a 
year apart. Intraclass correlation coefficients ranged from 0.49 (total vitamin A) to 0.79 (sucrose). ${ }^{98}$

Cronbach's Alpha is also a statistical method used to measure reliability, specifically internal consistency reliability. Cronbach's alpha assesses the variability between the individual nutrient intakes relative to the total variability of intakes, as measured by the administrations of the FFQ. A high coefficient alpha means the FFQ is able to differentiate between respondents' nutrient intake, meaning there is higher between-person variation in nutrient intakes than within-person variation, and is reliable. ${ }^{111}$ Ritter-Gooder, et al. validated an FFQ, to measure omega-3 fatty acid intakes, in women $(\mathrm{n}=17)$ and men $(\mathrm{n}=11)$ at an outpatient cardiac clinic. Test-retest reliability for the two administrations of the FFQ two weeks apart, indicated a coefficient alpha of 0.83. Researchers concluded that the FFQ was reliable to measure omega-3 fatty acid intakes in the study population. ${ }^{112}$ A multicultural FFQ was developed and validated to measure nutrient intakes in young women in the Southeastern United States. The dietary instrument was validated in two sample populations, college women $(n=95)$ and lowincome postpartum women $(\mathrm{n}=50)$. The Cronbach's alpha for internal consistency reliability was an average of 0.75 for the food groups represented in the FFQ, for college women and 0.73 for low-income women. ${ }^{113}$

In conclusion, even though a reliability study does not necessarily tell whether the instrument is producing the correct or same answer, there are definite benefits such as, they are: relatively easy to do and can uncover problems in instrument design, respondent instructions or quality control, which can aid in improvement of the questionnaire. ${ }^{108}$ Experts suggest the reliability of an FFQ depends on many variables, including: 
- $\quad$ time frame of the method ${ }^{29}$

- $\quad$ population group under study ${ }^{29}$

- $\quad$ nutrient of interest ${ }^{29}$

- technique used to measure the foods and quantities consumed ${ }^{29}$

- $\quad$ between- and within- subject variances ${ }^{29}$

- variability of portion sizes or frequency choices ${ }^{108}$

- adequacy of the instructions given to the respondent ${ }^{108}$

- poor quality control techniques, like inadequate attention to recoding or double keying leading to simple coding or typing errors ${ }^{108}$

\section{Validity}

Validity can be absolute or relative. Since absolute validity, which compares food intake during and either before or after the study period, is time consuming and fraught with practical difficulties, it is generally determined in dietary studies that have a limited number of subjects or only cover a relatively short time period. ${ }^{29}$ Relative validity, which can be assessed on dietary methods covering short- and long-term time frames, is defined as the comparison of the "test" method with another method, on the same subjects, termed the "reference' method or "gold standard."29,32,108 Researchers list several factors to consider when designing a validity study, including:

\section{- $\quad$ Selection of subjects}

When designing a validation study, the study should occur in a sample that is representative of the population under study. For example, the Diet and Physical Activity Sub-Study (DPASS), a sub-study within the Jackson Heart Study (a longitudinal cohort 
study to investigate risk factors associated with coronary vascular disease in African American populations in Jackson, MS), was conducted to examine the validity of The Delta NIRI Jackson Heart FFQ and Delta NIRI Jackson Heart Study FFQ, which were originally developed to measure nutrient intake in African American and White adults living in the lower Mississippi Delta. A representative subset of African American participants $(n=499)$ were chosen from the original cohort $(N=5,302)$ to participant in the validation study. ${ }^{114}$

- $\quad$ Sample size for validation study

Sample size is often determined based on the statistical methods used for reliability and validity of the questionnaire. ${ }^{108}$ For example, if using correlation coefficients, 100 to 200 participants should be adequate as long as a sufficient number of days of dietary intake, typically 14 to 28 , are obtained to reasonably describe an individual's diet. $^{32,102}$

- Selection of "reference" method

Since all dietary methods have inherent errors, the goal is to choose two methods which have errors that are independent or uncorrelated with each other to avoid high estimates of validity. ${ }^{32,102}$ The most practical reference methods, to validate an FFQ, are diet records or 24 hour recalls, but these are both considered to have errors that correlate with errors in the FFQ. ${ }^{30}$ Diet records are considered, by some researchers, to have fewer correlated errors, because they are open-ended, do not depend on memory, portion sizes are measured during recording and errors related to interpretation are more at the level of the coder than the subject. ${ }^{11}$ Thompson et al. states that neither recalls or records are good 
reference methods because neither represent the time period of interest ${ }^{30}$; but Willet et al. ${ }^{109}$ suggest that food records should be collected so that they cover the interval of time corresponding to the questionnaire. Even though errors inherent in 24 hour recalls may be similar to those found in FFQs, when subjects are illiterate or less motivated, recalls are the most reasonable option. ${ }^{109}$

- $\quad$ Sequence of the test and reference method administrations

In general, it is suggested that the test instrument is given prior to the reference method, because administration should mimic what would actually happen in the proposed study and the process of collecting one method could influence collection of the other method by possibly drawing attention to one's diet. ${ }^{29,102,109}$ Willet et al. suggests that the test method be completed before and after the reference method, especially with diet records; therefore providing a conservative estimate (administering an FFQ before the detailed assessment dietary intake seems to result in artificially low correlations) and an optimistic estimate (administrating an FFQ after a detailed assessment of intake may sensitize the subject to their food intake and artificially improve accuracy in completing the FFQ) of the true correlation between the FFQs and the reference method. ${ }^{29,109}$

- $\quad$ Time frame

The time frame of the method in relation to the FFQ needs to be considered when conducting a validation study. On average, "true" intake is usually measured over a long period of time, so the reference method reflects this longer time frame. ${ }^{109}$ Cade et al. provided the example of an FFQ that assesses intake over a period of one year that could be administered twice, a year apart, and compared to diet records that are collected in intervals during that year. ${ }^{102}$ 
There are several statistical methods used to measure validity. Correlation analysis, which was discussed earlier in this review of literature, is considered the most commonly used method to measure the strength of the relationship at the individual level, between intakes from the test and the reference dietary method. Gibson recommends that if the data are not normally distributed, it should be transformed to increase normality, before the correlation coefficients be computed. Other statistical methods include, the paired t-test or Wilcoxin signed rank test, regression analysis and Bland-Altman method. $^{29}$

\section{Reliability and validity of FFQs measuring omega-3 fatty acid and fish intakes}

Lora et al. validated a FFQ in first-generation Midwestern Latinas $(n=162)$ to measure intakes of omega 3 fatty acids. From a FFQ that was previously validated in a cardiac population, the culturally specific dietary instrument was developed by interviewing and obtaining 24 hour recall data from five first-generation Latinas, to help describe the major food contributors of omega-3 fatty acids, as well as obtain recipes and portion size information for culturally specific dishes. The FFQ was then pilot tested in a convenience representative sample of 10 Latinas. The resulting n-3 FFQ, which contained 183 food items and 26 prepared dishes (15 culturally-specific dishes), was administered twice, one month apart, and to test validity, three nonconsecutive 24 recalls were done within the corresponding month. Test-retest reliability coefficients for the two administrations of the FFQ were $0.71,0.65,0.74,0.54$ for total omega-3 fatty acids,

ALA, EPA and DHA $(\mathrm{P}<.01)$, respectively. The Pearson correlation coefficients for the 
means of the 2 FFQs and the 24 hour recalls were $0.32,0.34,0.28$ and 0.24 for total omega-3 fatty acids, ALA, EPA and DHA, respectively. After running a paired t-test, the means of the FFQs and 24 hour recalls were not significantly different for total omega-3 fatty acids and ALA (P>.05) indicating that there was no detectable bias and the FFQ was valid for measuring these nutrients. ${ }^{115}$

A FFQ to measure EPA and DHA intake in Canadian adults was assessed for relative validity in 78 Canadian men and women. Patterson et al. adapted an existing Australian FFQ previously assessed for validity and reproducibility by adding whole foods, functional foods and nutraceuticals containing EPA and/or DHA from the Canadian Nutrient File (a source of nutrition information for foods commonly eaten in Canada), internet searches and visits to local grocery chains and specialty food stores. For validity, the Canadian FFQ was compared to 3-day food records, typically returned within two weeks of FFQ administration, and whole blood biomarker measurements of EPA and DHA. After intakes were $\log _{\mathrm{e}}$ transformed, the food record and blood biomarker measurements of EPA and DHA were moderately correlated with the FFQ for EPA, DHA and EPA+DHA with Pearson correlation coefficients of $0.31,0.49,0.38$ and 0.31 , 0.42, 0.43, respectively. Using Wilcoxin signed rank test, no significant difference was found between intakes measured by the FFQ and food records $(\mathrm{P}=0.93)$. Overall, researchers concluded that the Canadian FFQ was an adequate tool for ranking and estimating habitual EPA and DHA intakes of Canadian adults. ${ }^{116}$

A brief 21-item FFQ, to measure ALA, EPA and DHA, was validated against plasma PUFA levels, in a sample of adults with $(n=34)$ and without $(n=27)$ Major Depressive Order living in New York City. The FFQ was developed using the National 
Cancer Institute's Diet History Questionnaire as a model and included specific seafood and fish available in the metropolitan New York area, as well as, foods rich in ALA. Blood samples were obtained on the same day that the FFQ was administered. Using Spearman's rho for nonparametric data, correlation coefficients between the FFQ and plasma values were $\mathrm{r}=0.50(\mathrm{p}<0.0001)$ for DHA, $\mathrm{r}=0.38(\mathrm{p}=0.002)$ for EPA and $\mathrm{r}=0.22$ $(p=0.086)$ for ALA. Since ALA intake as estimated by the FFQ and plasma levels were not correlated, so Sublette et al. concluded that the FFQ was valid to measure EPA and DHA intake in healthy and depressed patients. ${ }^{117}$

\section{Reliability and validity of FFQs measuring omega-3 fatty acid intake in pregnant populations}

FFQs to measure omega-3 fatty acid intakes, in pregnant women are limited, and due to the importance of omega-3 fatty acids in maternal and infant health outcomes, increased knowledge on intakes and appropriate dietary assessment methods to measure these intakes seems warranted.

As part of a larger study, pregnant women filled out a FFQ meant to measure intakes over the past year and provided blood samples. An FFQ, previously validated in Mexican women, was adapted by adding extra food sources of omega-3 fatty acids, and tested for validity in pregnant Mexican women ( $n=35)$.FFQ intake of ALA, DHA and EPA were validated against erythrocyte cell membrane phospholipid content of the three PUFAs. Pearson correlation coefficients were $0.32,0.35$ and $0.36(\mathrm{P}<0.05)$ for ALA, DHA and EPA, respectively. In a linear regression model, erythrocyte DHA and AA were significantly related to their dietary intakes $(\beta=0.30,95 \% \mathrm{CI}: 0.007-0.60, \mathrm{P}=0.045$ for DHA; $\beta=0.49,95 \%$ CI: $0.010-0.98$ for AA) and the relation between erythrocyte ALA 
and dietary ALA intake reached significance, after adjustment $(\beta=0.44,95 \%$ CI: 0.026 -

0.825). Parra et al. concluded these pregnant Mexican women's omega-3 fatty acid intakes correlated reasonably well with their erythrocyte cell membrane phospholipid status; however, it should be considered that the faster turnover of PUFAs from fat storage, intrinsic to pregnancy, may modify the profile of erythrocyte PUFAs resulting in lower correlations with dietary intake. ${ }^{33}$

Fawzi et al. calibrated an existing semi-quantitative FFQ to measure several nutrients, including long chain omega-3 fatty acids and ALA, in African American $(n=72)$ and Caucasian $(n=132)$ pregnant women. For calibration purposes, researchers pooled aliquots of individuals in the same decile of dietary intake for a particular nutrient, analyzed the samples then compared them to the biomarkers across categories of nutrient intakes. After combining two sets of deciles together, eight pooled specimens for each nutrient were prepared and separate pools were created for African Americans and Caucasians. Percentage of long-chain omega-3 fatty acids in red blood cell measurements increased $48 \%$ and $68 \%$ from the bottom to the top deciles of intake for African Americans and Caucasians, respectively. Increases of $1.72 \%$ and $4.79 \%$ per gram of intake were noted for erythrocyte concentrations of long chain n-3 fatty acids $(\mathrm{p}=0.09$ for African American women and $\mathrm{p}=0.0001$ for Caucasian women). There was no difference found for ALA between erythrocyte concentrations and deciles of intakes. This FFQ was considered valid to measure long chain omega-3 fatty acids but not ALA. ${ }^{38}$ Another FFQ was validated in a sample of 923 pregnant women. Fish intakes were compared to erythrocyte and plasma concentrations of omega-3 fatty acids. Researchers used a multivariable linear regression analyses with robust variances to 
assess associations between various fish intake or erythrocyte fatty acid content with plasma lipid concentrations. As frequency (less than once a week, once a week, twice a week and more than twice a week) of maternal self-reported fish consumption increased, so did mean erythrocyte omega-3 fatty acid (EPA, DHA, long chain omega-3 fatty acids) increased (all trend p-values were $<0.001$ ), with strong linear increases in mean erythrocyte EPA and DHA for each higher category of intake. ${ }^{11}$

\section{Reliability and validity of FFQs measuring omega-3 fatty acid intake in pregnant African American populations}

To date, there have not been any FFQs created specifically to measure omega-3 fatty acid intakes in African American pregnant women. As mentioned earlier, Fawzi et al. calibrated an FFQ in a sample of 72 African American pregnant women with an FFQ that was previously validated in a low-income multicultural population, including African Americans. ${ }^{38}$ But currently, no FFQ has been adapted by the addition of omega-3 fatty acid rich foods that are specific to African American culture and eaten commonly by this race of people. Since food and nutrient intakes vary among ethnic groups, dietary practices may help to provide an explanation for the diversity of disease and problematic outcomes. ${ }^{118}$ For example, African Americans suffer disproportionately from many health issues, when compared to other races, including preterm birth, which is possibly associated with lower omega-3 fatty acid intakes. ${ }^{28}$ Stark et al. administered an FFQ and determined fatty acid compositions of plasma and erythrocyte total lipid abstracts at 24 weeks gestation, at delivery and three months postpartum of 152 African American pregnant women. ${ }^{37}$ Omega-3 lipid intakes are listed in Table 2. Researchers concluded 
that the low intake amounts and blood levels of DHA may not support optimal fetal DHA accretion and subsequent neural development, in this population. ${ }^{37}$

Low fish or DHA intakes in African American women may be attributable to a variety of issues. James conducted six focus groups to explore the impact of culture and community on nutrition attitudes, food choices and dietary intake in a population of African American men and women in northern Florida. She found that barriers to healthy eating, included poor taste of healthy foods, the expense of healthy foods and lack of information. To this population, eating healthfully was perceived as giving up part of ones' cultural heritage and trying to conform to the dominant culture. ${ }^{119}$

When specifically focusing on fish and DHA intakes, fish intakes vary by region of the United States. Mahaffey et al. looked at blood mercury $(\mathrm{BHg})$ distributions within U.S. Census regions and within coastal and noncoastal areas among women of childbearing age, their association with fish consumption and changes from 1999 through 2004. Intakes and BHg concentrations were obtained from NHANES 1999-2004 data. Elevated $\mathrm{BHg}$ occurred more commonly in women in coastal regions and the lowest exposures were reported in the Midwest. Results suggest women living in coastal areas consume more fish and shellfish when compared to those living in non-coastal areas. ${ }^{120}$ In conclusion, omega-3 fatty acid intakes of pregnant and non-pregnant women have been found to be below recommended levels. FFQs to measure these intakes are limited but this is especially seen in African American cultures who suffer from health disparities. Experts suggest that development and validation of culturally appropriate dietary measures are important to identify the role diet plays in the etiology of diseases. ${ }^{118}$ 


\section{References}

1. Genius SJ. A fishy recommendation: omega-3 fatty acid intake in pregnancy. BJOG. 2008;115(1):1-4.

2. Ratnayake WM, Galli C. Fat and fatty acid terminology, methods of analysis and fat digestion and metabolism: a background review paper. Ann Nutr Metab. 2009;55(13):8-43.

3. Simopoulos, AP. Evolutionary aspects of diet: the omega-6/omega-3 ratio and brain. Mol Neurobiol. 2011;44(2):203-215.

4. Institute of Medicine. Dietary Reference Intakes for Energy, Carbohydrate, Fiber, Fat, Fatty Acids, Cholesterol, Protein, and Amino Acids. Washington DC: National Academy Press; 2005: 427.

5. Kris-Etherton PM, Shaffer Taylor D, Yu-Poth S, Huth P, Moriarty K, Fishell V, Hargrove RL, Zhao G, Etherton TD. Polyunsaturated fatty acids in the food chain in the United States. AM J Clin Nutr. 2000;71(suppl):S179-S188.

6. Innis SM. Dietary (n-3) fatty acids and brain development. J Nutr. 2007;137(4):855859.

7. Olson DM. The role of prostaglandins in the initiation of parturition. Best Pract Res Cl Ob.2003;17(5):717-730.

8. Olsen SF, Secher NJ, Tabor A, Weber T, Walker JJ, Gluud C. Randomised clinical trials of fish oil supplementation in high risk pregnancies. Brit J Obstet Gynaec. 2000;107(3):382-395.

9. Olsen SF, Secher NJ. Low consumption of seafood in early pregnancy as a risk factor for preterm delivery: prospective cohort study. BMJ. 2002;324(7335):447-451.

10. Olafsdottir AS, Magnusardottir AR, Thorgeirsdottir H, Hauksson A, Skuladottir GV, Steingrimsdottir L. Relationship between dietary intake of cod liver oil in early pregnancy and birthweight. BJOG. 2005;112(4):424-429.

11. Williams MA, Zingheim RW, King IB, Zebelman AM. Omega-3 fatty acids in maternal erythrocytes and risk of preeclampsia. Epidemiology. 1995;6(3):232-237. 
12. Williams MA, Frederick IO, Qiu C, Meryman LJ, King IB, Walsh SW, Sorensen TK. Maternal erythrocyte omega-3 and omega- 6 fatty acids, and plasma lipid concentrations are associated with habitual dietary fish consumption in early pregnancy. Clin Biochem. 2006;39(11):1063-1070.

13. Freeman MP, Hibbeln JR, Wisner KL, Brumbach BH, Watchman M, Gelenberg AJ. Randomized dose-ranging pilot trial of omega-3 fatty acids for postpartum depression. Acta Psychiatr. 2006;113(1):31-35.

14. Hibbeln JR. Seafood consumption, the DHA content of mother's milk and prevalence rates of postpartum depression: a cross-national, ecological analysis. J Affect Disorders.2002;69(1):15-29.

15. McNamara RK, Carlson SE. Role of omega-3 fatty acids in brain development and function: potential implications for the pathogenesis and prevention of psychopathology. Prostaglandins Leukot Essent Fatty Acids. 2006;75(4-5):329-349.

16. Greenberg JA, Bell SJ, Van Ausdal W. Omega-3 fatty acid supplementation during pregnancy. Rev Obstet Gynecol. 2008;1(4):162-169.

17. Burdge GC, Calder PC. Conversion of $\alpha$-linolenic acid to longer-chain polyunsaturated fatty acids in human adults. Repro Nutr Dev. 2005;45(5)581-597.

18. Brenna JT, Salem Jr. N, Sinclair AJ, Cunnane SC. $\alpha$-linolenic acid supplementation and conversion to n-3 long-chain polyunsaturated fatty acids in humans.

Prostaglandins Leukot Essent Fatty Acids. 2009;80(2-3):85-91.

19. Arterburn LM, Hall EB, Oken H. Distribution, interconversion, and dose response of n-3 fatty acids in humans. Am J Clin Nutr. 2006;83(6suppl):S1467-S1476.

20. ISSFAL. Recommendations for Intake of Polyunsaturated Fatty Acids in health Adults Web site.

http://www.issfal.org.uk/index.php?option=com_content\&task=view\&id=23\&Itemid $=8$. Published 2004. Accessed February 2, 2013.

21. Koletzko B, Cetin I, Brenna JT. Perinatal Lipid Intake Working Group Consensus Statement. Dietary fat intakes for pregnant and lactating women. Brit J Nutr.2007;98(5):873-877. 
22. U.S. Department of Agriculture, Agricultural Research Service. 2012. Nutrient Intakes from Food: Mean Amounts Consumed per Individual, by Gender and Age, What We Eat in America, NHANES 2009-2010. Available at: www.ars.usda.gov/ba/bhnrc/fsrg. Accessed February 15, 2013.

23. Lewis NM, Widga AC, Buck JS, Frederick AM. Survey of omega-3 fatty acids in diets of Midwest low-income pregnant women. J Agromedicine. 1995;2(4):49-57.

24. Donahue SMA, Rifas-Shiman SL, Olsen SF, Gold DR, Gillman MW, Oken E. Associations of maternal prenatal dietary intake of n-3 and n- 6 fatty acids with maternal and umbilical cord blood levels. Prostaglandins Leukot Essent Fatty Acids.2009;80(5-6):289-296.

25. Nochera CL, Goossen LH, Brutus AR, Cristales M, Eastman B. Consumption of DHA+EPA by low-income women during pregnancy and lactation. 2011;26(4):445450.

26. Loosemore ED, Judge MP, Lammi-Keefe CJ. Dietary intake of essential and longchain polyunsaturated fatty acids in pregnancy. Lipids.2004;39(5):421-424.

27. Wijendran V, Bendel RB, Couch SC, Philipson EH, Thomsen K, Zhang Xuefei, Lammi-Keefe CJ. Maternal plasma phospholipid polyunsaturated fatty acids in pregnancy with and without gestational diabetes mellitus: relations with maternal factors. Am J Clin Nutr.1999;70(1):53-61.

28. Dunlop AL, Kramer MR, Hogue CJR, Menon R, Ramakrishan U. Racial disparities in preterm birth: an overview of the potential role of nutrient deficiencies. Acta Obstet Gyn Scan. 2011;90(12):1332-1341

29. Gibson RS. Principles of Nutritional Assessment. $2^{\text {nd }}$ ed. New York, Oxford: Oxford University Press; 2005:41-196.

30. Hu FB. Obesity Epidemiology. New York, Oxford: University Press; 2008:84-118.

31. Thompson FE, Subar AF. Dietary assessment methodology. In Coulston AM, Boushey CJ, Ferruzzi MG, eds. Nutrition in the Prevention and Treatment of Disease. $3^{\text {rd }}$ ed. Amsterdam, Boston: Elsevier;2013:5-44. 
32. Willet W ed. Nutritional Epidemiology. $2^{\text {nd }}$ ed. New York, Oxford: Oxford University Press; 1998:74-94.

33. Parra MS, Schnaas L, Meydani M, Perroni E, Martinez S, Romieu I. Erythrocyte cell membrane phospholipid levels compared against reported dietary intakes of polyunsaturated fatty acids in pregnant Mexican women. Public Health Nutr. 2002;5(6A):931-937.

34. Erkkola M, Karppinen M, Javanainen J, Ränäen L, Knip M, Virtanen SM. Validity and reproducibility of a food frequency questionnaire for pregnant Finnish women. Am J Epidemiol. 2001;154(5):466-476.

35. Otto SJ, van Houwelingen AC, Bardart-Smook A, Hornstra G. Changes in the maternal essential fatty acid profile during early pregnancy and the relation of the profile to diet. Am J Clin Nutr. 2001;73(2):302-307.

36. Sontrop JM, Campbell MK, Speechley KN, Avison WR, Evers SE. Fish consumption among pregnant women in London, Ontario. Can J Public Health. 2007;98(5):389394.

37. Stark KD, Beblo S, Murthy M, Buda-Abela M, Janisse J, Rockett H, Whitty JE, Martier SS, Sokol RJ, Hannigan JH, Salem N Jr. Comparison of bloodstream fatty acid composition from African-American women at gestation, delivery, and postpartum. J Lipid Res. 2005;46(3):516-525.

38. Fawzi WW, Rifas-Shiman SL, Rich-Edwards JW, Willett WC, Gillman MW. Calibration of semi-quantitative food frequency questionnaire in early pregnancy. Ann Epidemiol. 2004;14(10):754-762.

39. Lunn J, Theobald HE. The health effects of dietary unsaturated fatty acids. Nutrition Bulletin.2006;31(3):178-224.

40. Harris WS, Mozaffarian D, Rimm E, Kris-Etherton P, Rudel LL, Appel LJ, Engler MM, Engler MB, Sacks F. Omega-6 fatty acids and risk for cardiovascular disease: a science advisory from the American Heart Association Nutrition Subcommittee of the Council on Nutrition, Physical Activity, and Metabolism; Council on Cardiovascular Nursing; and Council on Epidemiology and Prevention. Circulation. 2009;119(6):902-907. 
41. Gibson RA, Muhlhausler B, Makrides M. Conversion of linoleic acid and alphalinolenic to long-chain polyunsaturated fatty acids (LCPUFAs), with a focus on pregnancy, lactation and the first 2 years of life. Matern Child Nutr. 2011;7(suppl2):17-26.

42. Harnack K, Andersen G, Somoza V. Quantitation of alpha-linolenic acid elongation to eicosapentaenoic and docosahexaenoic acid as affected by the ratio of n6/n3 fatty acids. Nutr Metab (Lond). 2009;6(8).

43. Blank C, Neumann MA, Makrides M, Gibson RA. Optimizing DHA levels in piglets by lowering the linoleic acid to $\alpha$-linolenic acid ratio. J Lipid Res. 2002;43(9):15371543.

44. Lands WE, Morris A, Libelt B. Quantitative effects of dietary polyunsaturated fats on the composition of fatty acids in rat tissues. Lipids. 1990;25(9):505-516.

45. Brenna JT, Lapillonne A. Background paper on fat and fatty acid requirements during pregnancy and lactation. Ann Nutr Metab. 2009;55(1-3):97-122.

46. Dietary Sources of Omega-3 Fatty Acids. DHA/EPA Omega-3 Institute Web site. http://www.dhaomega3.org/Overview/Dietary-Sources-of-Omega-3-Fatty-Acids. Published 2006-2012. Accessed February 15, 2013.

47. Joint FAO/WHO Expert Consultation on Fats and Fatty Acids in Human Nutrition. Interim Summary of Conclusions and Dietary Recommendations on Total Fat \& Fatty Acids. Geneva, 2003.

48. Kris-Etherton PM, Taylor DS, Yu-Poth S, Huth P, Moriarty K, Fishell V, Hargrove RL, Zhao G, Etherton TD. Polyunsaturated fatty acids in the food chain in the United States. Am J Clin Nutr. 2000;71(1suppl):S179-S188.

49. U.S. Food and Drug Administration. Safe Eats-Eating Out \& Bringing in. http://www.fda.gov/Food/ResourcesForYou/HealthEducators/ucm082539.htm. Updated March 14, 2012. Accessed 02/15/13.

50. Mozurkewich EL, Klemens C. Omega-3 fatty acids and pregnancy: current implications for practice. Curr Opin Obstet Gynecol. 2012;24(2):72-77. 
51. U.S. Department of Agriculture (USDA), Agriculture Research Service, 2002. USDA National Nutrient Database for Standard Reference. Release 25. Web site. http://ndb.nal.usda.gov/. Updated December 7, 2011. Accessed January 15, 2011.

52. World Health Organization. Health status statistics: morbidity. Newborns with low birthweight (percentage) Web site. http://www.who.int/healthinfo/statistics/indlowbirthweight/en/index.html. Accessed March 15, 2013.

53. US. Department of Health \& Human Services. The Office of Minority Health. Infant Mortality and African Americans. Web site. http://minorityhealth.hhs.gov/templates/content.aspx?ID=3021. Modified July 3, 2012. Accessed 03/01/2013.

54. PubMedHealth. Preeclampsia. Web site. http://www.ncbi.nlm.nih.gov/pubmedhealth/PMH0001900/. Updated August 23, 2012. Accessed February 15, 2013.

55. Preeclampsia Foundation. About Preeclampsia. Web site. http://www.preeclampsia.org/health-information/about-preeclampsia. Accessed February 15, 2013.

56. Clark SL, Belfort MA, Dildy GA, Herbst MA, Meyers JA, Hankins GD. Maternal death in the 21st century: causes, prevention, and relationship to cesarean delivery. Am J Obstet Gynecol. 2008;199(1):36e1-e5.

57. McGregor JA, Allen KGD, Harris MA, Reece M, Wheeler M, French JI, Morrison J. The omega-3 story: nutritional prevention of preterm birth and other adverse pregnancy outcomes. Obstet Gynecol Surv. 2001;56(5suppl):S1-S13.

58. Wang Y, Walsh SW, Kay HH. Placental tissue levels of nonesterified polyunsaturated fatty acids in normal and preeclamptic pregnancies. Hypertens Pregnancy. 2005;24(3):235-245.

59. Kulkarni AV, Mehendale SS, Yadav HR, Joshi SR. Reduced placental docosahexaenoic levels associated with increased levels of sFlt-1 in preeclampsia. Prostaglandins Leukot Essent Fatty Acids.2011;84(1-2):51-55. 
60. Olafsdottir AS, Skuladottir GV, Thorsdottir I, Hauksson A, Thorgeirsdottir H, Steingrimsdottir L. Relationship between high consumption of marine fatty acids in early pregnancy and hypertensive disorders in pregnancy. BJOG. 2006;113(3):301309.

61. American Psychological Association. Postpartum Depression. Web site. http://apa.org/pi/women/programs/depression/postpartum.aspx. Published 2013. Accessed March 1, 2013.

62. Shapiro GD, Fraser WD, Seguin JR. Emerging risk factors for postpartum depression: serotonin transporter genotype and omega-3 fatty acid status. Can J Psychiatr. 2012;57(11):704-712.

63. Strom M, Mortensen EL, Halldorsson TI, Thorsdottir I, Olsen SF. Fish and longchain n-3 polyunsaturated fatty acid intakes during pregnancy and risk of postpartum depression: a prospective study based on a large national birth cohort. Am J Clin Nutr. 2009;90(1):149-155.

64. Jans LA, Giltay EJ, Van der Does AJ. The efficacy of n-3 fatty acids DHA and EPA (fish oil) for perinatal depression. Br J Nutr. 2010;104(11):1577-1585.

65. Mozurkewich E, Chilimigras J, Klemens C, Keeton K, Allbaugh L, Hamilton S, Berman D, Vazquez D, Marcus S, Djuric Z, Vahratian A. The mothers, omega-3 and mental health study. BMC Pregnancy Childbirth. 2011;11(46).

66. Inns SM. Fatty acids and early human development. Early Hum Dev. 2007;83(12):761-766.

67. Cetin I, Alvino G, Cardellicchio M. Long chain fatty acids and dietary fats in fetal nutrition. J Physiol. 2009;587(Pt 14):3441-3451.

68. Sangiovanni JP, Chew EY. The role of omega-3 long chain polyunsaturated fatty acids in health and disease of the retina. Prog Retin Eye Res. 2005;24(1):87-138.

69. Ahmad A, Moriguchi T, Salem N. Decrease in Neuron Size in docosahexaenoic aciddeficient brain. Pediatr Neurol. 2002;26(3):210-218.

70. Neuringer M, Conner WE, Lin DS, Barstad L, Luck S. Biochemical and functional effects of prenatal and postnatal omega-3 fatty acid deficiency on retina and brain in 
rhesus monkeys. omega-3 fatty acid deficiency on retina and brain in rhesus monkeys. Proc Natl Acad Sci USA. 1986;83(11):4021-4025.

71. Haggarty P, Ashton J, Joynson M, Abramovich DR, Page K. Effect of maternal polyunsaturated fatty acid concentration on transport by the human placenta. Biol Neonate.1999;75(6):350-359.

72. Cetin I, Giovannini N, Alvino G, Agostoni C, Riva E, Giovannini M, Pardi G. Intrauterine growth restriction is associated with changes in polyunsaturated fatty acid fetal-maternal relationships. Pediatr Res. 2002;52(5):750-755.

73. Ruyle M, Connor WE, Anderson GJ, Lowensohn RI. Placental transfer of essential fatty acids in humans: venous-arterial difference for docosahexaenoic acid in fetal umbilical erythrocytes. Proc Natl Acad Sci U SA. 1990;87(20):7902-7906.

74. Hibbeln JR, Davis JM, Steer C, Emmett P, Rogers I, Williams C, Golding J. Maternal seafood consumption in pregnancy and neurodevelopmental outcomes in childhood (ALSPAC study): an observational cohort study. Lancet. 2007;369(9561):578-585.

75. Helland IB, Smith L, Saarem K, Saugstad OD, Drevon CA. Maternal Supplementation with very-long-chain n-3 fatty acids during pregnancy and lactation augments children's IQ at 4 years of age. Pediatrics. 2003;111(1):e39-e44.

76. Birch EE, Garfield S, Hoffman DR, Uauy R, Birch DG. A randomized controlled trial of early dietary supply of long-chain polyunsaturated fatty acids and mental development in term infants. Dev Med Child Neurol. 2000;42(3):174-181.

77. Dustan JA, Simmer K, Dixon G, Prescott SL. Cognitive assessment of children at age $2 \frac{1}{2}$ years after maternal fish oil supplementation in pregnancy: a randomized controlled trial. Arch Dis Child Fetal Neonatal Ed. 2008;93(1):F45-F50.

78. Innis SM, Gilley J, Werker J. Are human milk long-chain polyunsaturated acids related to visual and neural development in breast-fed term infants? J Pediatr. 2001;139(4):532-538.

79. Lauritzen L, Jorgensen MH, Mikkelsen TB, Skovgaard IM, Straarup EM, Olsen SF, Hoy CE, Michaelsen KF. Maternal fish oil supplementation: effect on visual acuity and n-3 fatty acid content of infant erythrocytes. Lipids. 2004;39(3):195-206. 
80. Hoffman DR, Birch EE, Castaneda YS, Fawcett SL, Wheaton DH, Birch DG, Uauy R. Visual function in breast-fed term infants weaned to formula with or without longchain polyunsaturates at 4 to 6 months: a randomized clinical trial. $J$ Pediatr. 2003;142(6):669-677.

81. Innis SM, Friesen RW. Essential n-3 fatty acids in pregnant women and early visual acuity maturation in term infants. Am J Clin Nutr. 2008;87(3):548-557.

82. U.S. Department of Agriculture, Agricultural Research Service, Beltsville Human Nutrition Research Center, Food Surveys Research Group (Beltsville, MD).

Continuing Survey of Food Intakes by Individuals 1994-96, 1998 and Diet and Health Knowledge Survey 1994-96: Documentation (csfii9498_documentationupdated.pdf). http://www.ars.usda.gov/Services/docs.htm?docid=14531. Accessed March 01, 2013.

83. Williamson CS. Nutrition in pregnancy. Nutrition Bulletin. 2006;31(1):28-59.

84. Picciano MF. Pregnancy and lactation: physiological adjustments, nutritional requirements and the role of dietary supplements. J Nutr. 2003;133(6suppl):s1997s2002.

85. National Children's Study Dietary Assessment Literature Review. Chapter 2: Pregnancy and Lactation. National Institutes of Health, Applied Research Program and Westat (Rockville, MD). 2007. Available at: http://riskfactor.cancer.gov/tools/children/review/pdf/ncs_chapter2.pdf. Accessed February 12, 2013.

86. Verbeke W, Bourdeaudhuij ID. Dietary behavior of pregnant versus non-pregnant women. Appetite. 2007;48(1):78-86.

87. Oken E, Kleinman KP, Berland WE, Simon SR, Rich-Edward JW, Gillman MW. Decline in fish consumption among pregnant women after a national mercury advisory. Obstet Gynecol. 2003;102(2):346-351.

88. US Department Agriculture. Agricultural Research Service. Automated Multiple Pass Method Web site. http://www.ars.usda.gov/Services/docs.htm?docid=7711. Accessed February 15, 2010. 
89. Conway JM, Ingwersen LA, Vinyard BT, Moshfegh AJ. Effectiveness of the US Department of Agriculture 5-step multiple pass method in assessing food intake in obese and nonobese women. Am J Clin Nutr. 2003;77(5):1171-1178.

90. Burke BS. The dietary history as a tool in research. J Am Diet Assoc. 1947;23:10411046.

91. Kristal AR, Shattuck AL, Williams AE. Food frequency questionnaires for diet intervention. Proceedings of the $17^{\text {th }}$ National Nutrient Databank Conference; 1994.

92. Nutrition Quest: Questionnaires \& Screeners. Nutrition Quest Web site. http://www.nutritionquest.com/assessment/list-of-questionnaires-and-screeners/. Accessed March 15, 2013.

93. Block G, Hartman AM, Dresser CM, Carroll MD, Gannon J, Gardner L. A data-based approach to diet questionnaire design and testing. Am J Epidemiol. 1986;124(3):453469.

94. Block G, Woods M, Potosky A, Clifford C. Validation of a self-administered diet history questionnaire using multiple diet records. J Clin Epidemiol. 1990;43(12):1327-1335.

95. Caan BJ, Slattery ML, Potter J, Quensenberry CP Jr, Coates AO, Schaffer DM. Comparison of the Block and the Willett self-administered semi-quantitative food frequency questionnaires with an interview-administered diet history. Am J Epidemiol. 1998;148(12):1137-1147.

96. Subar AF, Thompson FE, Kipnis V, Midthune D, Hurwitz P, McNutt S, McIntosh A, Rosenfeld S. Comparative validation of the Block, Willett, and National Cancer Institute food frequency questionnaires: the Eating at American's Table Study. Am J Epidemiol. 2001;154(12):1089-1099.

97. McCann SE, Marshall JR, Trevisan M, Russell M, Muti P, Markovic N, Chan AW, Freudenheim JL. Recent alcohol intake as estimated by the Health Habits and History Questionnaire, The Harvard Semi quantitative Food Frequency Questionnaire, and a more detailed alcohol intake questionnaire. Am J Epidemiol. 1999;150(4):334-340. 
98. Willett WC, Sampson L, Stampfer MJ, Rosner B, Bain C, Witschi J, Hennekens CH, Speizer FE. Reproducibility and validity of a semi quantitative food frequency questionnaire. Am J Epidemiol. 1985;122(1):51-65.

99. Fred Hutchinson Cancer Research Center. Nutrition Assessment Website. http://sharedresources.fhcrc.org/core-facilities/nutrition-assessment. Accessed March $15,2013$.

100. Patterson RE, Kristal AR, Tinker LF, Carter RA, Bolton MP, Agurs-Collins T. Measurement characteristics of the Women's Health Initiative food frequency questionnaire. Ann Epidemiol. 1999;9(3):178-187.

101. McNutt S, Zimmerman TP, Hull SG. Development of food composition databases for food frequency questionnaires. J Food Compos Anal. 2008;21(1suppl):s20-s26.

102. Cade J, Thompson R, Burkey V, Warm D. Development, validation and utilization of food-frequency questionnaires-a review. Public Health Nutrition. 2002;5(4):567-587.

103. Subar A. Developing dietary assessment tools. J Am Diet Assoc. 2004;104(5):769-770.

104. Jensen JK, Gustafson D, Boushey CJ, Auld G, Bock MA, Bruhn CM, Gabel K, Misner S, calcium intake of Asian, Hispanic and White youth. J Am Diet Assoc. 2004;104(5):762-769.

105. Sharma S, Cao X, Arcan C, Mattingly M, Jennings S, Song H, Gittelsohn J. Assessment of dietary intake in an inner-city African American population and development of a quantitative food frequency questionnaire to highlight foods and nutrients for a nutritional invention. Int J Food Sci Nutr. 2009;60(5suppl):155-167.

106. Buchowski MS, Schlundt DG, Hargreaves MK, Hankin JH, Signorello LB, Blot WB. Development of culturally sensitive food frequency questionnaire for use in the southern community cohort study. Cell Mol Biol (Noisy-le-grand). 2003;49(8):12951304.

107. Subar AF, Thompson FE, Smith AF, Jobe JB, Ziegler RG, Potischman N, Schatzkin A, Hartman A, Swanson C, Kruse L, Hayes RB, Riedel Lewis D, Harlan 
LC. Improving food frequency questionnaires: A qualitative approach using cognitive interviewing. J Am Diet Assoc. 1995;95(7):781-788.

108. Block G, Hartman AM. Issues in reproducibility and validity of dietary studies. Am J Clin Nutr. 1989;50(5suppl):1133-1138.

109. Willett W, Lenart E. Reproducibility and validity of food-frequency questionnaires, in: Nutritional Epidemiology $2^{\text {nd }}$ ed. New York, Oxford: Oxford University Press;2005:101-147.

110. Boucher B, Cotterchio M, Kreiger N, Nadalin V, Block T, Block G. Validity and reliability of the Block98 food frequency questionnaire in a sample of Canadian women. Public Health Nutr.2006;9(1):84-93.

111. Salkind NJ. Statistics for people who hate statistics. $3^{\text {rd }}$ ed. Los Angeles, CA: Sage Publications;2008:97-118.

112. Ritter-Gooder P, Lewis NM, Barber-Heidal K, Waltz-Hill M. Development and pilot testing of an omega-3 food frequency questionnaire. J Food Compos Anal. 2008;21(suppl):s43-s49.

113. George GC, Milani TJ, Hanss-Nuss H, Kim M, Freeland-Graves JH. Development and validation of a semi-quantitative food frequency questionnaire for young adult women in the southwestern United States. Nutr Res. 2004;24(1):29-43.

114. Carithers TC, Talegawkar SA, Rowser ML, Henry OR, Dubbert PM, Bogle ML, Taylor HA, Tucker KL. Validity and calibration of food frequency questionnaires used with African-American adults in the Jackson Heart Study. J Am Diet Assoc. 2009;109(7):1184-1193.

115. Lora KR, Lewis NM, Eskridge KM, Stanek-Krogstrand K, Ritter-Gooder P. Validity and reliability of an omega-3 fatty acid food frequency questionnaire for first-generation Midwestern Latinas. Nutr Res. 2010;30(8):550-557.

116. Patterson AC, Hogg RC, Kishi DM, Stark KD. Biomarker and dietary validation of a Canadian food frequency questionnaire to measure eicosapentaenoic, and docosahexaenoic acid intakes from whole food, functional food and nutraceutical sources. J Acad Nutr Diet. 2012;112(7):1005-1014. 
117. Sublette ME, Segal-Isaacson CJ, Cooper TB, Fakri S, Vanegas N, Galfalvy HC, Oquendo MA, Mann J. Validation of a food frequency questionnaire to assess intake of n-3 polyunsaturated fatty acids in subjects with and without Major Depressive Disorder. J Am Diet Assoc. 2011;111(1):117-123.

118. Hankin JH, Wilkens LR. Development and validation of dietary assessment methods for culturally diverse populations. Am J Clin Nutr. 1994;(suppl):s198-s200.

119. James DCS. Factors influencing food choices, dietary intake, and nutrition-related attitudes among African Americans: application of a culturally sensitive model. Ethn Health. 2004;9(4):349-367.

120. Mahaffey KR, Clickner RP, Jeffries RA. Adult women's blood mercury concentrations vary regionally in the United States: association with patterns of fish consumption (NHANES 19-2004). Environ Health Perspect. 2009;117(1):47-53. 
Study I:

Reliability and Validity of a Culturally Appropriate Food Frequency Questionnaire to Measure Omega-3 Fatty Acid Intakes in Midwestern African American Women, of Childbearing Age. 


\section{Abstract}

Background: Omega-3 fatty acid intakes may play an important role in maternal health outcomes and infant brain and neural development. Research has shown that pregnant African American women have intakes below recommended levels for optimal health. Objective: The aim of this pilot study was to determine the reliability and validity of a culturally specific FFQ to measure total omega-3 (n-3) fatty acid, ALA, EPA and DHA intake of Midwestern African American women $(n=49)$ of child-bearing age and examine associations between these intakes with maternal health issues from previous pregnancies.

Methods: The omega-3 FFQ questionnaire was developed by 24 hour recall interviews, analyzed for content validity and pilot tested. The final culturally appropriate 187 item FFQ was then completed by women three times, via interview by an RD, along with three non-consecutive 24 hour food recalls, during a two week period. Maternal health issues were assessed by demographic questionnaire. The reliability and validity of the FFQ was assessed by Cronbach's coefficient alpha and Pearson correlation coefficients, respectively.

Results: Mean daily consumption of total omega-3 fatty acid, ALA, EPA, DHA and DPA as estimated by the 3 administrations of the FFQ, were $2.68 \pm 1.37 \mathrm{~g} / \mathrm{day}, 2.45 \pm$ $1.30 \mathrm{~g} /$ day, $0.07 \pm 0.07 \mathrm{~g} /$ day, $0.12 \pm 0.11 \mathrm{~g} /$ day and $0.03 \pm 0.02 \mathrm{~g} /$ day, respectively. The Cronbach's coefficient alphas, for reliability of the FFQ, were 0.89 for total omega-3, 0.89 for ALA, 0.89 for EPA, 0.88 for DHA and 0.83 for DPA. Pearson correlation coefficients as measured for validity between the FFQ and the recalls, were $0.44,0.44$, 0.59 and 0.60 for total n-3 fatty acid, ALA, EPA and DHA $(\mathrm{P}<.01)$, respectively. African 
American women with past history of low birth weight, preterm labor, premature rupture of membranes and post-partum depression had a significant difference in omega- 3 fatty acid intakes when compared to those without prior history.

Conclusions: In conclusion, this culturally appropriate FFQ seems to be reliable and valid in measuring omega-3 fatty acid intake in Midwestern African American women. This tool may be used to assess other populations of African American women's intake of omega-3 fatty acids. 


\section{Introduction}

Omega-fatty acids, alpha-linolenic acid (ALA), eicosapentaenoic acid (EPA) and docosahexaenoic acid (DHA), may have an impact on the occurrence of preterm birth, low birth weight, preeclampsia and postpartum depression. Research indicates that avoidance of seafood rich in omega-3 fatty acids, may lead to increased risk of preterm labor $^{1}$ and intake of cod liver oil (an oil rich in omega-3 fatty acids) has been associated with longer gestation and higher birth weights. ${ }^{2}$ A moderate increase in consumption of omega-3 fatty acids has also been associated with a risk reduction in the occurrence of preeclampsia. ${ }^{3}$ Omega-3 fatty acids, especially DHA, are found abundantly in retinal and neural tissues and studies have reported that restricting these fatty acids in developing animals results in reduced brain DHA and deficits in behavioral tasks of learning. ${ }^{4}$ During the last three months of gestation and the first few months after birth, the brain is at its highest rate of growth, which suggests that a third trimester fetus and a newborn may suffer developmentally without adequate amounts of omega- 3 fatty acids. ${ }^{5}$ Therefore, omega-3 fatty acid intake in pregnant women may have a role in positive maternal and infant health outcomes.

ALA can be found in soybean, canola, and flaxseed oils and some nuts ${ }^{4,6}$ and can be further metabolized to DHA through the intermediate fatty acids, EPA and DPA. ${ }^{7}$ Researchers suggest that this is a slow process, with humans including newborns, converting less than 1\% ALA to DHA. However, DHA from food sources is well absorbed and readily incorporated into human plasma and blood cell lipids. ${ }^{4,8}$ Women of childbearing age should obtain DHA from food sources including eggs, poultry and cold water fish, i.e. salmon, tuna and shellfish. ${ }^{6}$ The U.S. Food and Drug Administration 
recommends that women of childbearing age, pregnant or lactating should eat up to 12 ounces ( 2 average meals) a week of a variety of fish and shellfish that are lower in mercury, which would meet EPA and DHA needs. ${ }^{9,10}$ Several studies have reported that omega-3 fatty acid intake during pregnancy and lactation is very important to pregnancy outcomes, and fetus or infant development, but little research has been done on the intakes of pregnant women in the United States, especially African American women. According to the Continuing Survey of Individuals 1994-1996, 1998 (CSFII), pregnant and lactating women in the United States are consuming approximately $50 \mathrm{mg}$ of DHA/day.${ }^{11}$ Low income pregnant women in the Midwest were found to consume 980 mg/day, $23 \mathrm{mg} /$ day and $48 \mathrm{mg} /$ day of ALA, EPA and DHA, respectively. ${ }^{12}$ The International Society for the Study of Fatty Acids and Lipids (ISSFAL) recommends 500 mg of EPA and DHA per day for cardiovascular health ${ }^{13}$ and that pregnant and lactating women should attempt to achieve an average of $200 \mathrm{mg}$ DHA per day. ${ }^{10}$ These results suggest that women from the United States are potentially not meeting the recommendations for omega-3 fatty acids, according to experts and government agencies. Food frequency questionnaires (FFQ) are often used to assess nutrient intakes because they can be self-administered, inexpensive to process and tend to avoid changes in diet. ${ }^{14}$ FFQs should be culturally and population specific and can be created or adapted to fit the population or purpose needed for the specific study by adding foods commonly eaten by the study population. ${ }^{15,16}$ Newly developed FFQs should be measured for validity and reliability in the population of interest. ${ }^{16}$ Ritter-Gooder et al. validated an omega-3 fatty acid FFQ with three 24 hour recalls in cardiac patients. The validity coefficient was 0.42 and test-retest reliability was $0.83 .{ }^{17}$ Lora et al. did a similar 
reliability and validity study in first-generation Latinas. Correlations for two administrations of the omega-3 FFQ were 0.71 for total omega-3 fatty, 0.65 for ALA, 0.74 for EPA, and 0.54 for DHA and the FFQ was considered valid for total omega-3 and ALA. ${ }^{18}$ Currently, no FFQs exist that are specifically created to measure omega-3 fatty acid intakes in African American women.

Therefore, the purpose of this study was to validate and determine the reliability of a culturally specific FFQ to measure omega-3 fatty acid intakes in Midwestern African American women of childbearing age and to examine associations between health outcomes from prior pregnancies with their current omega-3 fatty acid intakes. 


\section{Methods}

\section{Subjects and Study Design}

African American women of childbearing age, 16 to 49 years old, were recruited from the Special Supplemental Nutrition Program for Women, Infants and Children (WIC), emergency pregnancy centers, schools and churches that have a high African American population, in Lincoln and Omaha, Nebraska. A total of 49 subjects were recruited, 11 non-pregnant and 38 pregnant women. Pregnant subjects were recruited between 8 and 37 weeks gestation. A registered dietitian completed one-on-one interviews with each participant, three times, one week apart, to obtain sociodemographic information and dietary intakes. Interviews were conducted at WIC sites, in the participant's home, library or grocery store and mall food courts. Participants received a \$20 Wal-Mart gift certificate as compensation for their participation. The study was approved by the Institutional Review Board at the University of Nebraska-Lincoln.

\section{Dietary Intake Methods}

Two dietary assessment methods were used: three food frequency questionnaires, a week apart, and three, non-consecutive 24 hour dietary recalls, within a two week period.

\section{Food Frequency Questionnaire}

A food frequency questionnaire that was previously validated in a Caucasian cardiac population ${ }^{17}$ and a first-generation Latina population ${ }^{18}$ was adapted to be used in this African American female population. To identify omega-3 rich culturally appropriate foods and dishes that are commonly eaten by African Americans, interviews were conducted with a convenience sample of five African American women. These women 
filled out a 24 hour recall and answered the following questions: Are the foods listed on the 24 hour recall a part of your daily diet? What foods do you eat during special events or holidays? What foods do you eat that make you unique to your peers, co-workers, friends, etc.? What foods do you eat that may be considered soul food? Subjects also answered questions about the types of fats and oils used to cook their foods, as well as fish, seafood and other meats that they eat. ${ }^{18}$ A $\$ 5$ Wal-Mart gift card was provided for compensation for participation. Common foods and dietary intakes of African Americans were also obtained from research literature.$^{19}$

The resulting FFQ contained 209 food items and culturally specific dishes which were analyzed for total omega-3 fatty acid, ALA, EPA, DPA and DHA content in grams per medium serving and contained $\geq 10 \mathrm{mg}$ of omega- 3 fatty acid/medium serving. A medium serving size of each food was equivalent to one serving as described by the US Department of Agriculture (USDA) MyPyramid daily recommendation guidelines ${ }^{21}$ and the USDA Nutrient Database for Standard Reference, ${ }^{21}$ where a small serving size equals 0.5 times and the large equals 1.5 times the medium serving size, respectively. Serving size estimates for the culturally specific dishes were based on amounts commonly eaten by the study population. Foods were grouped in the following sections: meats, seafood, eggs, dairy, vegetables, fruit, breads and cereals, condiments and snacks, oils, nuts and seeds, beans, and prepared dishes. This FFQ was analyzed for content validity by three nutrition experts and then pilot tested with the first 10 African American pregnant women, involved in the study $(n=49)$. These women were asked questions adapted from Lora et al., ${ }^{18}$ which assesses the level of difficulty of the instructions given, whether or not the FFQ was understandable and any reasons to not answer questions. After each 
section of the FFQ, each pilot study participant was asked: Are there any foods that are not on the FFQ, which are part of your daily diet $?^{18}$ Recipes and serving sizes were also checked for accuracy.

After changes were made, the final culturally appropriate FFQ contained 187 food items, culturally specific dishes (i.e. featherbones, black eyed peas with ham hocks or neck bones, salmon croquettes) and food items commonly eaten by African Americans (i.e. fried catfish). All foods contained $\geq 10 \mathrm{mg}$ omega-3 fatty acid/medium serving. A large serving size was considered two times the medium serving size due to reported amounts consumed during the pilot study. Frequency amounts were as follows (frequency weights): once a month (0.03), 2-3 times per month (0.08), 1-2 times a week (0.2), 3-4 times a week (0.5), 5-6 times a week (0.8), one time daily (1) and two or more times daily (2). ${ }^{16}$ Food models, bowls, drinking cups and measuring cups were used to illustrate portion sizes for foods on the FFQ. To measure reliability, this FFQ was given three times, in a two week period, one week apart, to 40 African American women of childbearing age (four women completed two FFQs and five completed one FFQ).

\section{4 hour recalls}

The 24 hour recall was used as the reference method in this validation study. For the three days of recalls $(n=42)$, a registered dietitian did one-on-one interviews with the participants in a requested place, including: their home, their WIC clinic, library or local food courts. Recalls were done on non-consecutive days so that they represented all days of the week, including weekend days.

\section{Sociodemographic questionnaire}


During the first appointment, participants filled out a demographic questionnaire, which was adapted from the Behavioral Risk Factor Surveillance System 2010 Questionnaire. $^{22}$ The questionnaire obtained information on marital status, income, education level, employment status, whether participants were pregnant, weeks of gestation and number of prior pregnancies. The questionnaire also contained questions adapted from the 2008 Maternal and Infant Health Assessment which asks information about health outcomes during previous pregnancies. ${ }^{23}$

\section{Dietary Intake Analysis}

Dietary intakes measured by both recalls and FFQs were analyzed using the Nutrition Data System for Research software version NDSR 2009, developed by the Nutrition Coordinating Center (NCC), University of Minnesota, Minneapolis, $\mathrm{MN} .{ }^{24}$ On the FFQ, estimated intakes of omega-3 fatty acids were calculated by multiplying the amount of the omega-3 fatty acids in each food by the frequency weight of the selected frequency (as described above) by the selected serving size: small (0.5), medium (1) and large (2). Estimated omega-3 fatty acid intakes from the FFQ, were calculated using a template created in Microsoft Excel 2010 (Microsoft Corp, Seattle, WA).

\section{Statistical Analysis}

Data were analyzed using Statistical Analysis System (SAS) (version 9.2, 2008, SAS Institute, Inc., Cary, NC). Descriptive statistics were determined for individual total omega-3 fatty acid, ALA, EPA DPA and DHA intake from both the 24 hour recalls and FFQs and the sociodemographic information. These statistics included the means, frequencies and standard deviations. Cronbach's coefficient alpha was used to assess internal consistency reliability between individual nutrient intakes, from the three FFQ 
administrations, and food groups. Since individual intake varies, a reliable FFQ will discern between individual dietary intakes or higher between-person variation. A high Cronbach's coefficient alpha represents low within-person variation relative to among person variation; therefore, signifying a reliable dietary instrument. Validity was measured by Pearson correlation coefficients, which were calculated to assess relationships between mean intakes of the 24 hour recalls and mean intakes of the FFQs. Statistical significance for validity correlation coefficients was set at $\mathrm{p}<0.05$. The nutrient intakes were skewed and not normally distributed, so all data was log transformed $(x+1)$ to better approximate the normality of the distribution before Cronbach's alpha and Pearson correlation coefficients were computed. Analysis of variance and covariance was used to evaluate the effects of demographic and pregnancy related health variables on omega-3 fatty acid intakes.

\section{Results}

Sociodemographic factors of the study population are found in Table 1. In the present study, out of 49 African American women, 38 were pregnant and an average of 26.7 years old. More than a third (39\%), had one to three years of college, $45 \%$ had an income of less than 10,000 dollars a year and 73\% were either unemployed or full-time employed. Almost half of the participants (49\%) had never been married.

\section{Mean Intakes}

Mean intakes for both the three administrations of the FFQ and the 24 hour recalls are represented in Table 2. Mean intakes, estimated by the FFQs, for total omega-3, ALA, EPA, DPA and DHA were $2.68 \mathrm{~g} / \mathrm{d}, 2.45 \mathrm{~g} / \mathrm{d}, 0.07 \mathrm{~g} / \mathrm{d}, 0.03 \mathrm{~g} / \mathrm{d}$ and $0.12 \mathrm{~g} / \mathrm{d}$ 
respectively. When compared to recalls, the FFQ overestimated total omega-3, ALA, EPA, DPA and DHA intakes by approximately 145\%, 142\%, 140\%, 150\% and 170\%, respectively. The mean intakes of total omega-3 ALA, EPA, DHA and DPA by food groups are represented in Table 3. Oils, prepared dishes and vegetables provided the most total omega-3 and ALA intakes, while seafood and meat provided the most EPA and DHA intakes. Seafood, meat and prepared dishes provided the most DPA intake. Oils, prepared dishes and vegetables provided more than $50 \%$ of the total omega-3 fatty acid for the study population (Table 4). Approximately, 50\% of EPA and DHA, which represented 7\% of the total omega-3 fatty acids consumed by these African American women, were provided by tilapia, fresh or frozen salmon, crab legs and fried catfish (Table 5).

\section{Reliability}

The culturally appropriate FFQ for Midwestern African American women was administered three times to 40 women to assess reliability (four women only completed two FFQs and five only completed one FFQ). Cronbach's coefficient alpha for the test administrations of the FFQ was $0.89,0.89,0.89,0.83$ and 0.88 for total omega-3, ALA, EPA, DPA and DHA, respectively (Table 6). Alpha correlation coefficients for food groups are represented in Table 7. The lowest to highest coefficient alpha for each nutrient is as follows: 0.17 (breads) to 0.86 (oils) for total omega-3, 0.15 (seafood) to 0.86 (oils/nuts and seeds) for ALA, 0.62 (meats) to 0.88 (dairy) for EPA, 0.17 (Seafood) to 0.69 (breads, cereals) for DPA and 0.62 (meats) to 0.86 (breads, cereals) for DHA.

\section{Validity}


To assess validity, the FFQs or "test" method was compared to a "reference" method, which was three 24 hour recalls. Pearson correlation coefficients between the two dietary assessment methods were $0.44(\mathrm{p}<0.01)$ for total omega-3, $0.44(\mathrm{p}<0.01)$ for ALA, $0.59(\mathrm{p}<0.001)$ for EPA and $0.60(\mathrm{p}<0.001)$ for DHA. Validity coefficients for DPA were not statistically significant. These values are reported in Table 2.

\section{Maternal characteristics and health outcomes}

The 38 pregnant women, had an average gestation of 25 weeks. EPA and DHA intakes were significantly different $(\mathrm{p}<.05)$ between the pregnant and non-pregnant women, with non-pregnant women having higher intakes (Table8). Approximately 70\% of the African American women had prior pregnancies. Figure 1 provides the maternal health questions and any significant difference in intakes of those who had these health conditions, compared to those who did not. The ten women, who had babies born at less than 5 pounds 8 ounces, ate significantly more $(\mathrm{p}<0.05)$ total omega- 3 and DHA than those women who did not. Of the women who reported a previous diagnosis of postpartum depression, approximately $24 \%$ of those who had previous pregnancies, had significantly higher intakes $(\mathrm{p}<0.05)$ of total omega-3 and ALA, which was also found in the seven women who reported premature rupture of membranes. Total omega-3 and EPA intakes were higher $(\mathrm{p}<0.05)$ in those women who reported past history of preterm or early labor.

\section{Demographics and mean intakes}

The average body mass index (BMI) for these subjects was 30.4, which is considered overweight by the Centers for Disease Control (CDC). ${ }^{25} \mathrm{BMI}$ information is reported in Table 9. More than half of these women were overweight or obese according 
to their BMI, which is based on reported pre-pregnancy or current weights for the pregnant and non-pregnant participants, respectively. When comparing omega-3 intakes for those women who were obese $(\mathrm{BMI}>30)$ and non-obese, no significant difference in intakes was found (data not shown).

Analysis of covariance was used to evaluate the effects of age (quantitative variable) and education and income (both categorical variables) on omega-3 fatty acid intakes. No significant differences were found with age and income. EPA and DHA intakes were significantly different $(\mathrm{p}<0.05)$ between education levels (Table 10). Those women who were college graduates had higher EPA and DHA intakes than those women with less education.

\section{Discussion}

The following study assessed the reliability and validity of a culturally appropriate questionnaire created to measure omega-3 fatty acid intakes in Midwestern African American women of childbearing age. As assessed by the administrations of the FFQ, women in the current study met the AI for ALA, which is $1.1 \mathrm{~g} / \mathrm{d}$ and $1.4 \mathrm{~g} / \mathrm{d}$ for non-pregnant and pregnant women, respectively. ${ }^{26}$ Similar results have been found in other diverse populations of women, including African American, ${ }^{27}$ French-Canadian ${ }^{28}$ and Mexican women. ${ }^{29}$ ALA contributed approximately $90 \%$ of total omega-3 fatty acid intakes of the African American women, in the present study. Intake of ALA is essential due to the body's inability to synthesize this fatty acid and it can be further metabolized to the longer chain polyunsaturated fatty acids (LCPUFAs) EPA and DHA, which are needed for optimal health. ${ }^{30,31}$ But due to the inefficiency of conversion of EPA and DHA from ALA, experts suggest obtaining these omega-3 fatty acids in preformed options, like 
foods or supplements. ${ }^{31-33}$ For cardiovascular health, the International Society for the Study of Fatty Acids and Lipids (ISSFAL) recommends an intake of $500 \mathrm{mg}$ of EPA+DHA daily. ${ }^{13}$ Women in the present study ate approximately $190 \mathrm{mg}$ of EPA and DHA per day, which does not meet the recommendation set by The ISSFAL. ${ }^{13}$

Furthermore, the 38 pregnant women in the present study, with mean DHA intakes of $100 \mathrm{mg} / \mathrm{d}$ only met approximately $50 \%$ of the ISSFAL recommendation of 200 mg per day of DHA for pregnant and lactating women. ${ }^{10}$ Stark et al. found that African American pregnant women, at 24 weeks gestation, ate approximately $81 \mathrm{mg} / \mathrm{d}$ of DHA. ${ }^{27}$ African American women involved in Project Viva, an observational cohort study of factors in pregnancy, including gestational diet and its' impact on pregnancy outcomes and offspring health, ate approximately $70 \mathrm{mg} / \mathrm{d}$ of EPA+DHA per day. ${ }^{35}$ In a predominantly, Caucasian sample of pregnant women, DHA intakes were $48 \mathrm{mg} / \mathrm{d}$, as assessed by 24 hour recalls. ${ }^{12}$ Higher DHA intakes have been found in other diverse populations of pregnant women, including $140 \mathrm{mg} /$ day in pregnant Mexicans ${ }^{29}, 140 \mathrm{mg} / \mathrm{d}$ in pregnant Dutch women ${ }^{35}$ and $160 \mathrm{mg} /$ day in pregnant Canadians. ${ }^{36}$ Interestingly, EPA and DHA intakes of pregnant African American women were significantly different than intakes of non-pregnant women, in the present study, with pregnant women consuming fewer LCPUFAs. Similarly, Stark et al. ${ }^{27}$ found that African American women three months postpartum had a higher mean intake of DHA than women at 24 weeks gestation. In contrast, Nochera et al. ${ }^{37}$ found that pregnant women $(2.37 \mathrm{~g} / \mathrm{mo})$ consumed more EPA+DHA when compared to lactating women (2.04 g/mo). EPA and DHA are found predominantly in cold water fish, i.e. salmon, tuna and shellfish, eggs, and poultry. ${ }^{4,9}$ In 
the present study, women consumed approximately 50\% of their EPA and DHA from tilapia, fresh/frozen salmon, crab and fried catfish.

Several factors may play a role in fish consumption. After conducting focus groups with low-income African American women, non-Hispanic white women, Spanish and non-Spanish speaking Latinas, Troxel et al. found that cost, lack of knowledge in food preparation and dislike of foods that are rich in DHA were some of the reported barriers for choosing foods rich in this omega-3 fatty acid. ${ }^{38}$ Living in a non-coastal community may impact fish consumption; for example, NHANES 1999-2004 data found that the lowest mercury exposures from fish consumption were found in the the noncoastal Midwest. ${ }^{39}$ Cultural food traditions, which seem to play a large role in African American food choices, may also impact fish and other DHA rich food consumption ${ }^{37,40}$ Sociodemographic factors were associated with omega-3 fatty acid intake. In Project Viva, higher education was related with higher fish intake.${ }^{34}$ In the current study, EPA and DHA intake was significantly different across education levels (some high school, high school graduate, college 1-3 years and college graduate). Those who reported graduating from college had the highest intakes of EPA and DHA. Education was positively correlated with EPA+DHA intakes in a first-generation Latina population $^{41}$ and with fish consumption in a Swedish ${ }^{42}$ and European ${ }^{43}$ male and female population. Researchers suggest education is the most used, reliable and valid indicator of socioeconomic status (SES) ${ }^{44}$ Living a healthy lifestyle, recognizing the importance of preventative health measures and making behavioral choices that bring about lifetime health benefits may all be influenced by the level of education and knowledge that a person acquires. ${ }^{43}$ When using occupation as the SES, Wardle et al. found that those of 
lower SES were less likely to think about "things to do to keep healthy," the future, and had stronger beliefs in the influence of "chance" on health. ${ }^{45}$ African American college graduates, in the present study, may have had more knowledge of the health benefits of EPA and DHA, as well as, which foods are rich in these nutrients or due to educational level, and/or increased ability to purchase EPA+DHA rich foods. ${ }^{43}$ Intakes, however, were not significantly different across income levels, in the present study.

Obesity is also a determinant of health and more than a third of the study population was obese, with an average BMI of 30.4. In the current study, omega- 3 fatty acid intakes between obese and non-obese women were not significantly different. This differs from what Donahue et al. ${ }^{34}$ found in a large cohort of pregnant women. Women who were obese prior to pregnancy had significantly higher total omega-3 fatty acid intakes than women who had normal pre-pregnancy weights. In a large cohort of Canadian pregnant women, a higher percentage of obese women ate fish more than once a week when compared to underweight, normal weight and overweight women ${ }^{46}$

The omega-3 fatty acid FFQ was administered to 40 of the AA women three times (four women only completed two FFQs and five only completed one FFQ) to assess reliability. The Cronbach's coefficient alphas for total n-3, ALA, EPA, DPA and DHA were $0.89,0.89,0.89,0.83$ and 0.88 , respectively. The closer the coefficient alpha is to 1.00 indicates the ability of the FFQ to distinguish intakes between participants. The current FFQ is considered reliable with high between-person variation, which is to be expected because subjects differ from each other in their usual daily food intake ${ }^{33}$ The coefficient alphas in the current study, may suggest that the current FFQ was able to distinguish between subject's omega-3 fatty acid intakes and participants were able to 
provide the same information between all three administrations of the FFQ, though there is a risk that participants remember responses with shorter intervals between questionnaire administrations. ${ }^{16}$ The current study provided a week between each administration of the FFQ. These results are similar to the results of the reliability study done by Ritter-Gooder et al., with a coefficient alpha of 0.83 measured between two administrations of an omega-3 fatty acid food frequency questionnaire used with Caucasian cardiac patients. ${ }^{17}$ In the current study reliability was assessed for each food group with the use of Cronbach's coefficient alpha. Oils, nuts and seeds, eggs and seafood had the highest coefficient alphas for total omega-3 and breads and cereals had the lowest. Similar results were found in ALA, except the lowest coefficient alpha for ALA was seafood. Seafood and eggs had the highest coefficient alphas for EPA and DHA, with a high reliability also found in dairy for EPA, which seemed to be based on ice cream intakes. Those food groups with the highest coefficient alpha seem to be the most prevalent in these women's diets. Those with low coefficient alphas may reflect actual changes in intakes or they are eaten inconsistently by the study population.

During one-on-one interviews, over a two week period, subjects provided three non-consecutive 24 hour recalls, including one weekend day. Validity of the FFQ was measured by computing Pearson correlation coefficients, with log transformed data, between the omega 3 fatty acid mean intakes from 24 hour recalls and FFQs. The correlation coefficients were 0.44 for total n-3, 0.44 for ALA, 0.59 for EPA, 0.25 for DPA and 0.60 for DHA. All correlations were statistically significant at $\mathrm{p}<0.05$ except for DPA. The correlation coefficients calculated between the two dietary methods, in the present study, are similar to those computed in other omega-3 fatty acid FFQ validation 
studies. Lora et al. ${ }^{18}$ validated an omega-3 FFQ to measure intakes in a sample of firstgeneration Latinas against 24-hour recalls. Pearson correlation coefficients were 0.32 for total n-3, 0.34 for ALA, 0.28 for EPA and 0.24 for DHA. The FFQ was found to only be valid for total n-3 and ALA. ${ }^{18}$ In another study omega-3 fatty acid FFQ was validated against three 24 hour recalls, with a Pearson correlation coefficient of 0.42 between the two dietary methods. ${ }^{17}$ In a sample of pregnant Finnish women, an FFQ to assess dietary intakes during pregnancy was validated against two 5-day food records. After attenuation and adjustment for energy, the Pearson correlation coefficient for total omega-3 fatty acid intake, between the two methods, was $0.39 .{ }^{47} \mathrm{~A}$ semi-quantitative FFQ was validated in a multicultural pregnant population with maternal erythrocyte and cord plasma EPA + DHA concentrations, at mid and late pregnancy. At mid-pregnancy, the Spearman correlations were 0.38 and 0.36 between the FFQ and the two biomarkers: maternal erythrocyte and cord blood plasma, respectively. The Spearman correlations between the FFQ and biomarkers were 0.18 and 0.21 , in late pregnancy.$^{34}$

All dietary methods have inherent errors so when developing a validation study, the goal is to find a reference method that has error which does not correlate with the error found in the test method. ${ }^{16,48}$ Biochemical indicators of dietary intakes are advantageous over other dietary methods as the "reference" method in a validation study, because measurement errors should not be correlated with errors found in any dietary assessment methods. ${ }^{16}$ They do, however, have their own sources of error, i.e. individual variations in absorption and metabolism of nutrients or technical error associated with laboratory measurement. The next choice seems to be food records. When compared to 24 hour recalls, food records are the preferred test method, due to less correlated error 
between them and FFQs. ${ }^{14,16}$ But since, food records require subjects to be motivated and literate, a 24 hour recall is sometimes the best option. ${ }^{16}$ In the current study, the all of the omega-3 fatty acid intakes measured by the FFQ were at least $142 \%$ higher than the intakes measured by the 24 hour recalls. Other studies have reported subjects underreporting energy intakes with the use of 24 hour recalls. Thirty-five weight stable women, with a mean age of 30 years, completed four multiple pass 24 hour recalls, inperson and on the phone. When comparing the recall intakes against doubly labeled water measurements of total energy expenditure (TEE), subjects underreported their intakes by an average of $16 \% .^{49}$ A similar result of underreporting was found when men and women completed three 24- hour recalls using the USDA Automated Multiple Pass Method, a computer-assisted version of the USDA 5-step method. When the recall data was compared to the TEE, measured by doubly labeled water, subjects underreported intakes by $11 \%{ }^{50}$ Poslusna et al. ${ }^{51}$ stated that underreporting is associated higher BMI, being a women, lower socioeconomic status and lower education level. In the present study, $40 \%$ of women were considered obese, based on reported pre-pregnancy or current body weight. Almost half of the subjects have not been to college and approximately, $18 \%$ did not graduate high school. These characteristics of the current population, may have contributed to the underreporting of intakes, measured by recalls, when compared to the FFQs.

Preterm birth, low birth weight, preeclampsia and postpartum depression are all health issues which may be influenced by maternal omega-3 fatty acid intakes. African American infants have approximately 2.3 times the mortality rate of non-Hispanic white infants and some of this can be explained by preterm birth and low birth weight.$^{52,53}$ 
Preterm birth is defined as a baby born at less than 37 weeks gestation. ${ }^{52}$ Researchers, after a structured literature review, found that an imbalance of omega- 3 and omega- 6 fatty acids may have an impact on preterm birth occurrence in African American women. ${ }^{52}$ In the current study, $39 \%$ of women with previous pregnancies reported having a preterm baby, but there was not a significant difference in omega-3 fatty acid intakes, when compared to women who did not have a preterm baby. African American women who reported history of preterm labor (18\%) ate significantly more foods containing total omega-3 fatty acids and EPA, furthermore, those who reported history of premature rupture of membranes $(21 \%)$ ate significantly more foods containing total omega-3 and ALA. Intakes of EPA and DHA may play a protective role in decreasing the occurrence of preterm birth and preterm labor, because of the eicosanoids derived from these LCPUFAs may relax the uterine wall and competitively inhibit those eicosanoids that lead to rupture of membranes and contractions. ${ }^{54}$ Dhobale et al. found that placental DHA levels were lower in preterm deliveries when compared to term deliveries,${ }^{55}$ and placental DHA is dependent on metabolism of maternal DHA intakes. ${ }^{56}$ In the current study, EPA and DHA intakes were below recommended levels. If this is any indication of previous intakes, then these African American women are not meeting their needs which may lead to reoccurrence of this maternal health outcome. Klebanoff et al. found that moderate fish intake (up to three meals per week) before 22 weeks gestation was associated with a reduction in repeat preterm labor ${ }^{57}$ In addition, fish oil supplementation in Danish pregnant women decreased the risk of preterm birth occurrence from $33 \%$ to $21 \% .^{58}$ 
History of low birth weight, a birth weight below 5 pounds 8 ounces, was reported by $30 \%$ of the African American women with previous pregnancies, in the current study. African American infants are three times more likely to die from complications of low birth weight than non-Hispanic white infants. ${ }^{53}$ Researchers have found that pregnant women who took EPA and DHA rich cod liver oil gave birth to larger babies, when compared to mothers who took olive oil (a poor source of EPA and DHA).$^{58}$ Interestingly, in the current study, participants who had a history a of low birth weight infants ate significantly more foods containing DHA than those moms who did not have a low birth weight baby. Their mean intakes were $196 \mathrm{mg}$ of DHA, which meets $98 \%$ of the guidelines set by ISSFAL for pregnant women, compared to $96 \mathrm{mg}$ of DHA intake of those participants who have not had low birth weight babies.

Preeclampsia, defined as high blood pressure (blood pressure > 140/90 mm Hg over time) and protein in the urine, after 20 weeks of pregnancy, ${ }^{59}$ was reported by $27 \%$ of AA women, with previous pregnancies, in the current study. No significant difference was found between these women's intakes and participants who did not have history of preeclampsia. EPA derived eicosanoids are thought to have a beneficial effect on decreasing the occurrence of preeclampsia ${ }^{54}$ In placental tissues of preeclamptic women, EPA and DHA decreased, when compared to normotensive women, in a sample of pregnant Indian ${ }^{60}$ and American women. ${ }^{61}$ Williams et al. found that pregnant women with the lowest total omega-3 fatty acid erythrocyte levels were 7.6 times more likely to have preeclampsia than those with the highest erythrocyte levels. ${ }^{3}$ Currently women, in the present study, had mean DHA intakes of $110 \mathrm{mg}$, which is not meeting their needs and may put them at risk for reoccurrence of preeclampsia. 
Twenty-four percent of women, in the current study, who had previous pregnancies, reported a diagnosis of postpartum depression. Postpartum depression is characterized as a nonpsychotic depressive illness of mild-to moderate severity occurring in a mother during the first postnatal year, which is a time of major change and increased responsibilities in the care of a newborn infant.${ }^{62,63}$ A possible factor in postpartum depression is inflammation, which may be inhibited by intake of EPA and DHA secondary to their anti-inflammatory nature. Also, researchers have reported that populations which have higher intakes of omega-3 fatty acids, have lower rates of depression ${ }^{64}$ and bipolar disorder ${ }^{65}$ Limited research supports the role of EPA and DHA in the prevention of depression. Hibbeln et al. found that lower amounts of DHA in breast milk and lower amounts of seafood intakes were associated with higher amounts of postpartum depression. ${ }^{66}$ Another study found that a $1 \%$ higher plasma DHA status was associated with a 59\% reduction in the likelihood of reporting depressive symptoms postpartum ${ }^{67}$ In the current study, those participants who had a prior diagnosis of postpartum depression $(3.73 \mathrm{~g} / \mathrm{d}$ vs. $2.19 \mathrm{~g} / \mathrm{d})$ consumed significantly more foods containing total omega-3 fatty acids and ALA but their EPA and DHA intakes were not significantly different. Researchers suggest that high ALA intakes can inhibit further conversion of ALA to DHA ${ }^{68}$ In rats, linoleic acid was held at a constant level and ALA was increased from 0.1 to $2.8 \%$ of energy. While dietary intake of both ALA and EPA content in both plasma and liver follow a linear pattern, DHA status follows a curvilinear pattern with ALA intake. DHA status increases up to a dietary level of ALA approximately $1 \%$ of energy and then plateaus and eventually declines ${ }^{69}$ The Acceptable Macronutrient Distribution Range for ALA is 0.6 to $1.1 \%$ of energy. ${ }^{26}$ Similar results 
were reported in piglets at a dietary level of ALA at $2 \%$ of energy and any intake above this level inhibited DHA conversion.$^{70}$ Chan et al. found that EPA increased in a dosedependent manner with low (0.8\% of energy), intermediate $(6.6 \%)$ and high $(13.4 \%)$ intakes of ALA, but DHA did not change in a population of normolipidemic Canadian men. ${ }^{71}$ African American women, who had a prior diagnosis of postpartum depression, ALA intakes were $339 \%$ higher than the Adequate Intake for women between the ages of 14-50 years. ${ }^{26}$ If current intakes reflect past intakes, then the high amount of ALA consumed by these women may have inhibited further conversion of ALA to DHA and with current low intakes of DHA, at approximately $127 \mathrm{mg} / \mathrm{d}$, this could have possibly increased their risk for postpartum depression.

\section{Conclusions}

Currently, this is the first food frequency questionnaire developed to specifically measure Midwestern African American omega-3 fatty acid intakes. The omega-3 fatty acid FFQ had acceptable reliability and validity to measure nutrients studied in this population. In the current study, intakes exceeded the recommended amounts for ALA but did not meet the recommended amounts for EPA and DHA, including those who were pregnant. African Americans suffer disproportionately from several diseases, including preterm birth and low birth weight, which may be associated with low omega-3 intakes in this population. Omega-3 fatty acid rich foods may be too expensive, not appetizing to these women or considered going against the cultural norm, leading to lower intakes. Further research is needed to find out factors that influence these intakes. Assessment of low income African American women's knowledge of omega-3 rich foods and their role in health is warranted, as well as, what would be the best way to provide 
educational information to this population. Nutrition educators can then tailor educational materials to the targeted audience and possibly increase access to information about the importance of these nutrients. 


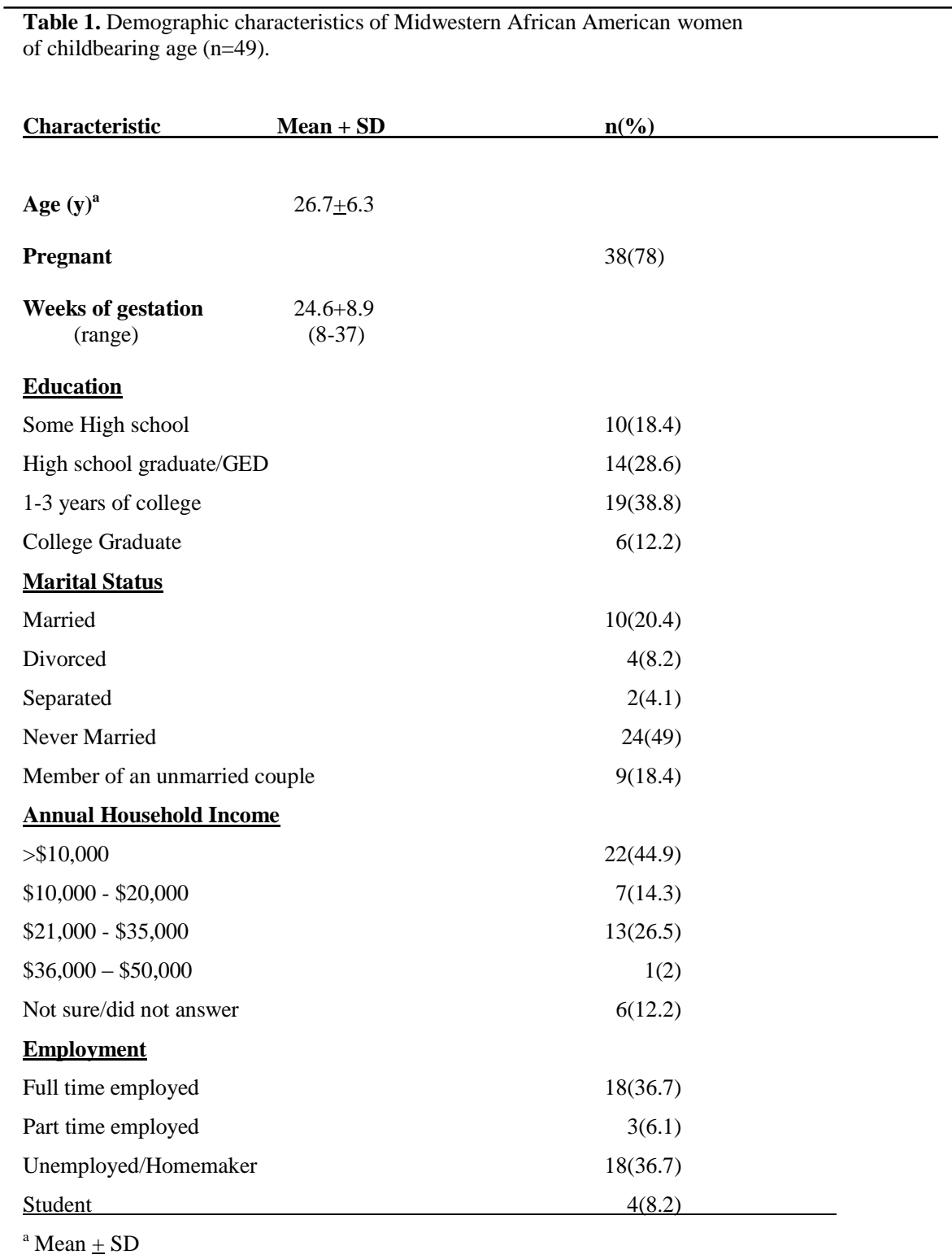


Table 2. Mean intakes ( \pm SD) of total omega-3 (Total n-3), alpha-linolenic acid (ALA), eicosapentaenoic acid (EPA), docosahexaenoic acid (DHA) and docosapentaenoic acid estimated by the three FFQs and three 24 hour recalls with correlations between the two methods.

\begin{tabular}{lccc} 
& $\begin{array}{l}\text { FFQs } \\
(\mathrm{g} / \mathrm{d})\end{array}$ & $\begin{array}{c}\text { 24-h recalls } \\
(\mathrm{g} / \mathrm{d})\end{array}$ & Pearson Correlation $^{\mathrm{a}}$ \\
\hline & & & \\
Total n-3 & $2.68 \pm 1.37$ & $1.85 \pm 0.86$ & $0.44^{\mathrm{b}}$ \\
ALA & $2.45 \pm 1.30$ & $1.72 \pm 0.81$ & $0.44^{\mathrm{b}}$ \\
EPA & $0.07 \pm 0.07$ & $0.05 \pm 0.08$ & $0.59^{\mathrm{c}}$ \\
DPA & $0.03 \pm 0.02$ & $0.02 \pm 0.02$ & 0.25 \\
DHA & $0.12 \pm 0.11$ & $0.07 \pm 0.09$ & $0.60^{\mathrm{c}}$ \\
\hline${ }^{\mathrm{a}}$ Calculed
\end{tabular}

${ }^{\mathrm{a}}$ Calculated based on log-transformed values.

${ }^{\mathrm{b}} \mathrm{p}<.01$

${ }^{c} \mathrm{p}<.00$ 
Table 3. Mean intakes of total omega-3 (total n-3), alpha-linolenic acid (ALA), eicosapentaenoic acid (EPA), docosapentaenoic acid (DPA), and docosahexaenoic acid (DHA) by food groups as estimated by the three FFQs.

\begin{tabular}{lccccc} 
Food Groups & Total n-3 & ALA & $\begin{array}{c}\mathbf{E P A}^{\mathbf{a}} \\
\mathrm{g} / \mathrm{d}\end{array}$ & DPA $^{\mathbf{a}}$ & DHA $^{\mathbf{a}}$ \\
\hline Meat & $0.22 \pm 0.18$ & $0.18 \pm 0.15$ & $0.005 \pm 0.005$ & $0.01 \pm 0.01$ & $0.02 \pm 0.02$ \\
Seafood & $0.21 \pm 0.22$ & $0.05 \pm 0.08$ & $0.07 \pm 0.07$ & $0.02 \pm 0.03$ & $0.09 \pm 0.09$ \\
Eggs & $0.09 \pm 0.08$ & $0.07 \pm 0.07$ & $0.002 \pm 0.002$ & - & $0.01 \pm 0.01$ \\
Dairy & $0.25 \pm 0.17$ & $0.25 \pm 0.17$ & $0.001 \pm 0.001$ & - & - \\
Vegetables & $0.35 \pm 0.25$ & $0.35 \pm 0.25$ & - & - & - \\
Fruit & $0.05 \pm 0.05$ & $0.05 \pm 0.05$ & - & - & - \\
Bread, cereals & $0.19 \pm 0.22$ & $0.19 \pm 0.22$ & $0.001 \pm 0.002$ & $0.00005 \pm 0.0001$ & $.0001 \pm .0001$ \\
Condiments, snacks & $0.17 \pm 0.11$ & $0.17 \pm 0.11$ & - & - & - \\
Oil & $0.73 \pm 0.70$ & $0.73 \pm 0.11$ & - & - & - \\
Nuts & $0.04 \pm 0.14$ & $0.04 \pm 0.14$ & $0.0001 \pm 0.00002$ & - & - \\
Beans & $0.005 \pm 0.007$ & $0.005 \pm 0.007$ & - & - & $0.002 \pm 0.003$ \\
Prepared Dishes & $0.42 \pm 0.27$ & $0.43 \pm 0.31$ & $0.003 \pm 0.006$ & $0.01 \pm 0.01$ & - \\
\hline
\end{tabular}

${ }^{\mathrm{a}}$ Blanks signify that the food group contains below detectable amounts of the fatty acid 
Table 4. Rank order listing of food groups that provided total omega-3 fatty acid intakes consumed by African American women, as measured by three FFQs.

\begin{tabular}{llc} 
Rank order & Food group & \% of total omega-3 intake \\
\hline 1. & Oils & 26.9 \\
2. & Prepared Dishes & 15.5 \\
3. & Vegetable & 12.9 \\
4. & Dairy & 9.1 \\
5. & Meat & 8.1 \\
6. & Seafood & 7.8 \\
7. & Bread, cereals & 6.9 \\
8. & Condiments, snacks & 6.4 \\
9. & Eggs & 3.2 \\
10. & Fruit & 1.7 \\
11. & Nuts and Seeds & 1.4 \\
12. & Beans & 0.2 \\
\hline
\end{tabular}


Table 5.Rank order listing of foods that provided approximately 90\% of eicosapentaenoic acid (EPA) + docosahexaenoic acid (DHA) in the study population, as assessed by the means of the FFQs.

\begin{tabular}{llc}
\multicolumn{1}{c}{ Rank order } & \multicolumn{1}{c}{ Food } & $\begin{array}{c}\text { \% each food provided to } \\
\text { EPA+DHA intake }\end{array}$ \\
\hline 1. & Tilapia & 21.8 \\
2. & Salmon, frozen/fresh & 12.0 \\
3. & Crab & 7.5 \\
4. & Fried Catfish & 7.4 \\
5. & Tuna, canned in water & 5.9 \\
6. & Fried/scrambled egg, in butter & 5.4 \\
7. & Shrimp & 5.2 \\
8. & Fried shrimp & 4.3 \\
9. & Sardines & 3.8 \\
10. & Salmon, canned & 3.6 \\
11. & Fried wings & 2.9 \\
12. & Salmon croquettes & 2.6 \\
13. & Chicken breast & 1.9 \\
14. & Boiled eggs & 1.7 \\
15. & Fried chicken legs & 1.5 \\
16. & Chicken wing & 1.2 \\
17. & Chicken leg & 1.1 \\
\hline
\end{tabular}


Table 6. Cronbach's coefficient alphas ${ }^{\mathrm{a}}$ of total omega-3 (Total n-3), alpha-linolenic acid (ALA), eicosapentaenoic acid (EPA), docosapentaenoic acid (DHA), and docosahexaenoic acid (DPA) from the three FFQs.

Nutrient

Coefficient

Total n-3

0.89

ALA

0.89

EPA

0.89

DPA

0.83

DHA

0.88

${ }^{a}$ Calculated based on log-transformed values. 
Table 7. Cronbach's coefficient alphas of food groups by total omega-3 (total n-3), alpha-linolenic acid (ALA), eicosapentaenoic acid (EPA), docosapentaenoic acid (DPA), docosahexaenoic acid (DHA) between the three FFQs.

\begin{tabular}{lccccc} 
Food Groups & Total n-3 & ALA & EPA $^{\mathbf{a}}$ & DPA $^{\mathbf{a}}$ & DHA $^{\mathbf{a}}$ \\
\hline Meats & 0.77 & 0.79 & 0.62 & 0.62 & 0.17 \\
Seafood & 0.82 & 0.15 & 0.83 & - & 0.82 \\
Eggs & 0.83 & 0.82 & 0.82 & - & - \\
Dairy & 0.80 & 0.80 & 0.88 & - & - \\
Vegetables & 0.68 & 0.68 & - & - & - \\
Fruits & 0.79 & 0.16 & 0.68 & - & - \\
Breads, cereals & 0.17 & 0.58 & - & - & - \\
Condiments, snacks & 0.59 & 0.86 & 0.70 & - & - \\
Oils & 0.86 & 0.86 & - & - & - \\
Nuts and seeds & 0.85 & 0.80 & 0.79 & - & - \\
Beans & 0.79 &
\end{tabular}

${ }^{a}$ Blanks signify that the food group contains below detectable amounts of the fatty acid 
Table 8. Mean intakes $( \pm \mathrm{SD})$ of total omega-3 (Total $n-3)$, alpha-linolenic acid (ALA), eicosapentaenoic acid, docosapentaenoic acid (DPA) and docosahexaenoic acid (DHA) of pregnant and non-pregnant African American women.

\begin{tabular}{|c|c|c|c|c|c|c|}
\hline & $\mathbf{N}$ & Total n-3 & ALA & $\mathbf{E P A}^{\mathbf{a}}$ & DPA & $\mathrm{DHA}^{\mathrm{a}}$ \\
\hline Pregnant & 38 & $2.70 \pm 1.46$ & $2.50 \pm 1.38$ & $0.06+0.06$ & $0.02 \pm 0.02$ & $0.10 \pm 0.09$ \\
\hline Non-pregnant & 11 & $2.58+1.09$ & $2.24+1.00$ & $0.12+0.09$ & $0.04+0.02$ & $0.19+0.13$ \\
\hline
\end{tabular}


Table 9. Midwestern African American women's body mass index (BMI) $(n=49)$.

$\begin{array}{lll}\text { Characteristic } & \text { Mean }(+\mathrm{SD}) & \mathbf{n}(\%)\end{array}$

BMI $^{\mathbf{a}} \quad 30.4 \pm 8.5$

Body mass index category:

$18.5-24.9^{\mathrm{b}}$

$14(28.6)$

$25-29.9^{c}$

$15(30.6)$

$>30^{\mathrm{d}}$

20(40.8)

${ }^{a}$ Based on pre-pregnancy weight $(n=37)$

${ }^{\mathrm{b}}$ Normal weight

${ }^{\mathrm{c}}$ Overweight

${ }^{\mathrm{d}}$ Obese 
Figure 1. Previous pregnancy maternal health issues of African American women as assessed by questions adapted from the 2008 Maternal and Infant Health Assessment $^{30}(\mathrm{n}=33)^{\mathrm{a}}$.

Did you ever:

have a baby that weighed less than 5 pounds, 8 ounces ( $2 \frac{1}{2}$ kilos) at birth?

$10(30)^{\mathrm{b}}$

have a baby that was born prematurely (before you reached 37 weeks of pregnancy)?

have labor pains more than 3 weeks before your baby was due (preterm/early labor)?

have your water break more than 3 weeks before you baby was due (premature rupture of membranes)?

$13(39)$

have pregnancy induced high blood pressure (preeclampsia, eclampsia or toxemia)? 
Table 10. Mean intakes ( \pm SD) of Total omega-3 (total n-3), alpha-linolenic acid (ALA), eicosapentaenoic acid (EPA), docosapentaenoic acid (DPA) and docosahexaenoic acid (DHA) of African American women by education level, from the three FFQs.

\begin{tabular}{lcccccc} 
Education level & $\mathbf{n}$ & Total n-3 & ALA & EPA $^{\mathbf{a}}$ & DPA & DHA $^{\mathbf{a}}$ \\
\hline Some high school & 9 & $3.77 \pm 1.93$ & $3.52 \pm 1.87$ & $0.08 \pm 0.07$ & $0.03 \pm 0.03$ & $0.13 \pm 0.13$ \\
High school graduate & 14 & $2.05 \pm 0.76$ & $1.94 \pm 0.70$ & $0.03 \pm 0.03$ & $0.02 \pm 0.01$ & $0.06 \pm 0.03$ \\
College 1-3 years & 20 & $2.61 \pm 1.20$ & $2.37 \pm 1.12$ & $0.08 \pm 0.06$ & $0.03 \pm 0.02$ & $0.13 \pm 0.09$ \\
College graduate & 6 & $2.71 \pm 1.27$ & $2.23 \pm 1.21$ & $0.17 \pm 0.11$ & $0.05 \pm 0.02$ & $0.25 \pm 1.27$ \\
\hline
\end{tabular}

${ }^{\mathrm{a}}$ Intakes are significantly different at $\mathrm{p}<.05$ 


\section{References}

1. Olsen SF, Secher NJ. Low consumption of seafood in early pregnancy as a risk factor for preterm delivery: prospective cohort study. BMJ. 2002;324(7335):447-451.

2. Olafsdottir AS, Magnusardottir AR, Thorgeirsdottir H, Hauksson A, Skuladottir GV, Steingrimsdottir L. Relationship between dietary intake of cod liver oil in early pregnancy and birthweight. BJOG. 2005;112(4):424-429.

3. Williams MA, Zingheim RW, King IB, Zebelman AM. Omega-3 fatty acids in maternal erythrocytes and risk of preeclampsia. Epidemiology. 1995;6(3):232-237.

4. Innis SM. Dietary (n-3) fatty acids and brain development. J Nutr. 2007;137(4):855859.

5. Innis SM. Perinatal biochemistry and physiology of long-chain polyunsaturated fatty acids. J Pediatr. 2003; 143: S1-S8.

6. Kris-Etherton PM, Shaffer Taylor D, Yu-Poth S, Huth P, Moriarty K, Fishell V, Hargrove RL, Zhao G, Etherton TD. Polyunsaturated fatty acids in the food chain in the United States. AM J Clin Nutr. 2000;71(suppl):S179-S188.

7. Ratnayake WM, Galli C. Fat and fatty acid terminology, methods of analysis and fat digestion and metabolism: a background review paper. Ann Nutr Metab. 2009;55(1$3): 8-43$.

8. Arterburn LM, Hall EB, Oken H. Distribution, interconversion, and dose response of n-3 fatty acids in humans. Am J Clin Nutr. 2006;83(6suppl):S1467-S1476.

9. U.S. Food and Drug Administration. Safe Eats-Eating Out \& Bringing in. http://www.fda.gov/Food/ResourcesForYou/HealthEducators/ucm082539.htm. Updated March 14, 2012. Accessed 02/15/13

10. Koletzko B, Cetin I, Brenna JT. Perinatal Lipid Intake Working Group Consensus Statement. Dietary fat intakes for pregnant and lactating women. Brit J Nutr.2007;98(5):873-877.

11. U.S. Department of Agriculture, Agricultural Research Service, Beltsville Human Nutrition Research Center, Food Surveys Research Group (Beltsville, MD). Continuing Survey of Food Intakes by Individuals 1994-96, 1998 and Diet and Health 
Knowledge Survey 1994-96: Documentation (csfii9498_documentationupdated.pdf). http://www.ars.usda.gov/Services/docs.htm?docid=14531. Accessed March 01, 2013.

12. Lewis NM, Widga AC, Buck JS, Frederick AM. Survey of omega-3 fatty acids in diets of Midwest low-income pregnant women. J Agromedicine. 1995;2(4):49-57.

13. ISSFAL. Recommendations for Intake of Polyunsaturated Fatty Acids in health Adults Web site.

http://www.issfal.org.uk/index.php?option=com_content\&task=view\&id=23\&Itemid =8. Published 2004. Accessed February 2, 2013.

14. Gibson RS. Principles of Nutritional Assessment. $2^{\text {nd }}$ ed. New York, Oxford: Oxford University Press; 2005:41-196.

15. Hu FB. Obesity Epidemiology. New York, Oxford: University Press; 2008:84-118.

16. Willet W ed. Nutritional Epidemiology. $2^{\text {nd }}$ ed. New York, Oxford: Oxford University Press; 1998:74-94.

17. Ritter-Gooder P, Lewis NM, Barber-Heidal K, Waltz-Hill M. Development and pilot testing of an omega-3 food frequency questionnaire. J Food Compos Anal. 2008;21(suppl):s43-s49.

18. Lora KR, Lewis NM, Eskridge KM, Stanek-Krogstrand K, Ritter-Gooder P. Validity and reliability of an omega-3 fatty acid food frequency questionnaire for firstgeneration Midwestern Latinas. Nutr Res. 2010;30(8):550-557.

19. Kittler PG, Sucher KP. Food and Culture. Wadsworth; 2008:205-229.

20. United States Department of Agriculture. Mypyramid. Steps to a healthier weight. Web site. http://www.mypyramid.gov/steps/howmuchshouldyoueat.html. Accessed January 15, 2011.

21. U.S. Department of Agriculture (USDA), Agriculture Research Service, 2002. USDA National Nutrient Database for Standard Reference. Release 25. Web site. http://ndb.nal.usda.gov/. Updated December 7, 2011. Accessed January 15, 2011. 
22. Centers for Disease Control and Prevention (CDC). Behavioral Risk Factor Surveillance System Survey Questionnaire. Atlanta, Georgia: U.S. Department of Health and Human Services, Centers for Disease Control and Prevention, 2010.

23. University of California at Berkeley. Survey Research Center. Maternal and Infant Health Assessment Survey, 2008. Web site. http://www.cdph.ca.gov/data/surveys/Documents/MO-MIHA-English2008.pdf. Accessed January 15, 2011.

24. Nutrition Coordinating Center (NCC), University of Minnesota, Minneapolis, MN Nutrition Data System for Research software version NDSR 2009.

25. Centers for Disease Control and Prevention. Healthy Weight- it's not a diet it's a lifestyle! Web site. http://www.cdc.gov/healthyweight/assessing/bmi/adult_bmi/index.html. Accessed February 09, 2013.

26. Institute of Medicine. Dietary Reference Intakes for Energy, Carbohydrate, Fiber, Fat, Fatty Acids, Cholesterol, Protein, and Amino Acids. Washington DC: National Academy Press; 2005: 427.

27. Stark KD, Beblo S, Murthy M, Buda-Abela M, Janisse J, Rockett H, Whitty JE, Martier SS, Sokol RJ, Hannigan JH, Salem N Jr. Comparison of bloodstream fatty acid composition from African-American women at gestation, delivery, and postpartum. J Lipid Res. 2005;46(3):516-525.

28. Garneau V, Rudkowska I, Paradis AM, Godin G, Julien P, Perusse L, Vohl MC. Omega-3 fatty acids status in human subjects estimated using a food frequency questionnaire and plasma phospholipids levels. Nutr J. 2012;11:46.

29. Parra MS, Schnaas L, Meydani M, Perroni E, Martinez S, Romieu I. Erythrocyte cell membrane phospholipid levels compared against reported dietary intakes of polyunsaturated fatty acids in pregnant Mexican women. Public Health Nutr. 2002;5(6A):931-937.

30. Ratnayake WM, Galli C. Fat and fatty acid terminology, methods of analysis and fat digestion and metabolism: a background review paper. Ann Nutr Metab. 2009;55(13):8-43. 
31. Simopoulos, AP. Evolutionary aspects of diet: the omega-6/omega-3 ratio and brain. Mol Neurobiol. 2011;44(2):203-215.

32. Arterburn LM, Hall EB, Oken H. Distribution, interconversion, and dose response of n-3 fatty acids in humans. Am J Clin Nutr. 2006;83(6suppl):S1467-S1476.

33. Gibson RA, Muhlhausler B, Makrides M. Conversion of linoleic acid and alphalinolenic to long-chain polyunsaturated fatty acids (LCPUFAs), with a focus on pregnancy, lactation and the first 2 years of life. Matern Child Nutr. 2011;7(suppl2):17-26.

34. Donahue SMA, Rifas-Shiman SL, Olsen SF, Gold DR, Gillman MW, Oken E. Associations of maternal prenatal dietary intake of n-3 and n-6 fatty acids with maternal and umbilical cord blood levels.Prostaglandins Leukot Essent Fatty Acids. 2009;80(5-6):289-296.

35. Otto SJ, van Houwelingen AC, Bardart-Smook A, Hornstra G. Changes in the maternal essential fatty acid profile during early pregnancy and the relation of the profile to diet. Am J Clin Nutr. 2001;73(2):302-307.

36. Innis SM, Elias SL. Intakes of n-6 and n-3 fatty acids among pregnant Canadian women. Am J Nutr. 2003;77(2):473-478.

37. Nochera CL, Goossen LH, Brutus AR, Cristales M, Eastman B. Consumption of DHA+EPA by low-income women during pregnancy and lactation. 2011;26(4):445450.

38. Troxell H, Anderson J, Auld G, Marx N, Harris M, Reese M, Allen K. Omega-3 for baby and me: Material development for a WIC intervention to increase DHA intake during pregnancy. Matern Child Health J. 2005;9(2):189-197.

39. Mahaffey KR, Clickner RP, Jeffries RA. Adult women's blood mercury concentrations vary regionally in the United States: association with patterns of fish consumption (NHANES 19-2004). Environ Health Perspect. 2009;117(1):47-53.

40. James DCS. Factors influencing food choices, dietary intake, and nutrition-related attitudes among African Americans: application of a culturally sensitive model. Ethn Health. 2004;9(4):349-367. 
41. Lora KR, Lewis NM, Eskridge KM, Stanek-Krogstrand K, Travnicek DA. Correlation of omega-3 fatty acid intakes with acculturation and socioeconomic status in Midwestern Latinas. J Immigr Minor Health. 2011;13(1):111-118.

42. Wennberg M, Tornevi A, Johansson I, Hornell A, Norberg M, Bergdahl IA. Diet and lifestyle factors associated with fish consumption in men and women: a study of whether gender differences can results in gender-specific confounding. Nutr J. 2012;11:101.

43. Galobardes B, Morabia A, Berstein MS. Diet and socioeconomic position: does the use of different indicators matter? Int J Epidemol 2001;30(2):334-340.

44. Berkman LF, Macintyre S. The measurement of social class in health studies: old measures and new formulas. In: Kogevinas M, Pearce N, Susser M, Boeffetta P, eds. Social Inequalities and Cancer. IARC Scientific Publications No. 138; 1997:51-64.

45. Wardle J, Steptoe A. Socioeconomic differences in attitudes and beliefs about healthy lifestyles. J Epidemiol Community Health. 2003;57(6):440-443.

46. Sontrop JM, Campbell MK, Speechley KN, Avison WR, Evers SE. Fish consumption among pregnant women in London, Ontario. Can J Public Health. 2007;98(5):389394.

47. Erkkola M, Karppinen M, Javanainen J, Räsänen L, Knip M, Virtanen SM. Validity and reproducibility of a food frequency questionnaire for pregnant Finnish women. Am J Epidemiol. 2001;154(5):466-476.

48. Thompson FE, Subar AF. Dietary assessment methodology. In Coulston AM, Boushey CJ, Ferruzzi MG, eds. Nutrition in the Prevention and Treatment of Disease. $3^{\text {rd }}$ ed. Amsterdam, Boston: Elsevier;2013:5-44.

49. Tran KM, Johnson RK, Soultanakis RP, Matthews DE. In-person vs. telephoneadministered multiple-pass 24 hour recalls in women: validation with doubly labeled water. J Am Diet Assoc. 2000;100(7):777-780,783.

50. Moshfegh AJ, Rhodes DG, Baer DJ, Murayi T, Clemens JC, Rumpler WV, Paul DR, Sebastian RS, Kuczynski KJ, Ingwersen LA. Staples RC, Cleveland LE. The US Department of Agriculture Automated Multiple-Pass Method reduces bias in the collection of energy intakes. Am J Clin Nutr. 2008;88(2):324-332. 
51. Poslusna K, Ruprich J, de Vries JHM, Jakubikova M, van't Veer Pieter. Misreporting of energy and micronutrient intake estimated by food records and 24 hour recalls, control and adjustment methods in practice. Br J Nutr.101(suppl2):S73-S85.

52. Dunlop AL, Kramer MR, Hogue CJR, Menon R, Ramakrishan U. Racial disparities in preterm birth: an overview of the potential role of nutrient deficiencies. Acta Obstet Gyn Scan. 2011;90(12):1332-1341

53. US. Department of Health \& Human Services. The Office of Minority Health. Infant Mortality and African Americans. Web site. http://minorityhealth.hhs.gov/templates/content.aspx?ID=3021. Modified July 3, 2012. Accessed 03/01/2013.

54. Greenberg JA, Bell SJ, Van Ausdal W. Omega-3 fatty acid supplementation during pregnancy. Rev Obstet Gynecol. 2008;1(4):162-169.

55. Dhobale MV, Wadhwani N, Mehendale SS, Pisal H, Joshi SR. Reduced levels of placental long chain polyunsaturated acids in preterm deliveries. Prostaglandins Leukot Essent Fatty Acids. 2011;85(3-4):149-153.

56. Cetin I, Alvino G, Cardellicchio M. Long chain fatty acids and dietary fats in fetal nutrition. J Physiol. 2009;587(Pt 14):3441-3451.

57. Klebanoff MA, Harper M, Lai Y, Thorp J Jr, Sorokin Y, Varner MW, Wapner RJ, Caritis SN, Iams JD, Carpenter MW, Peaceman AM, Mercer BM, Sciscione A, Rouse DJ, Ramin SM, Anderson GD; Eunice Kennedy Shriver National Institute of Child Health and Human Development (NICHD) Maternal-Fetal Medicine Units Network (MFMU). Obstet Gynecol. 2011;117(5):1071-1077.

58. Olsen SF, Secher NJ, Tabor A, Weber T, Walker JJ, Gluud C. Randomised clinical trials of fish oil supplementation in high risk pregnancies. Brit J Obstet Gynaec. 2000;107(3):382-395.

59. PubMedHealth. Preeclampsia. Web site. http://www.ncbi.nlm.nih.gov/pubmedhealth/PMH0001900/. Updated August 23, 2012. Accessed February 15, 2013. 
60. Kulkarni AV, Mehendale SS, Yadav HR, Joshi SR. Reduced placental docosahexaenoic levels associated with increased levels of sFlt-1 in preeclampsia. Prostaglandins Leukot Essent Fatty Acids.2011;84(1-2):51-55.

61. Wang Y, Walsh SW, Kay HH. Placental tissue levels of nonesterified polyunsaturated fatty acids in normal and preeclamptic pregnancies. Hypertens Pregnancy. 2005;24(3):235-245.

62. American Psychological Association. Postpartum Depression. Web site. http://apa.org/pi/women/programs/depression/postpartum.aspx. Published 2013. Accessed March 1, 2013.

63. Shapiro GD, Fraser WD, Seguin JR. Emerging risk factors for postpartum depression: serotonin transporter genotype and omega-3 fatty acid status. Can J Psychiatr. 2012;57(11):704-712.

64. Tanskanen A, Hibbeln JR, Tuomilehto J, Uutela A, Haukkala A, Viinamaki H, Lehtonen J, Vartiainen E. Fish consumption and depressive symptoms in the general population in Finland. Psychiatr Serv. 2001;52(4):529-531.

65. Noaghiul S, Hibbeln JR. Cross-national comparisons of seafood consumption and rates of bipolar disorders. Am J Psychiatry. 2003;160(12):2222-2227.

66. Hibbeln JR. Seafood consumption, the DHA content of mother's milk and prevalence rates of postpartum depression: a cross-natinal, ecological analysis. J Affect Disorders.2002;69(1):15-29.

67. Rees AM, Austin MP, Parker G. Role of omega-3 fatty acids as a treatment for depression in the perinatal period. Aust N Z J Psychiatry. 2005;39(4):274-280.

68. Gibson RA, Muhlhausler B, Makrides M. Conversion of linoleic acid and alphalinolenic to long-chain polyunsaturated fatty acids (LCPUFAs), with a focus on pregnancy, lactation and the first 2 years of life. Matern Child Nutr. 2011;7(suppl2):17-26.

69. Tu WC, Cook-Johnson RJ, James MJ, Muhlhausler BS, Gibson RA. Omega-3 long chain fatty acid synthesis is regulated by substrate levels than gene expression. Prostaglandins Leukot Essent Fatty Acids. 2010;83(2):61-68. 
70. Blank C, Neumann MA, Makrides M, Gibson RA. Optimizing DHA levels in piglets by lowering the linoleic acid to $\alpha$-linolenic acid ratio. J Lipid Res. 2002;43(9):15371543.

71. Chan JK, McDonald BE, Gerrard J, Bruce VM, Weaver BJ, Holub BJ. Effect of dietary $\alpha$-linolenic acid and its ratio to linoleic acid on platelet and plasma fatty acids and thrombogenesis. Lipids. 1993;28(9):811-817. 


\section{APPENDIX A}

Institutional Review Board Letters 


\section{Nebraskisa \\ Lincoln}

INFORMED CONSENT FORM
COLLEGE OF EDUCATION AND HUMAN SCIENCES Department of Nutrition and Health Sciences

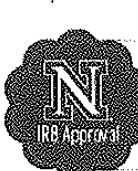

IRB\# $20110311493 \mathrm{EX}$

Date Approved: 03/04/2011

Valid Until: 01/01/2013

\section{Dear Participant:}

You are invited to participate in this research study because you are an African American woman. We want to learn more about the foods that you eat. The following information is provided in order to help you make an informed decision whether or not to participate.

Participation in this study is voluntary and does not pose any risk to you. All information is kept strictly confidential.

Identification of Project:

Validity and reliability of a culturally appropriate Food Frequency Questionnaire to measure omega-3 fatty acid food intake in African American Pregnant women-Phase 1/24 hour recall and preliminary interviews

Omega-3 fatty acid foods are important for maternal and infant health. For the mom, they can protect against high blood pressure during pregnancy and post partum depression. For the infant, they can protect against pre-term birth and promote a higher birth weight. We are conducting this study to know how much and how often you are eating foods that contain Omega- 3 fatty acids.

Purpose of the Research:

This research project aims develop a culturally competent Food Frequency Questionnaire to measure Omega-3 fatty acid intake in pregnant African American Pregnant Women. To participate in Phase 1 of this study, you must be an African American woman.

Procedures:

Participation in this study will require approximately 25 minutes of your time. You will be asked to fill out a 24 hour dietary recall, where a trained interviewer will ask you to recall and report your intake, including all food and beverages, consumed in the previous 24 hours or preceding day. You will also be asked some questions about foods that are a part of your daily diet, foods that you eat on special holidays, foods that you eat that are considered soul food and foods that you eat which make you unique to your others. You will also be asked to list the type of fats and/or oils you use to cook with and types of fish, seafood or other meats that you eat daily. You will not be required to write anything down. This study will take place at the Charles Drew WIC clinic.

Risks and/or Discomforts:

There are no known risk or discomforts associated with this research. You may experience very slight discomfort in answering some of the questions. You are free to not answer a question, or to discontinue the process at any time. 
Benefits:

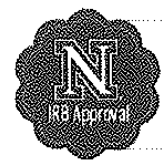

IRB\# $20110311493 \mathrm{EX}$

Date Approved: 03/04/2011

Valid Until: 01/01/2013

This study may not provide direct benefit to you. However, the information obtained during this study will help assess Omega 3 fatty acid intake of African American pregnant women. Omega 3 fatty acid intake may impact maternal and infant health.

Confidentiality:

Any information obtained during this study that could identify you will be kept strictly confidential. You will receive ID numbers that will be used throughout the study. Your name will not appear on the information collected. The data and identifying information will be stored in a locked cabinet in the main researcher's office and will only be seen by the researchers then destroyed five years after the research project is complete. The information obtained in this study may be published in scientific journals or presented at scientific meetings, but your identity will be kept strictly confidential.

Compensation:

You will receive a $\$ 10$ dollar gift certificate from Wal-Mart for participating in this study.

\section{Opportunity to Ask Questions:}

You may ask questions concerning this research and have those questions answered before agreeing to participate in or during the study. If you need more information or have questions about this research, please contact the principal investigator, Narissa Scales, office phone, $(402)$ $472-3836$ or by email at narissa $s(a)$ yahoo com. If you have any additional questions concerning your rights as a research participant, or to report any concerns, you may contact the University of Nebraska-Lincoln Institutional Review Board (UNL IRB), telephone (402) 472-6965.

Freedom to Withdrawal:

You are free to decide not to participate in this study or to withdraw at any time without adversely affecting your relationship with the investigator, the University of Nebraska-Lincoln or WIC. Your decision will not result in any loss of benefits to which you are otherwise entitled.

DOCUMENTATION OF INFORMED CONSENT

YOU ARE VOLUNTARILY MAKING A DECISION WHETHER OR NOT TO PARTICIPATE IN THIS RESEARCH STUDY. YOUR SIGNATURE CERTIFIES THAT YOU HAVE DECIDED TO PARTICPATE HAVING READ AND UNDERSTOOD THE INFORMATION PRESENTED. YOU WILL BE GIVEN A COPY OF THIS CONSENT FORM TO KEEP.

Signature of Participant: 
IN MY JUDGEMENT, THE PARTICIPANT IS VOLUNTARILY AND KNOWINGLY GIVING INFORMED CONSENT TO PARTICPATE IN THIS RESEARCH STUDY.

Signature of Investigator

Date

Name and phone number of investigator(s)

Narissa Scales, Principal Investigator

IRB\# $20110311493 \mathrm{EX}$

Date Approved: 03/04/2011

Valid Until: 01/01/2013

Kaye Stanek Krogstrand PhD., Secondary Investigator Office: (402) 472- 5285 


\section{Nebraskisa

INFORMED CONSENT FORM

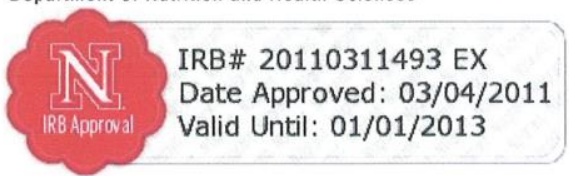

\section{Dear Participant:}

You are invited to participate in this research study because you are an African American pregnant woman. We want to learn more about the foods that you eat. The following information is provided in order to help you make an informed decision whether or not to participate. Participation in this study is voluntary and does not pose any risk to you. All information is kept strictly confidential.

\section{Identification of Project:}

Validity and reliability of a culturally appropriate Food Frequency Questionnaire to measure omega-3 fatty acid food intake in African American Pregnant women-Phase 2/24 hour recalls and food frequency questionnaires.

Omega-3 fatty acid foods are important for maternal and infant health. For the mom, they can protect against high blood pressure during pregnancy and post partum depression. For the infant, they can protect against pre-term birth and promote a higher birth weight. We are conducting this study to know how much and how often you are eating foods that contain Omega-3 fatty acids.

Purpose of the Research:

This research project aims to test a culturally competent Food Frequency Questionnaire to measure Omega-3 fatty acid intake in pregnant African American women. To participate in Phase 2 of this study, you must be an African American woman and in your second or third trimester of pregnancy.

\section{Procedures:}

For this study, you will be asked to fill out a demographic questionnaire and two dietary assessments. The demographic questionnaire ask you general questions such as your age, education level, ethnic background and questions about any previous pregnancies. You will be asked to fill out a 24 hour dietary recall, where a trained interviewer will ask you to recall and report your intake, including all food and beverages, consumed in the previous 24 hours or preceding day. You will need to complete 3 dietary recalls, one week apart each. To complete the 24 hour food recall, you will need to provide short answers and participation will take approximately 10-15 minutes. The next dietary assessment is a food frequency questionnaire, where you will report types and amounts of foods that you eat. You will complete two questionnaires, two weeks apart. Participation in the questionnaire will require approximately 15 to 20 minutes to complete. 


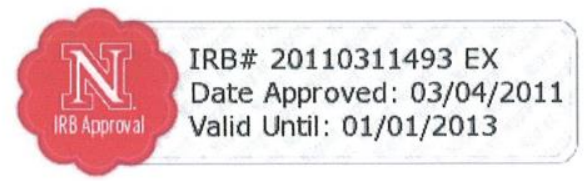

Participants will be required to 1) read and sign the consent form, 2) fill out a demographic questionnaire, 3) fill out three 24 hour recalls, one week apart each, and 4) fill out two food frequency questionnaires, two weeks apart. This study will take place at either one of the following locations: Charles Drew WIC, Douglas County WIC or University of Nebraska Medical Center WIC.

Risks and/or Discomforts:

There are no known risks or discomforts associated with this research. You may experience very slight discomfort in answering some of the questions. You are free to not answer a question, or to discontinue the process at any time.

\section{Benefits:}

This study may not provide a direct benefit to you. However, the information obtained during this study will help assess Omega 3 fatty acid intake of African American pregnant women. Omega 3 fatty acid intake may impact maternal and infant health.

\section{Confidentiality:}

Any information obtained during this study that could identify you will be kept strictly confidential. You will receive ID numbers that will be used throughout the study. Your name will not appear on the information collected. The data and identifying information will be stored in a locked cabinet in the main researcher's office and will only be seen by the researchers then destroyed five years after the research project is complete. The information obtained in this study may be published in scientific journals or presented at scientific meetings, but your identity will be kept strictly confidential.

\section{Compensation:}

You will receive a $\$ 20$ dollar gift certificate from Wal-Mart at the completion of this study for participating.

\section{Opportunity to Ask Questions:}

You may ask questions concerning this research and have those questions answered before agreeing to participate in or during the study. If you need more information or have questions about this research, please contact the principal investigator, Narissa Scales, office phone, (402) 472-3836 or by email at narissa s@yahoo.com. If you have any additional questions concerning your rights as a research participant, or to report any concerns, you may contact the University of Nebraska-Lincoln Institutional Review Board (UNL IRB), telephone (402) 472-6965.

\section{Freedom to Withdrawal:}

You are free to decide not to participate in this study or to withdraw at any time without adversely affecting your relationship with the investigator, the University of Nebraska-Lincoln or WIC. Your decision will not result in any loss of benefits to which you are otherwise entitled. 
DOCUMENTATION OF INFORMED CONSENT

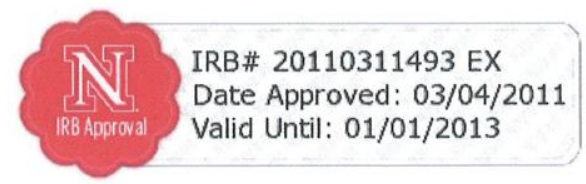

YOU ARE VOLUNTARILY MAKING A DECISION WHETHER OR NOT TO PARTICIPATE IN THIS RESEARCH STUDY. YOUR SIGNATURE CERTIFIES THAT YOU HAVE DECIDED TO PARTICPATE HAVING READ AND UNDERSTOOD THE INFORMATION PRESENTED. YOU WILL BE GIVEN A COPY OF THIS CONSENT FORM TO KEEP.

Signature of Participant:

$\overline{\text { Signature of Research Participant }}$

Date

IN MY JUDGEMENT, THE PARTICIPANT IS VOLUNTARILY AND KNOWINGLY GIVING INFORMED CONSENT TO PARTICPATE IN THIS RESEARCH STUDY.

Signature of Investigator

Date

Name and phone number of investigator(s)

Narissa Scales, Principal Investigator

Office: (402) 472-3836

Kaye Stanek Krogstrand PhD., Secondary Investigator Office: (402) 472- 5285 


\section{Nebraska

COLLEGE OF EDUCATION AND HUMAN SCIENCES

Department of Nutrition and Health Sciences

\section{INFORMED CONSENT FORM}

\section{Dear Participant:}

You are invited to participate in this research study because you are an African American woman of childbearing age, within the ages of 16 to 44 . We want to learn more about the foods that you eat. The following information is provided in order to help you make an informed decision whether or not to participate. Participation in this study is voluntary and does not pose any risk to you. All information is kept strictly confidential.

\section{Identification of Project:}

Validity and reliability of a culturally appropriate Food Frequency Questionnaire to measure omega-3 fatty acid food intake in African American women, of childbearing age-Phase 2/demographic questionnaire, 24 hour recalls and food frequency questionnaires.

Research has shown that omega-3 fatty acid foods are important for women's health. They may boost heart health by lowering the risk of blood clotting. They can protect against high blood pressure during pregnancy and postpartum depression. We are conducting this study to know how much and how often you are eating foods that contain Omega-3 fatty acid

\section{Purpose of the Research:}

This research project aims to test a culturally competent Food Frequency Questionnaire to measure Omega-3 fatty acid intake in African American women. To participate in Phase 2 of this study, you must be an African American woman, of childbearing age, within the ages of 16-44.

\section{Procedures:}

For this study, you will be asked to fill out a demographic questionnaire and two dietary assessments. The demographic questionnaire asks you general questions such as your age, education level, ethnic background and questions about any previous pregnancies. You will be asked to fill out a 24 hour dietary recall, where a trained interviewer will ask you to recall and report your intake, including all food and beverages, consumed in the previous 24 hours or preceding day. You will need to complete 3 dietary recalls, one week apart each. To complete the 24 hour food recall, you will need to provide short answers and participation will take approximately 10-15 minutes. The next dietary assessment is a food frequency questionnaire, where you will report types and amounts of foods that you eat. You will complete two questionnaires, two weeks apart. Participation in the questionnaire will require approximately 30 minutes to complete. 
Participants will be required to 1) read and sign the consent form, 2) fill out a demographic questionnaire, 3) fill out three 24 hour recalls, one week apart each, and 4) fill out two food frequency questionnaires, two weeks apart. This study will take place at either one of the following locations: Charles Drew WIC, Douglas County WIC, University of Nebraska Medical Center WIC or Immanuel Hospital WIC.

\section{Risks and/or Discomforts:}

There are no known risks or discomforts associated with this research. You may experience very slight discomfort in answering some of the questions. You are free to not answer a question, or to discontinue the process at any time.

\section{Benefits:}

This study may not provide a direct benefit to you. However, the information obtained during this study will help assess Omega 3 fatty acid intake of African American women.

\section{Confidentiality:}

Any information obtained during this study that could identify you will be kept strictly confidential. You will receive ID numbers that will be used throughout the study. Your name will not appear on the information collected. The data and identifying information will be stored in a locked cabinet in the main researcher's office and will only be seen by the researchers then destroyed five years after the research project is complete. The information obtained in this study may be published in scientific journals or presented at scientific meetings, but your identity will be kept strictly confidential.

\section{Compensation:}

You will receive a \$20 dollar gift certificate from Walmart at the completion of this study for participating.

\section{Opportunity to Ask Questions:}

You may ask questions concerning this research and have those questions answered before agreeing to participate in or during the study. If you need more information or have questions about this research, please contact the principal investigator, Narissa Scales, cell phone, (402) 213-8729 or by email at narissa_s@yahoo.com. If you have any additional questions concerning your rights as a research participant, you may contact the University of Nebraska-Lincoln Institutional Review Board (UNL IRB), telephone (402) 472-6965.

\section{Freedom to Withdrawal:}

You are free to decide not to participate in this study or to withdraw at any time without adversely affecting your relationship with the investigator, the University of NebraskaLincoln or WIC. Your decision will not result in any loss of benefits to which you are otherwise entitled. 


\section{DOCUMENTATION OF INFORMED CONSENT}

YOU ARE VOLUNTARILY MAKING A DECISION WHETHER OR NOT TO PARTICIPATE IN THIS RESEARCH STUDY. YOUR SIGNATURE CERTIFIES THAT YOU HAVE DECIDED TO PARTICPATE HAVING READ AND UNDERSTOOD THE INFORMATION PRESENTED. YOU WILL BE GIVEN A COPY OF THIS CONSENT FORM TO KEEP.

Signature of Participant:

Signature of Research Participant Date

IN MY JUDGEMENT, THE PARTICIPANT IS VOLUNTARILY AND KNOWINGLY GIVING INFORMED CONSENT TO PARTICPATE IN THIS RESEARCH STUDY.

Signature of Investigator

Date

Name and phone number of investigator(s)

Narissa Scales, Principal Investigator

Office: (402) 213-8729

Julie Albrecht, PhD., Secondary Investigator Office: (402) 472-8884 
APPENDIX B

Letter to Manager of Special Supplemental Nutrition Program for Women, Infants and Children (WIC) 
Kathy Blanke

WIC Manager

1819 Farnam

Room 403

Omaha, NE 68183

402-444-1770

Dear Kathy Blanke,

My name is Narissa Scales. I am a PhD student in the department of Nutrition and Health Sciences at the University of Nebraska Lincoln. I have also worked as a CPA at the Charles Drew Health Center WIC office.

I would like to request your permission to recruit and survey African American pregnant women at several of the WIC offices in the Omaha Metro area. These offices include: Charles Drew Health Center, University of Nebraska Medical Center, $120^{\text {th }}$ and Dodge, $42^{\text {nd }}$ and Center. My research aims to assess the intake of omega-3 fatty acids in African American pregnant women. The participants will be asked to complete two food frequency questionnaires and three 24 hour diet recalls. To accomplish that, I will meet with the participant twice and call the participant once in a two week period. During the first meeting, I will interview the participant about the foods that she ate the previous day and in the last month. During the second meeting, I will conduct an interview similar to the one in the first meeting. Participants will fill out a demographic questionnaire and a pregnancy health assessment during the first interview. Participation in this research study does not post any risk to the participants or anyone else.

I am also asking your permission to contact the Coordinator's of the above mentioned WIC clinics directly.

If you agree to grant me permission to carry out this study at the above mentioned WIC clinics, please let me know so by signing the attached letter of consent. The letter of consent needs to be printed on your letter head for use in our university's Institutional Review Board (IRB) process.

Thank you, Sincerely

Narissa Scales, M.S., R.D., L.M.N.T.

(Principal Investigator)

Graduate Student

Department of Nutrition \& Health Sciences

University of Nebraska-Lincoln

Lincoln, NE 68588-0806

Email: narissa s@yahoo.com
Dr. Kaye Stanek-Krogstrand

(Secondary Investigator)

Professor

Department of Nutrition \& Health

Sciences

University of Nebraska-Lincoln

Lincoln, NE 68588-0806 
APPENDIX C

Letter of Consent from WIC Manager 
Douglas/Sarpy County WIC

Room 403, Civic Center

1819 Farnam

Omaha, NE 68183-0401

(402) 444-1770

November 10, 2010

Narissa Scales, M.S., R.D., L.M.N.T.

Graduate Student

Department of Nutrition and Health Sciences

University of Nebraska-Lincoln

Lincoln, NE 68588-0806

\section{Dear Narissa;}

Thank you for meeting with me today to discuss your research project that would involve WIC participants. WIC is always open to research that will benefit our clients. Your project, to determine the intake of omega -3 fatty acids in African Amerian pregnant women, is research that will benefit WIC participants in the long run to have healthier pregnancies and healthier babies.

I will be glad to work with you and allow you to go into the following WIC clinics to conduct your research. The clinics are Charles Drew WIC, University of Nebraska WIC, Immanuel WIC and Douglas County WIC. The supervisor of these clinics and me will work closely with you to ensure that all the WIC participants will have to opportunity to refuse or accept the survey offer.

If you have any other questions please let me know. I am looking forward to working with you on this project.

Sincerely,

Kathy Blake, MS, RD

WIC Manager 
APPENDIX D

Flier Used for Recruitment of Participants 


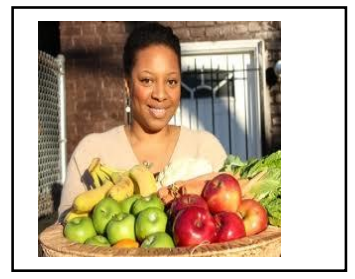

YOU ARE INVITED TO PARTICIPATE IN A NUTRITION RESEARCH STUDY

\title{
EARN A \$20 WAL-MART GIFT CERTIFICATE!
}

We want to learn more about how you eat.

\section{Eligibility:}

\author{
1.African American women \\ 2.16-44 years of age
}

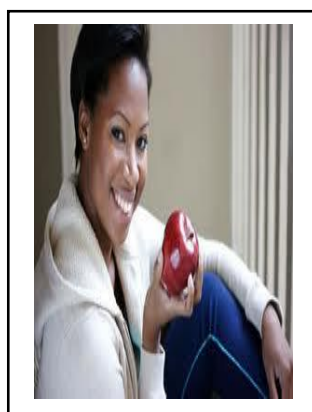

\section{Estimated Time:}

1.3 meetings over a 2 week period

2. Approx. 45 minutes/meeting

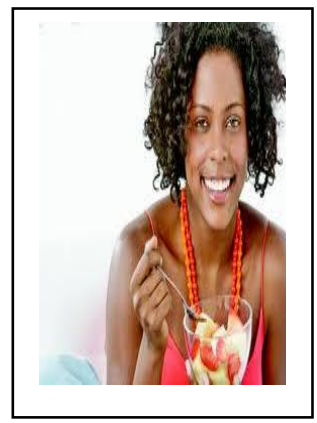

$* * * *$ If interested, Contact Narissa Scales at (402) $213-8729 * * * *$ 
APPENDIX E

Preliminary Interview Questions 
ID\#

\section{Preliminary Interview}

1. Are the foods listed here (on the $24 \mathrm{hr}$ recall) a part of your daily diet? Yes or No What are other foods that are part of your daily diet?

2. What foods do you eat during special events or holidays?

3. What foods do you eat that may be considered soul food? 
4. What foods do you eat that make you unique to your peers, co-workers, friends, etc.?

5. What types of fats and oils do you cook with?

6. What fish, seafood and other meats do you typically eat? 
APPENDIX F

Pilot Test Questionnaire 
Pilot test Questions-Omega 3 FFQ

1. Were the instructions easy to understand?

2. Did you know how to mark your answer?

3. Do you think or feel there were too many options to mark your answer?

4. How hard was it to answer the questions?

5. I saw that you hesitated to answer some questions, what did you think at that moment?

6. Did you find the questionnaire interesting?

7. Was there a time you wanted to stop answering the questions? Why?

8. Did any question offend you? 
APPENDIX G

Sociodemographic Questionnaire 


\section{DEMOGRAPHIC QUESTIONNAIRE}

We need to describe who was in the study. Your answers will be kept private. We will only report information about the entire group.

1. Age (years)

2. Are you

Married

Divorced

Widowed

Separated

Never married

A member of an unmarried couple

3. What is the highest grade or year of school you completed?

Never attended school or only attended kindergarten

Grades 1 through 8 (elementary school)

Grades 9 through 11 (some high school)

Grades 12 or GED (high school graduate)

College 1 year to 3 years (some college or technical school)

College 4 years or more (college graduate)

Refuse to answer

4. Are you

Full time employed

Part time employed

Unemployed

Homemaker

Student

5. Is your annual household income from all sources?
a. Less than $\$ 10,000$
f. Between $\$ 35,000$ and $\$ 50,000$
b. Between $\$ 10,000$ and $\$ 15,000$
g. Between $\$ 50,000$ and $\$ 75,000$
c. Between $\$ 15,000$ and $\$ 20,000$
h. 75,000 or more
d. Between $\$ 20,000$ and $\$ 25,000$
i. Do not know/she is not sure
e. Between $\$ 25,000$ and $\$ 35,000$
j. Refuse to answer 
6. What is your current height and weight?

Height: ___ feet __ inches

Weight: ___ pounds ( please estimate if not known )

7. Are you currently pregnant?

Yes No

8. If yes, how far along are you? (in weeks)

9. What was your weight before you became pregnant?

Weight:___ pounds ( please estimate if not known)

10. Have you been pregnant before?

Y Yes $\quad$ No

If yes, how many pregnancies have you had?

11. Did you ever have a baby that weighed less than 5 pounds, 8 ounces ( $2 \frac{1}{2}$ kilos) at birth?

_ Yes _ No

12. Did you ever have a baby that was born prematurely (before you reached 37 weeks of pregnancy)?

Y Yes $\quad \ldots$ No

13. Did you have any of these health problems during pregnancy? labor)

a. Labor pains more than 3 weeks before your baby was due (preterm/early

b. Water broke more than 3 weeks before your baby was due (premature rupture of membranes) 

toxemia)

c. Pregnancy induced high blood pressure (pre-eclampsia, eclampsia or

14. After any of your pregnancies, did you ever have 2 weeks or longer when you felt sad, empty, or depressed for most of the day?

Yes

No

15. After any of your pregnancies, has a doctor, nurse or midwife referred you to a counselor who helps people who are feeling sad, empty, or depressed?

_ Yes _

16. Have you ever been diagnosed with post-partum depression?

- Yes

No

17. Do you currently take a multivitamin or any other supplement?

Y Yes _ No

If yes, what kind? 
APPENDIX G

Twenty-four Hour Recall 
24-Hour Food Recall (Entry)

Do you take a vitamin supplement or other nutritional supplement?

What

kind?

List all foods and beverages you ate/drank in the last 24 hours.

- $\quad$ For Meal Type, please write: Morning, Noon, Afternoon, Evening or Late Evening

- List all ingredients in mixed dishes (ex: pizza, thin crust with sausage, pepperoni, mushroom)

- Include as much detail as possible regarding amount, type and preparation of food

- Use the following abbreviations: TBSP=tablespoon; tsp=teaspoon, $\mathrm{c}=\mathrm{cup} ; \mathrm{oz}=$ ounce; $\mathrm{lb}=$ pound; sl=slice

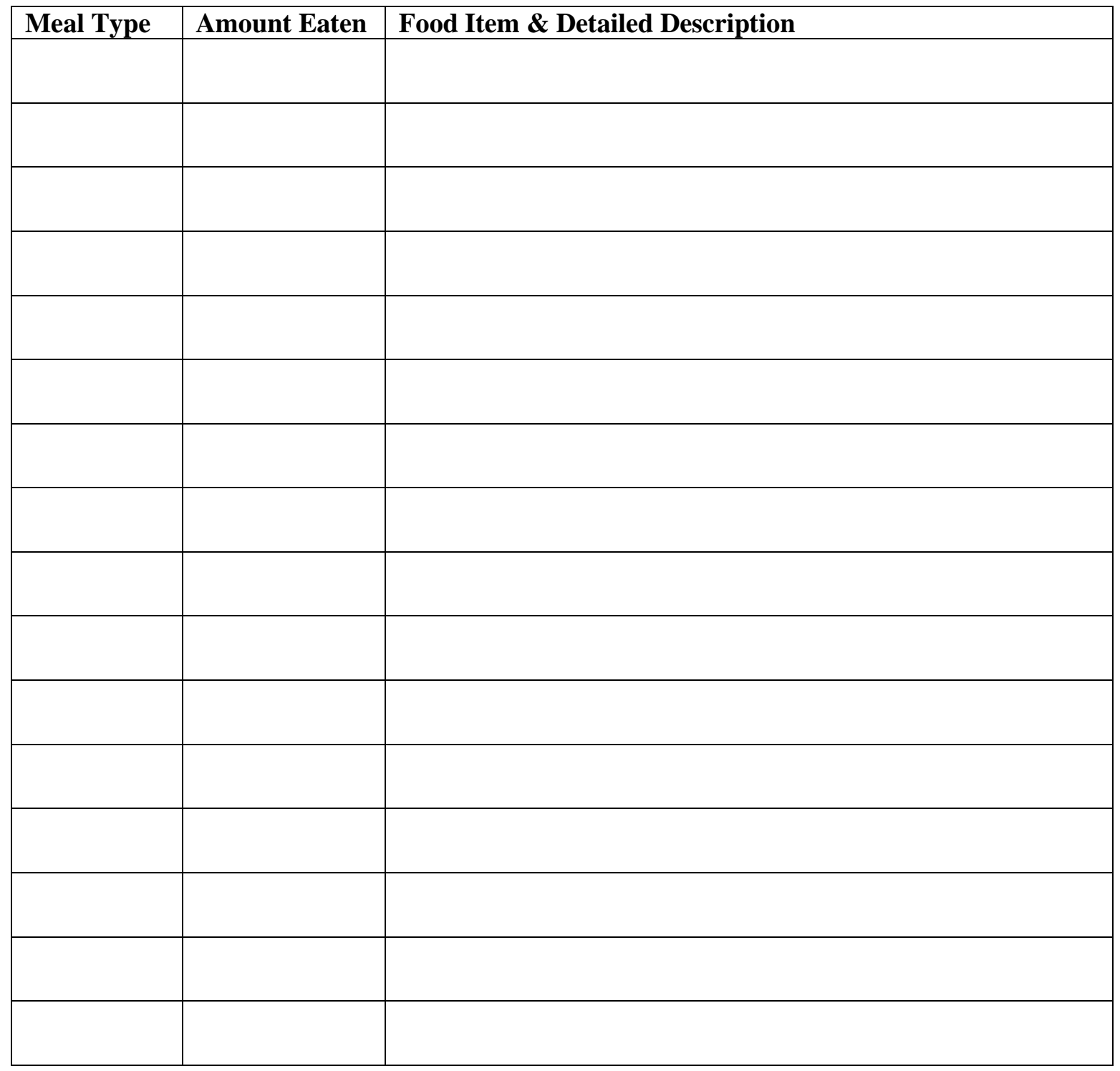


Appendix I

Food Frequency Questionnaire 


\section{Food Frequency Questionnaire}

Date

Code

This form asks about your usual dietary intake over the past month. It will require approximately 15 to 20 minutes of your time to complete. Please use the following instructions:

1. Read each food item. If you have not eaten this food in the past month, mark "none" and move onto the next food item.

2. Indicate whether you think your usual serving size is small (S), medium (M), or large (L) by marking the correct serving size box. The dietary interviewers will show you food models and pictures for visual reference of servings.

Note: A small (S) serving is equal to half (1/2) the usual serving

A medium (M) is equal to the medium servings listed on the form

A large (L) is equal to one and a half $\left(1 \frac{1 / 2}{2}\right)$ times as much or more of the medium serving

3. Think over the past month. How often do you usually eat each of the following items? Again, mark the box under the correct heading. Answer each question as best as you can; estimate if you are not sure. 


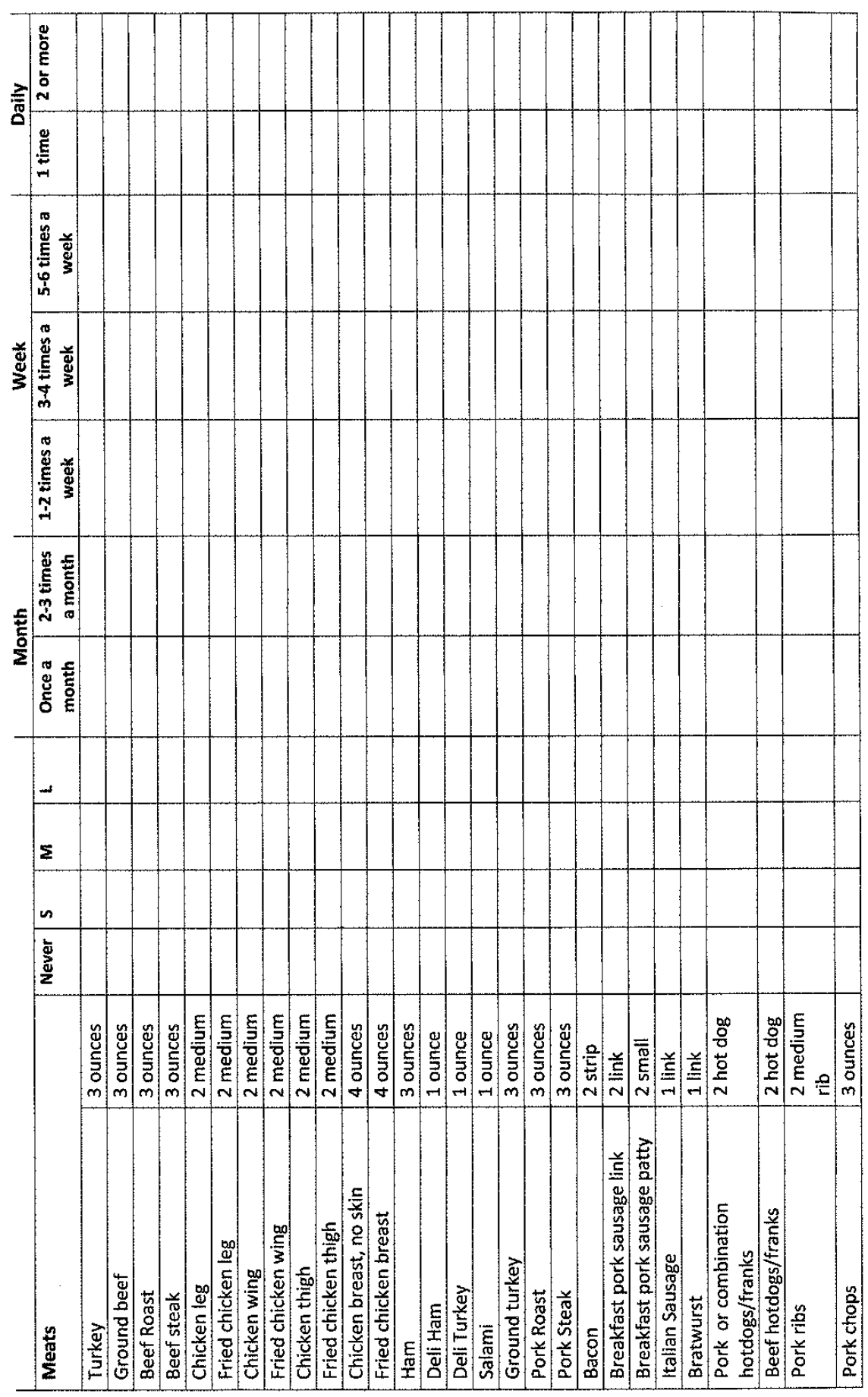



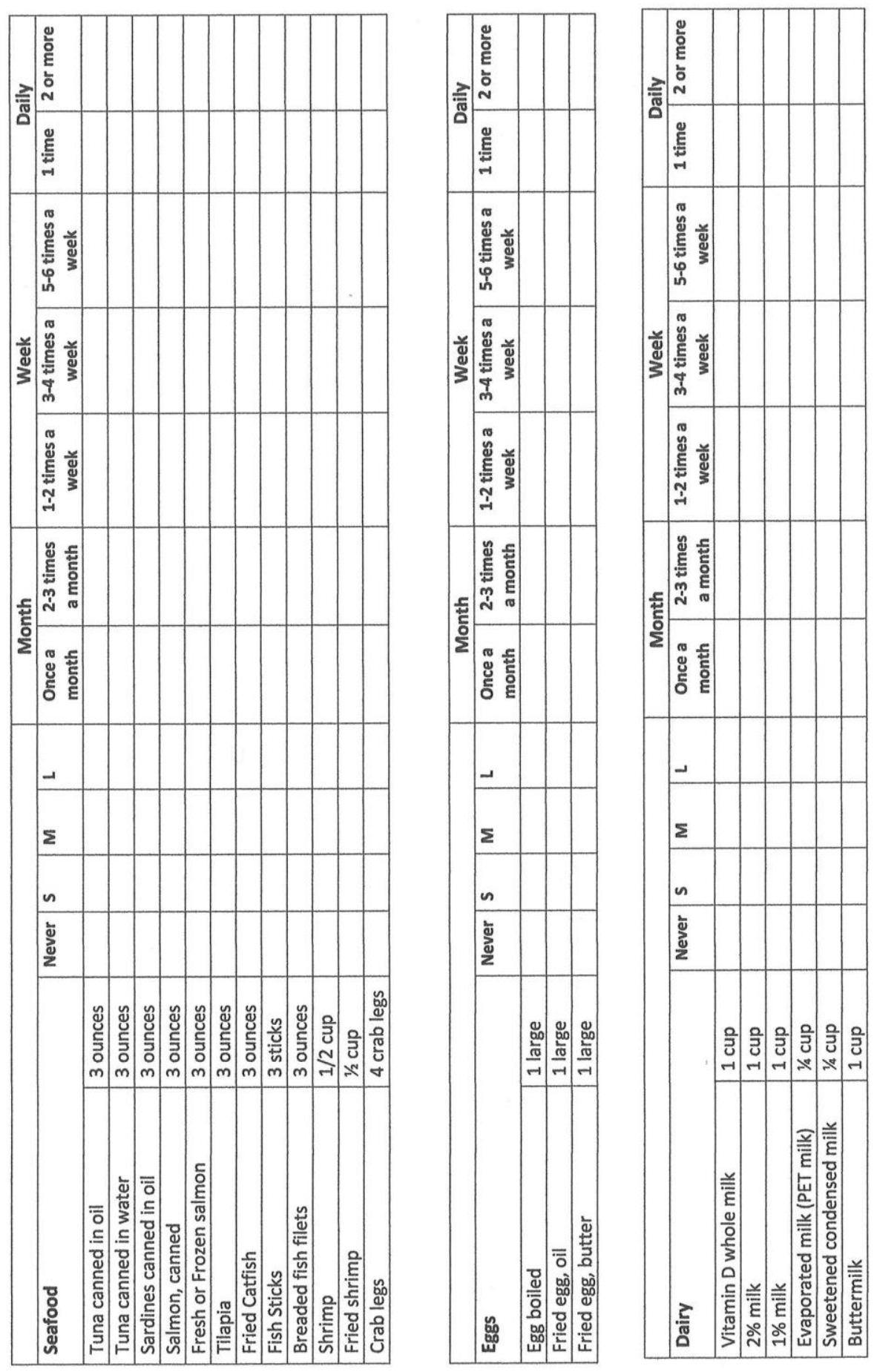


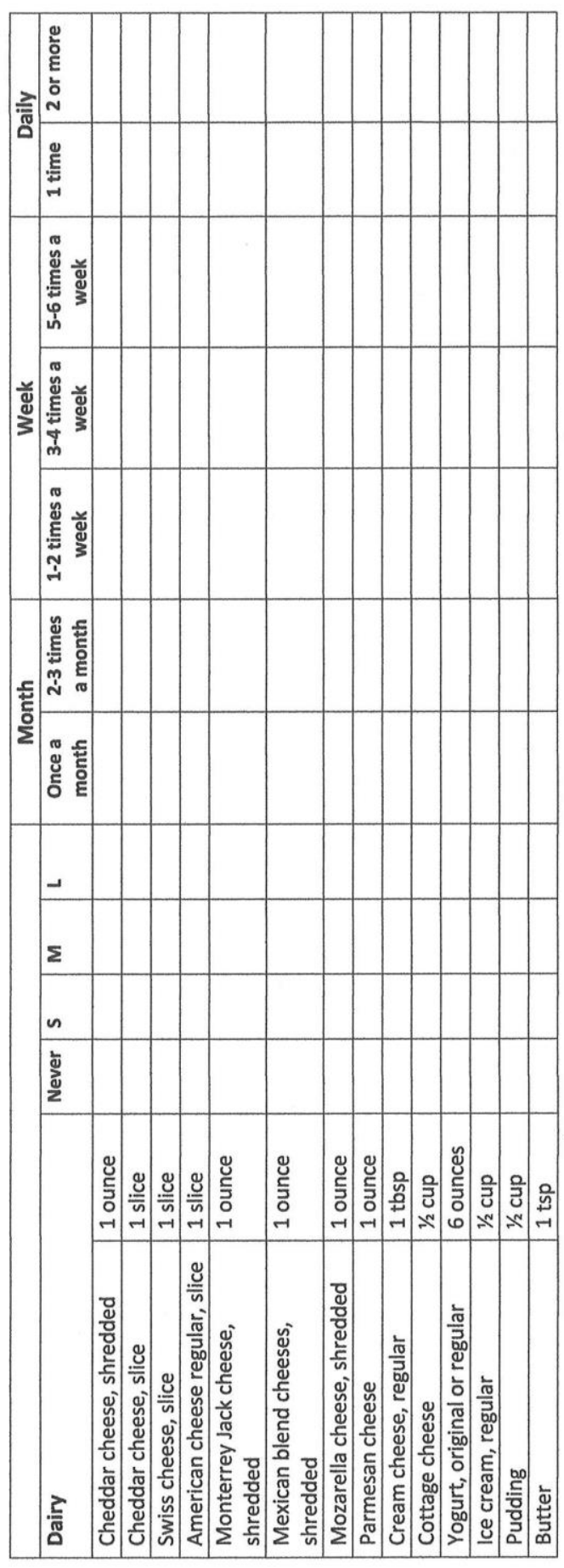




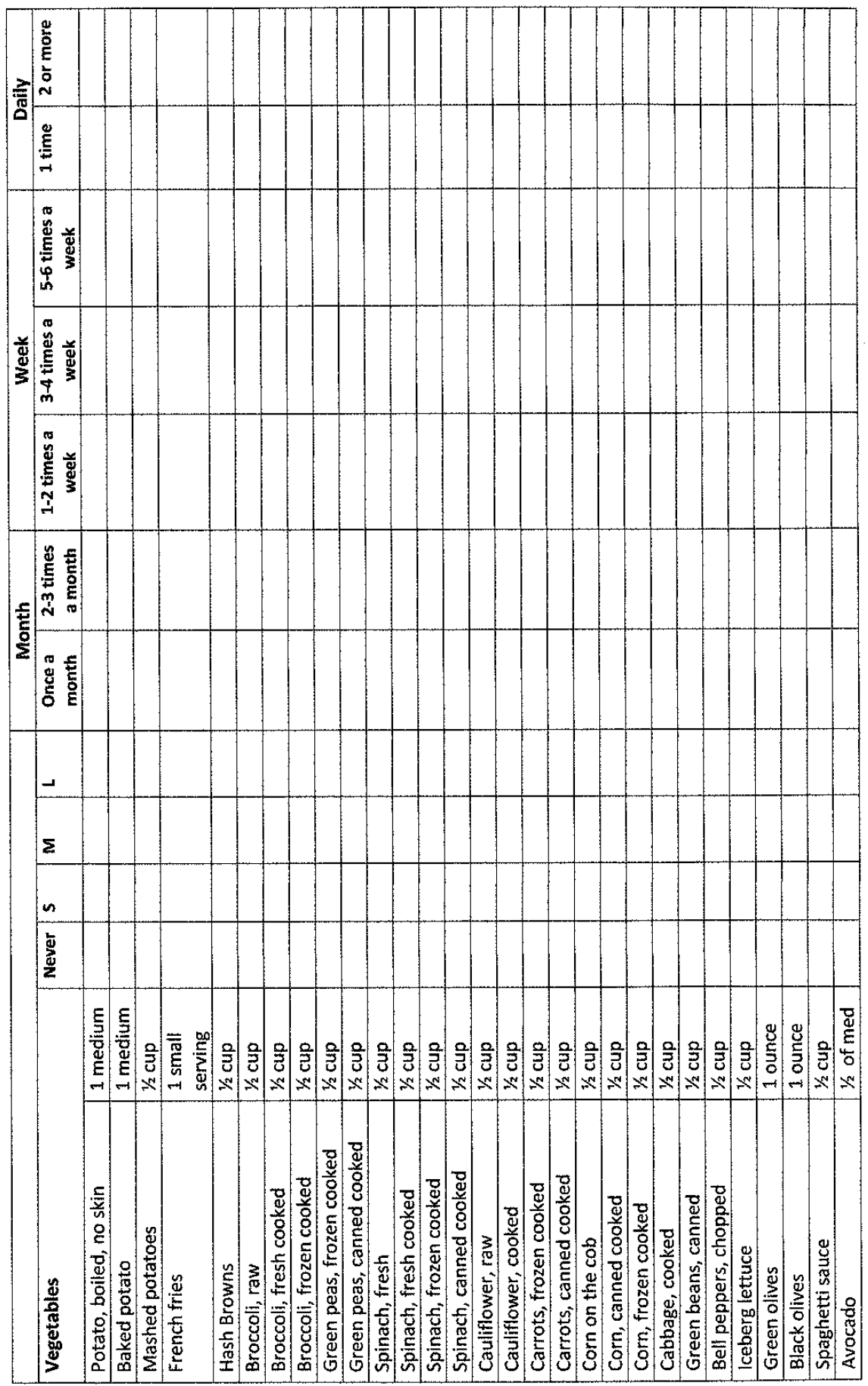



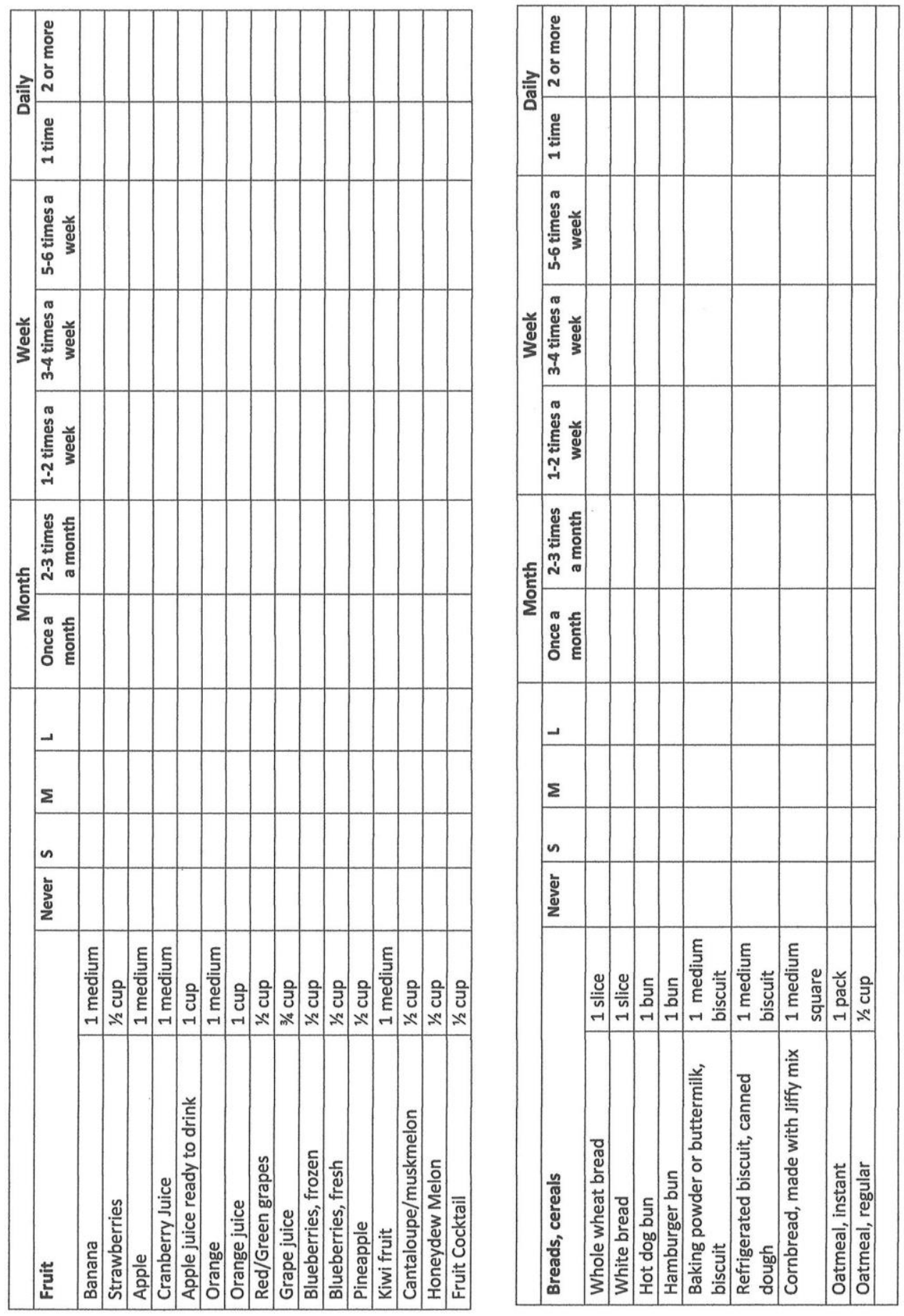


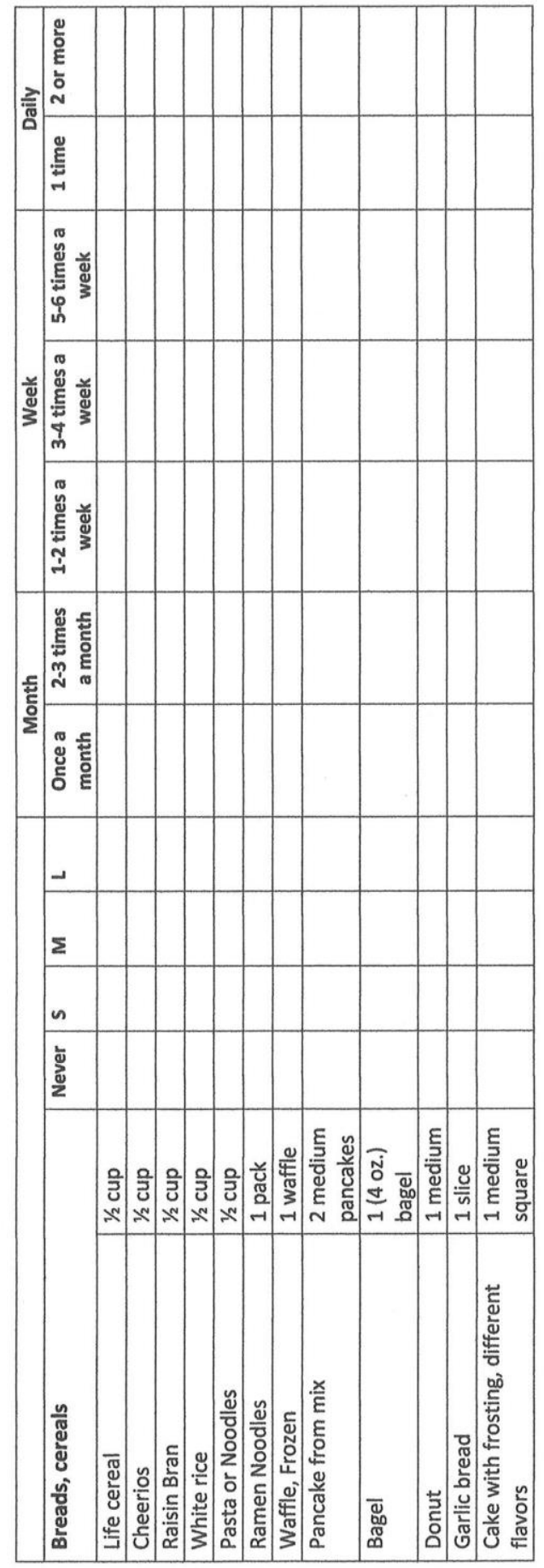



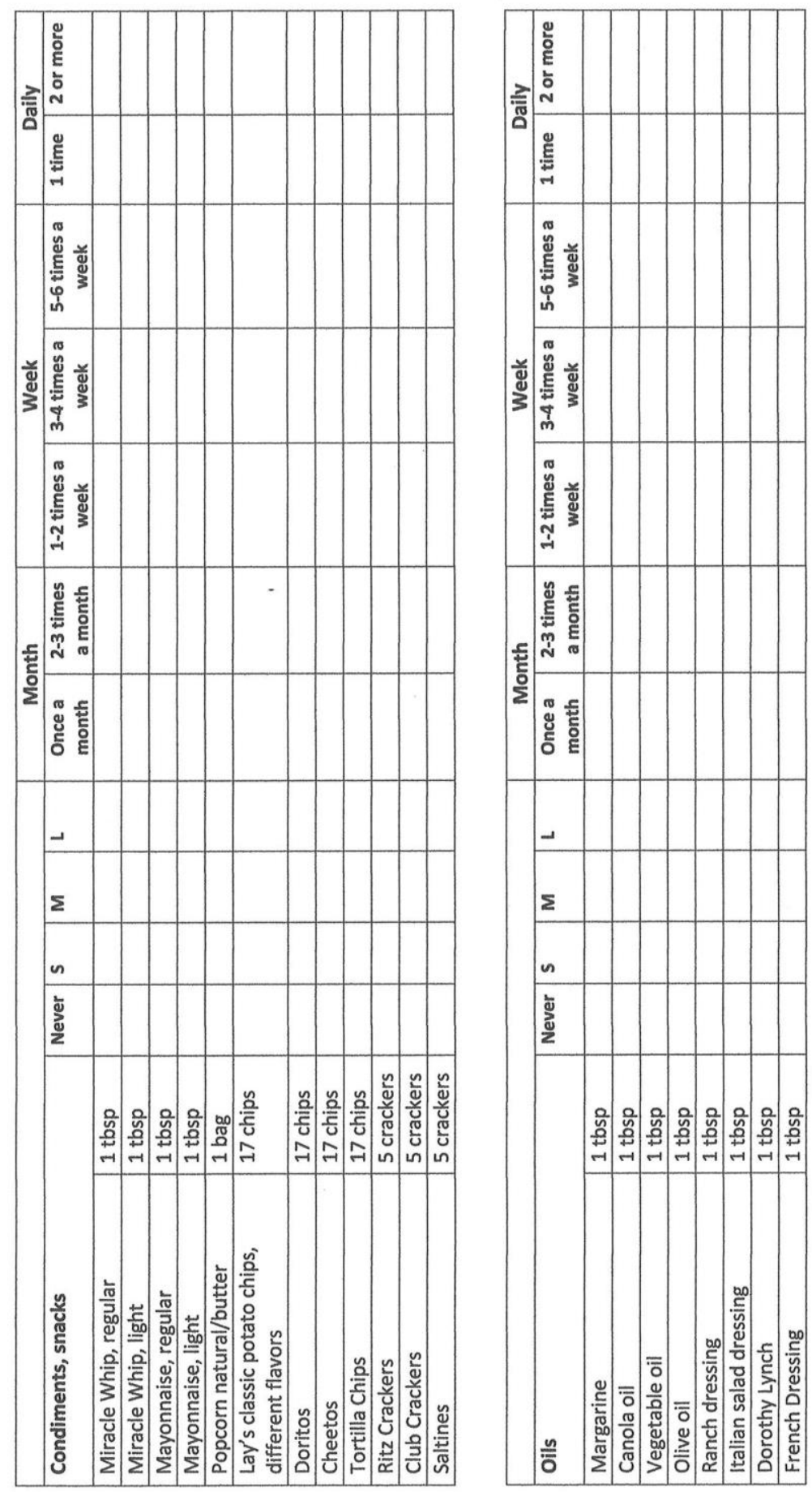

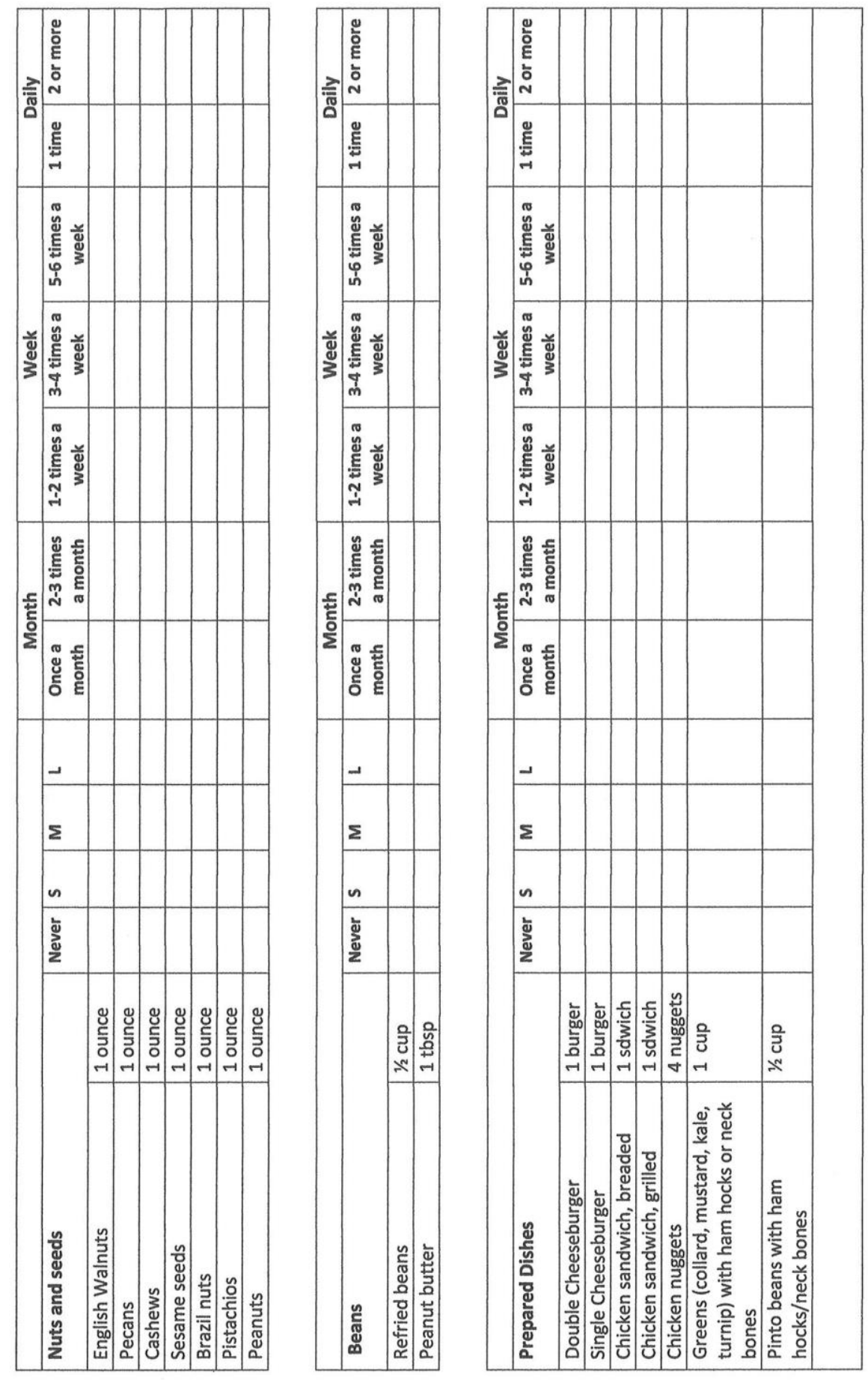


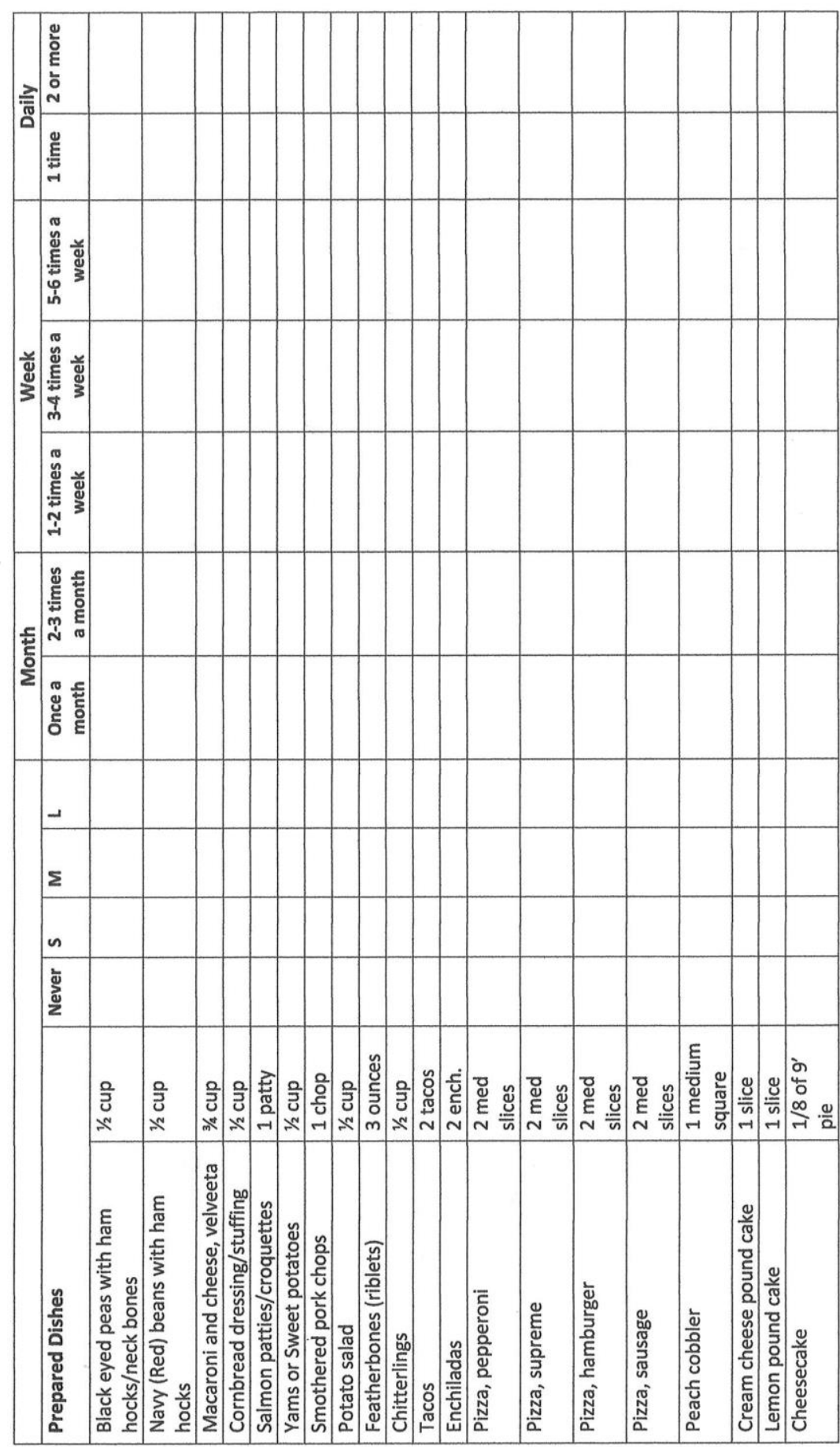

